\title{
Discovering the "Finnish Chopin"-Selim Palmgren's 24 Preludes, op. 17, and Tres Piezas para Piano, op. 54
}

\author{
Sijia Wang \\ West Virginia University, siwang@mix.wvu.edu
}

Follow this and additional works at: https://researchrepository.wvu.edu/etd

Part of the Music Pedagogy Commons, Music Performance Commons, and the Music Theory

\section{Commons}

\section{Recommended Citation}

Wang, Sijia, "Discovering the "Finnish Chopin"-Selim Palmgren's 24 Preludes, op. 17, and Tres Piezas para Piano, op. 54" (2019). Graduate Theses, Dissertations, and Problem Reports. 4030.

https://researchrepository.wvu.edu/etd/4030

This Dissertation is protected by copyright and/or related rights. It has been brought to you by the The Research Repository @ WVU with permission from the rights-holder(s). You are free to use this Dissertation in any way that is permitted by the copyright and related rights legislation that applies to your use. For other uses you must obtain permission from the rights-holder(s) directly, unless additional rights are indicated by a Creative Commons license in the record and/ or on the work itself. This Dissertation has been accepted for inclusion in WVU Graduate Theses, Dissertations, and Problem Reports collection by an authorized administrator of The Research Repository @ WVU.

For more information, please contact researchrepository@mail.wvu.edu. 


\title{
Discovering the "Finnish Chopin"-Selim Palmgren's 24 Preludes, op. 17, and
} Tres Piezas para Piano, op. 54

\author{
Sijia Wang \\ Doctoral Document submitted to the \\ College of Creative Arts \\ at West Virginia University \\ in partial fulfillment of the requirements \\ for the degree of
}
Doctor of Musical Arts
in
Piano Performance
Peter Amstutz, D.M.A., Chair and Research Advisor William Haller, D.M.A. James Miltenberger, D.M.A. Nina Assimakopolous, M.M. Bruce S. Kang, Ph. D.

School of Music
Morgantown, West Virginia 2019

Keywords: Piano, Preludes, Character Pieces, Finnish Music, Selim Palmgren 


\begin{abstract}
Discovering the "Finnish Chopin"—Selim Palmgren's 24 Preludes, op. 17, and

Tres Piezas para Piano, op. 54
\end{abstract}

Sijia Wang

\begin{abstract}
Selim Palmgren (1878-1951) is one of the most significant musical figures in Finland. Unlike Jean Sibelius, who is undoubtedly the greatest Finnish symphonic composer of his time, Palmgren's concentration is more on smaller-scale character pieces. His contribution to the piano and vocal repertoires earned him the reputation of being the "Chopin of the North" and also the "Schumann of the North." Palmgren was not only prolific, having written over 300 piano works and 200 vocal pieces, but also versatile, frequently blending within his works various nationalistic, impressionistic, and other musical styles and elements within his works.
\end{abstract}

This paper is focused on the analytical study of two piano suites by Selim Palmgren-24 Preludes, op. 17, and Tres Piezas para Piano, op. 54. It aims to enhance our understanding of these two suites and to discover their pedagogical and aesthetic aspects. Palmgren's piano solo works are often written in miniature form and are not often performed. However, his works are well suited for intermediate-level piano study. Their forms, lyrical melodies, and technical approaches offer good examples for the study of several pedagogical aspects. They also enrich and contribute to the piano repertoire and they deserve to be better known among pianists and audiences alike. 


\section{ACKNOWLEGEMENTS}

I would like to express my grateful appreciation to my beloved parents who have been supporting and encouraging during my entire study.

Throughout the writing of this paper, I constantly received a great deal of support and assistance. Without that help, I would not have been able to complete my study and research. I would like to thank my committee chair, Dr. Amstutz, for consistently providing guidance and feedback throughout my research. Also, thanks to my committee members, Dr. Miltenberger, Dr. Haller, Prof. Assimakopolous, and Dr. Kang, who gave me useful help and support. Moreover, I would like to thank my former applied professor, Prof. Philip Thomson, and his wife, Mrs. Yangsoon Kim, who gave me invaluable assistance during my study.

I would also like to thank my boyfriend, Jiajie Qian, who helped and encouraged me throughout my studies in United States.

In addition, I would thank all my family members and friends for their endless love and trust.

Finally, I would like to thank my cutest cat, Brake, who was always by my side when I was struggling with my study. Thank you for saving me. 


\section{TABLE OF CONTENTS}

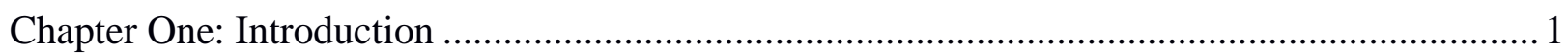

Chapter Two: About Selim Palmgren.................................................................................. 4

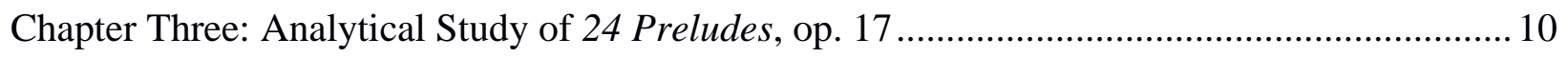

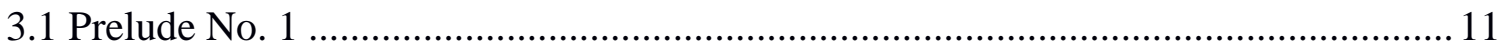

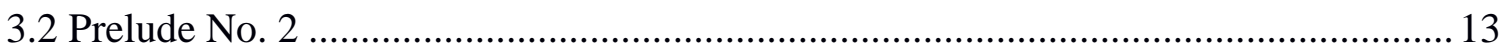

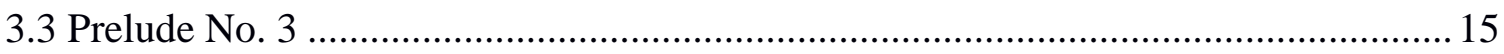

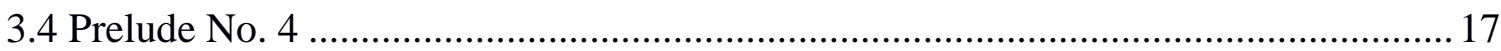

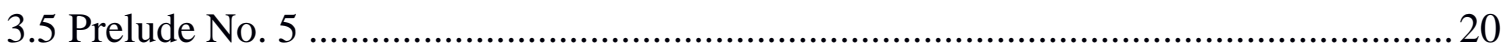

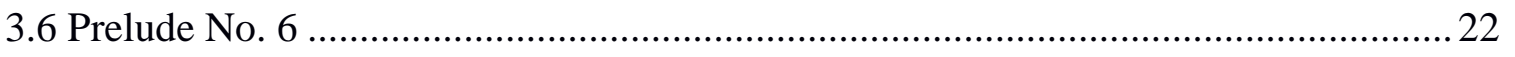

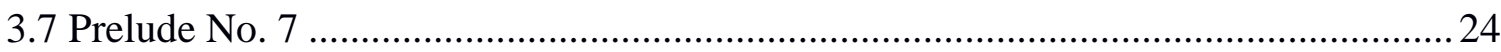

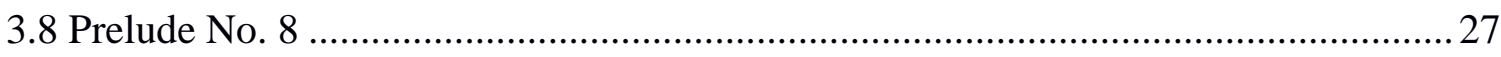

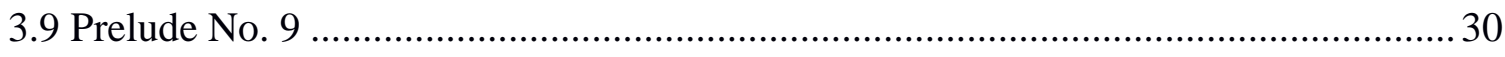

3.10 Prelude No. 10

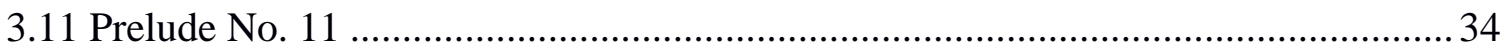

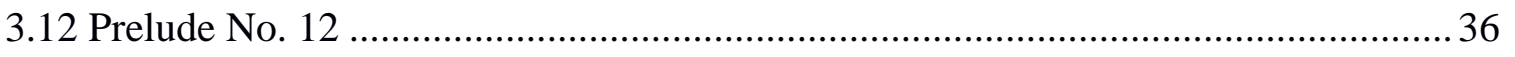

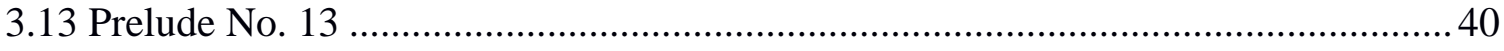

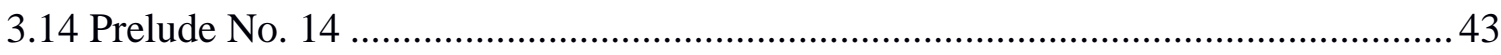

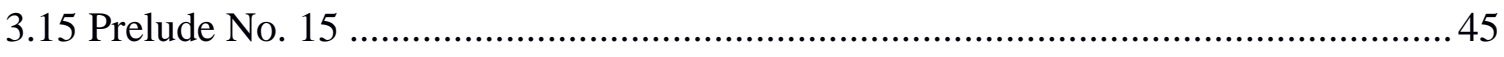

3.16 Prelude No. 16

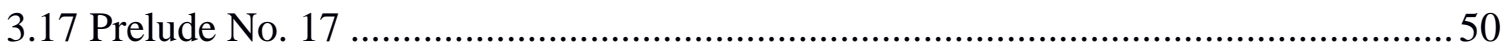

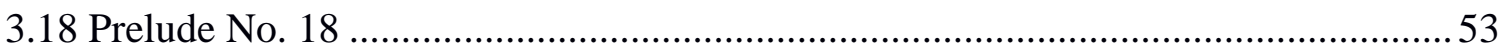

3.19 Prelude No. 19

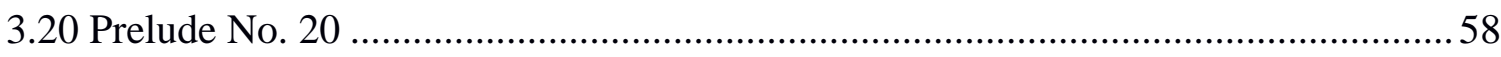

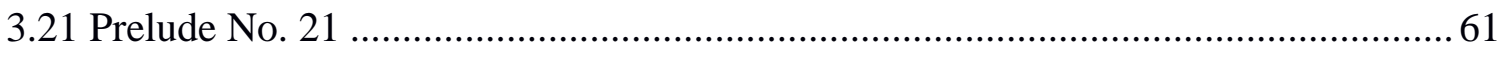

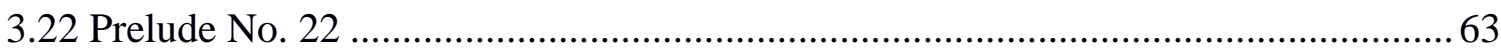




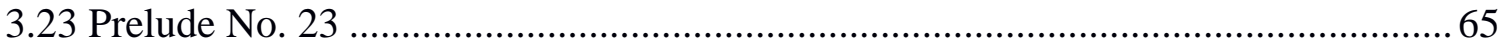

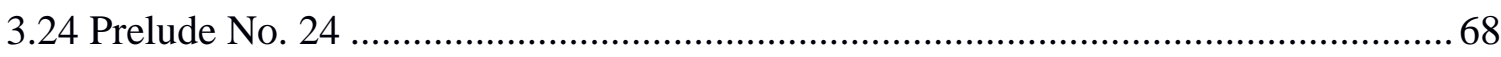

Chapter Four: Analytical Study of Tres Piezas para Piano, op. 54 ............................................ 73

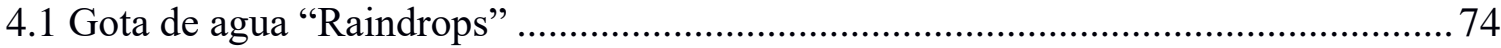

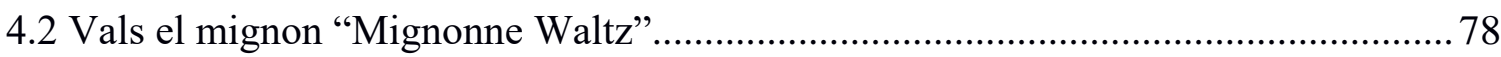

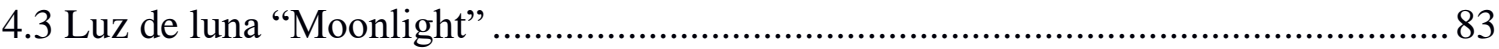

Chapter Five: Conclusion ................................................................................................. 89

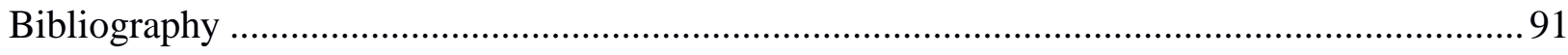

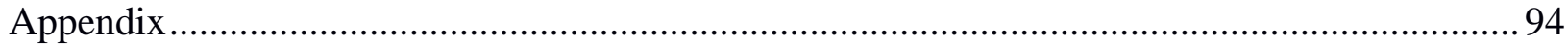




\section{LIST OF FIGURES}

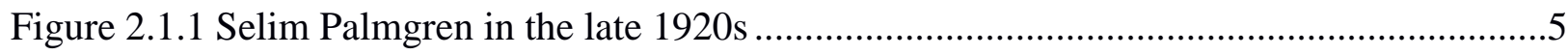

Figure 3.1.1 Selim Palmgren, 24 Preludes, op. 17, No. 1, mm. 1-3 ....................................... 11

Figure 3.1.2 Selim Palmgren, 24 Preludes, op. 17, No. 1, mm. 4-6....................................... 12

Figure 3.1.3 Selim Palmgren, 24 Preludes, op. 17, No. 1, mm. 8-10..................................... 13

Figure 3.2.1 Selim Palmgren, 24 Preludes, op. 17, No. 2, mm. 1-4, 9-12 .............................. 14

Figure 3.3.1 Selim Palmgren, 24 Preludes, op. 17, No. 3, mm. 16-21 .................................... 16

Figure 3.3.2 Selim Palmgren, 24 Preludes, op. 17, No. 3, mm. 28-45 ................................... 17

Figure 3.4.1 Selim Palmgren, 24 Preludes, op. 17, No. 4, mm. 1-7...................................... 18

Figure 3.4.2 Selim Palmgren, 24 Preludes, op. 17, No. 4, mm. 73-90..................................... 19

Figure 3.5.1 Selim Palmgren, 24 Preludes, op. 17, No. 5, mm. 1-8...................................... 20

Figure 3.5.2 Selim Palmgren, 24 Preludes, op. 17, No. 5, mm. 9-33 ..................................... 21

Figure 3.5.3 Selim Palmgren, 24 Preludes, op. 17, No. 5, mm. 88-95 .................................... 22

Figure 3.6.1 Selim Palmgren, 24 Preludes, op. 17, No. 6, mm. 1-2, 11-12 ............................ 23

Figure 3.6.2 Selim Palmgren, 24 Preludes, op. 17, No. 6, mm. 38-42 ................................... 24

Figure 3.7.1 Selim Palmgren, 24 Preludes, op. 17, No. 7, mm. 1-3 3....................................... 25

Figure 3.7.2 Selim Palmgren, 24 Preludes, op. 17, No. 7, mm. 10-16................................... 26

Figure 3.7.3 Selim Palmgren, 24 Preludes, op. 17, No. 7, mm. 31-33 ................................... 26

Figure 3.8.1 Selim Palmgren, 24 Preludes, op. 17, No. 8, mm. 1-4...................................... 28

Figure 3.8.2 Selim Palmgren, 24 Preludes, op. 17, No. 8, mm. 63-74 ................................... 29

Figure 3.8.3 Selim Palmgren, 24 Preludes, op. 17, No. 8, mm. 88-97................................... 29

Figure 3.9.1 Selim Palmgren, 24 Preludes, op. 17, No. 9, mm. 1-5 ...................................... 31

Figure 3.9.2 Selim Palmgren, 24 Preludes, op. 17, No. 9, mm. 25-28 ................................... 31

Figure 3.10.1 Selim Palmgren, 24 Preludes, op. 17, No. 10, mm. 1-8 .................................... 33

Figure 3.10.2 Selim Palmgren, 24 Preludes, op. 17, No. 10, mm. 9-13.................................. 34

Figure 3.11.1 Selim Palmgren, 24 Preludes, op. 17, No. 11, mm. 1-2, 


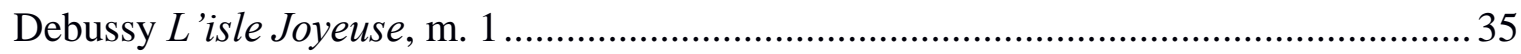

Figure 3.11.2 Selim Palmgren, 24 Preludes, op. 17, No. 11, mm. 52-60..................................... 35

Figure 3.11.3 Selim Palmgren, 24 Preludes, op. 17, No. 11, mm. 11-13, 19-21, 31-33 ...............36

Figure 3.12.1 Selim Palmgren, 24 Preludes, op. 17, No. 12, mm. 1-8 ......................................... 37

Figure 3.12.2 Selim Palmgren, 24 Preludes, op. 17, No. 12, mm. 12-17 .................................... 38

Figure 3.12.3 Selim Palmgren, 24 Preludes, op. 17, No. 12, mm. 29-34 ...................................... 39

Figure 3.13.1 Selim Palmgren, 24 Preludes, op. 17, No. 13, mm. 5-7 ......................................... 40

Figure 3.13.2 Selim Palmgren, 24 Preludes, op. 17, No. 13, mm. 11-18 ..................................... 41

Figure 3.13.3 Selim Palmgren, 24 Preludes, op. 17, No. 13, mm. 23-30.................................... 42

Figure 3.13.4 Selim Palmgren, 24 Preludes, op. 17, No. 13, mm. 55-60.................................... 42

Figure 3.14.1 Selim Palmgren, 24 Preludes, op. 17, No. 14, mm. 1-6 ........................................ 43

Figure 3.14.2 Selim Palmgren, 24 Preludes, op. 17, No. 14, mm. 13-18 ..................................... 44

Figure 3.14.3 Selim Palmgren, 24 Preludes, op. 17, No. 14, mm. 19-21 ..................................... 45

Figure 3.15.1 Selim Palmgren, 24 Preludes, op. 17, No. 15, mm. 1-3 ……………………........ 46

Figure 3.15.2 Selim Palmgren, 24 Preludes, op. 17, No. 15, mm. 6-10....................................... 46

Figure 3.15.3 Selim Palmgren, 24 Preludes, op. 17, No. 15, mm. 13-22 ..................................... 47

Figure 3.16.1 Selim Palmgren, 24 Preludes, op. 17, No. 16, mm. 1-4, 13-16 ............................. 48

Figure 3.16.2 Selim Palmgren, 24 Preludes, op. 17, No. 16, mm. 34-51 .................................... 49

Figure 3.17.1 Selim Palmgren, 24 Preludes, op. 17, No. 17, mm. 1-2........................................ 51

Figure 3.17.2 Selim Palmgren, 24 Preludes, op. 17, No. 17, mm. 10 .......................................... 51

Figure 3.17.3 Selim Palmgren, 24 Preludes, op. 17, No. 17, mm. 18-20.................................... 52

Figure 3.18.1 Selim Palmgren, 24 Preludes, op. 17, No. 18, mm. 1-10.......................................54

Figure 3.18.2 Selim Palmgren, 24 Preludes, op. 17, No. 18, mm. 13-15, 23-25 ......................... 54

Figure 3.18.3 Selim Palmgren, 24 Preludes, op. 17, No. 18, m. 27-29 …………………...........55

Figure 3.19.1 Selim Palmgren, 24 Preludes, op. 17, No. 19,

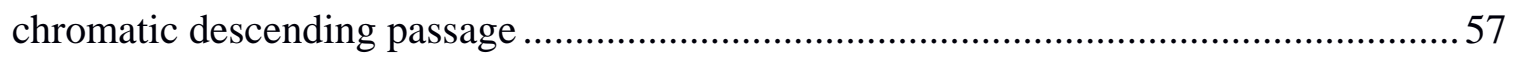

Figure 3.19.2 Selim Palmgren, 24 Preludes, op. 17, No. 19, ascending arpeggiated passage 
Figure 3.20.1 Selim Palmgren, 24 Preludes, op. 17, No. 20, mm. 11-13 ..................................... 60

Figure 3.20.2 Selim Palmgren, 24 Preludes, op. 17, No. 20, mm. 17-19..................................... 60

Figure 3.21.1 Selim Palmgren, 24 Preludes, op. 17, No. 21, mm. 1-6......................................... 61

Figure 3.21.2 Selim Palmgren, 24 Preludes, op. 17, No. 21,

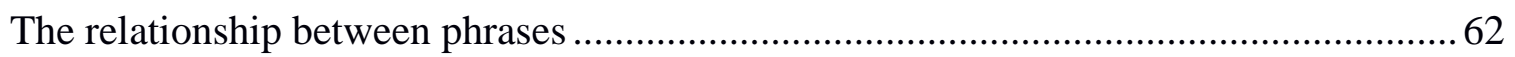

Figure 3.21.3 Selim Palmgren, 24 Preludes, op. 17, No. 21, mm. 28-31 .................................... 62

Figure 3.22.1 Selim Palmgren, 24 Preludes, op. 17, No. 22, mm. 1-3 ……………………......... 63

Figure 3.22.2 Selim Palmgren, 24 Preludes, op. 17, No. 22, mm. 12-16 ..................................... 64

Figure 3.23.1 Selim Palmgren, 24 Preludes, op. 17, No. 23, mm. 1-4,

Felix Mendelssohn Venetianisches Gondellied, mm. 1-3,

Tchaikovsky Barcarolle (June), mm. 1-3 …………………………………………........ 66

Figure 3.23.2 Selim Palmgren, 24 Preludes, op. 17, No. 23, mm. 17-24 .................................... 67

Figure 3.23.3 Selim Palmgren, 24 Preludes, op. 17, No. 23, mm. 40-42 ..................................... 68

Figure 3.24.1 Selim Palmgren, 24 Preludes, op. 17, No. 24, mm. 1-9......................................... 69

Figure 3.24.2 Selim Palmgren, 24 Preludes, op. 17, No. 24, mm. 23-29.................................... 70

Figure 3.24.3 Selim Palmgren, 24 Preludes, op. 17, No. 24, mm. 43-59 …………………....... 72

Figure 4.1.1 Selim Palmgren, Tres Piezas para Piano, op. 54, "Raindrops," mm. 1-3;

Chopin, Prelude op. 28, No. 15, mm. 1-4 ………………........................................... 74

Figure 4.1.2 Selim Palmgren, Tres Piezas para Piano, op. 54, “Raindrops, ” mm. 4-7 .............. 76

Figure 4.1.3 Selim Palmgren, Tres Piezas para Piano, op. 54, "Raindrops, ” mm. 14-24 ...........77

Figure 4.2.1 Selim Palmgren, Tres Piezas para Piano, op. 54, "Mignonne Waltz,"

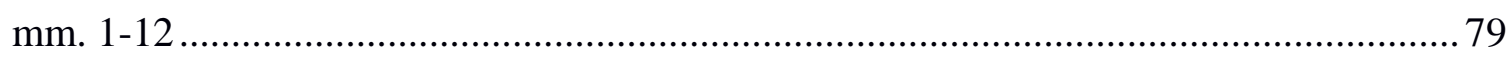

Figure 4.2.2 Selim Palmgren, Tres Piezas para Piano, op. 54, "Mignonne Waltz,"

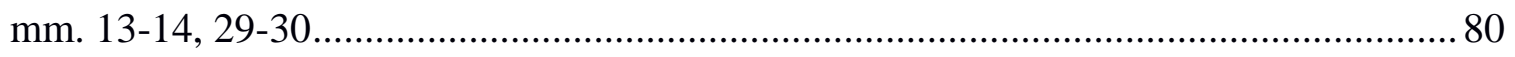

Figure 4.2.3 Selim Palmgren, Tres Piezas para Piano, op. 54, "Mignonne Waltz,"

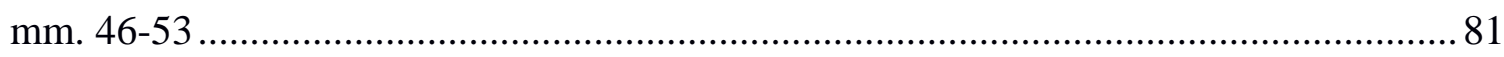

Figure 4.2.4 Selim Palmgren, Tres Piezas para Piano, op. 54, "Mignonne Waltz,"

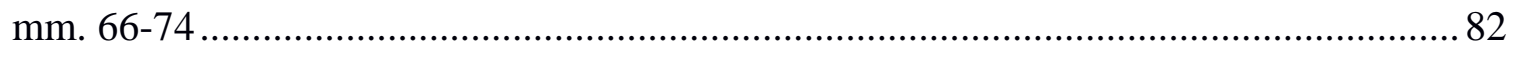


Figure 4.2.5 Selim Palmgren, Tres Piezas para Piano, op. 54, “Mignonne Waltz,”

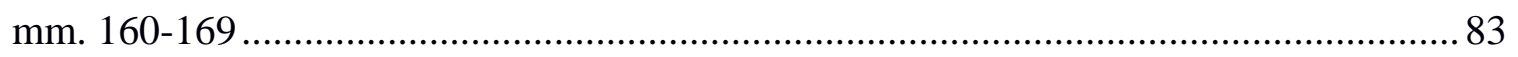

Figure 4.3.1 Selim Palmgren, Tres Piezas para Piano, op. 54, “Moonlight,” m. 1-8 ............... 85

Figure 4.3.2 Selim Palmgren, Tres Piezas para Piano, op. 54, “Moonlight,”

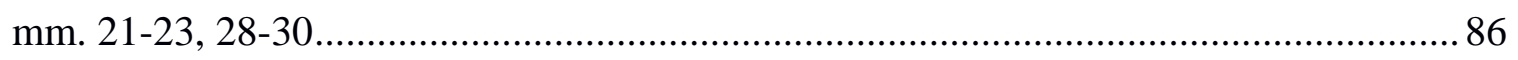

Figure 4.3.3 Selim Palmgren, Tres Piezas para Piano, op. 54, “Moonlight,” mm. 43-46 .........87

Figure 4.3.4 Selim Palmgren, Tres Piezas para Piano, op. 54, “Moonlight,” mm. 51-55 ..........88 


\section{Chapter One}

\section{Introduction}

Among Finnish composers of the $19^{\text {th }}$ and $20^{\text {th }}$ centuries, Jean Sibelius (1865-1957) consistently comes first to mind. Many great Finnish composers of the same generation lived under his towering shadow. Indeed, as a Romantic symphonist, Sibelius brought Finland its first great international cultural success. ${ }^{1}$ While Sibelius is best known for his orchestral writing, there is another composer in the realm of Finnish piano repertoire whose works should be far more widely known—Selim Palmgren (1878-1951).

Coming from a Finnish composer, Selim Palmgren's works “represent in microcosm his country's relationship to central European ideas during his years of productivity." ${ }^{2}$ Nationalistic and impressionistic elements saturate many of his works, and "his emulation of contemporary musical techniques fluctuates, as does his country's interest in whether or not to enter into the larger European community during the turbulence of the first half of the $20^{\text {th }}$ century." 3

Selim Palmgren's contribution to the repertoire lies mostly in miniature forms, songs, and short piano pieces. Much of his music is nationalistic, like that of his Norwegian contemporary, Edvard Grieg (1843-1907). Interestingly, their life experiences are striking similar. Although they lived in different periods, both of their nationalistic interests stem from their countries' achieving of independence: Norway was dominated by Denmark until 1814 and then tied to Sweden until 1905. And Finland, which was ceded by Sweden to Russia in 1809 , finally asserted its independence during the turbulent circumstances of the Russian Revolution in 1917. Both

\footnotetext{
${ }^{1}$ Tawaststjerna, Erik Thomas, “Finnish Piano Music Since 1945.” (PhD diss., New York University, 1982).

${ }^{2}$ Hong, Barbara Blanchard (1992), "The Five Piano Concertos of Selim Palmgren: A Finnish Nationalist Meets the Challenge of the Twentieth Century." (PhD diss., Indiana University, 1992).

${ }^{3}$ Ibid.
} 
countries were bilingual from Grieg's and Palmgren's early schooldays because of their countries' circumstances. ${ }^{4}$ Both composers were adept mainly in small lyrical genres instead of large-scale works. Both composed many songs due to their marriages with professional singers. Both made their livings either by various teaching, conducting and administrative positions, or as independent performers and composers. ${ }^{5}$

Most of Palmgren's works spring from Finnish traditional folk tunes and dance rhythms. As a result, he has been called "the Finnish Chopin," this comparison being based upon the almost exclusive position held by piano works in his total output. ${ }^{6}$ Many of his piano works utilize parallel dissonant chords and whole-tone scales, reflecting the strong influence of impressionism and Slavic melancholy as well as Palmgren's own contributions to that musical style.

This study aims to enhance our understanding of two important sets of piano works composed by Selim Palmgren and to discover his aesthetic aspects through these works. Throughout the study, I will analyze the basic structures and the composer's harmonic writing styles, also exploring the ways that the composer introduced and blended Finnish folk music as well as impressionist elements in his works. These concepts could provide a useful introduction, along with some performance suggestions, for a performer interested in playing these pieces.

There are five chapters in this research project:

1. Introduction

2. About Selim Palmgren

${ }^{4}$ Ibid.

${ }^{5}$ Ibid.

${ }^{6}$ Ibid. 
3. An Analytical Study of 24 Preludes, op. 17

4. An Analytical Study of Tres Piezas para Piano, op. 54

\section{Conclusion}

After the current introductory chapter, Chapter Two provides a brief overview of Selim Palmgren's biography, a list of his major piano works, and a review of existing literature. Chapter Three focuses on the analysis of Palmgren's 24 Preludes, op. 17, including discussions of structure, harmony, interesting points, and pedagogical concerns. Chapter Four offers an analysis of Palmgren's Tres Piezas para Piano, op. 54. It is divided into three sections, each discussing one movement. Chapter Five summarizes the most important findings of the previous chapters. 


\title{
Chapter Two
}

\begin{abstract}
About Selim Palmgren
Born in Finland, Selim Palmgren (1878-1951) is known as a teacher, a composer, a pianist, and a conductor (see Figure 2.1). His early studies (1895 to 1899) were at the Helsinki Music Institute, where he was a pupil of Wegelius (harmony and counterpoint) and of Petzet, MelcerSzczawiński and Ekman (piano). ${ }^{7}$ After he went to Germany and Italy to study with Conrad Ansorge, Wilhelm Berger, and Ferruccio Busoni, he returned to Finland and became the conductor of the Helsinki University Chorus (1902-1904, 1907-1908) and the Turku Musical Society (1909-1912). ${ }^{8}$ Palmgren then quit conducting and worked exclusively as composer and pianist. He toured the United States beginning in 1920 and was invited to teach at the Eastman School of Music, occupying the Chair of Music Composition there from 1923 to $1926 .{ }^{9}$ Later, he returned to Finland and became a professor of harmony and composition at the Sibelius Academy in Helsinki, from 1936 to 1951 . He received an honorary doctorate from Helsinki University in 1950. Palmgren died in 1951 in Helsinki at the age of 73.
\end{abstract}

\footnotetext{
${ }^{7}$ Oramo, Ilkka. "Palmgren, Selim," Grove Music Online, accessed April 10, 2019, https://doi-org.www.libproxy.wvu.edu/ 10.1093/gmo/9781561592630.article.20779.

${ }^{8}$ Ibid.

${ }^{9}$ Parsons, Charles H, “Palmgren: Daniel Hjort,” The Record Connoisseur's Magazine, (March/April 1998): 174-175.
} 


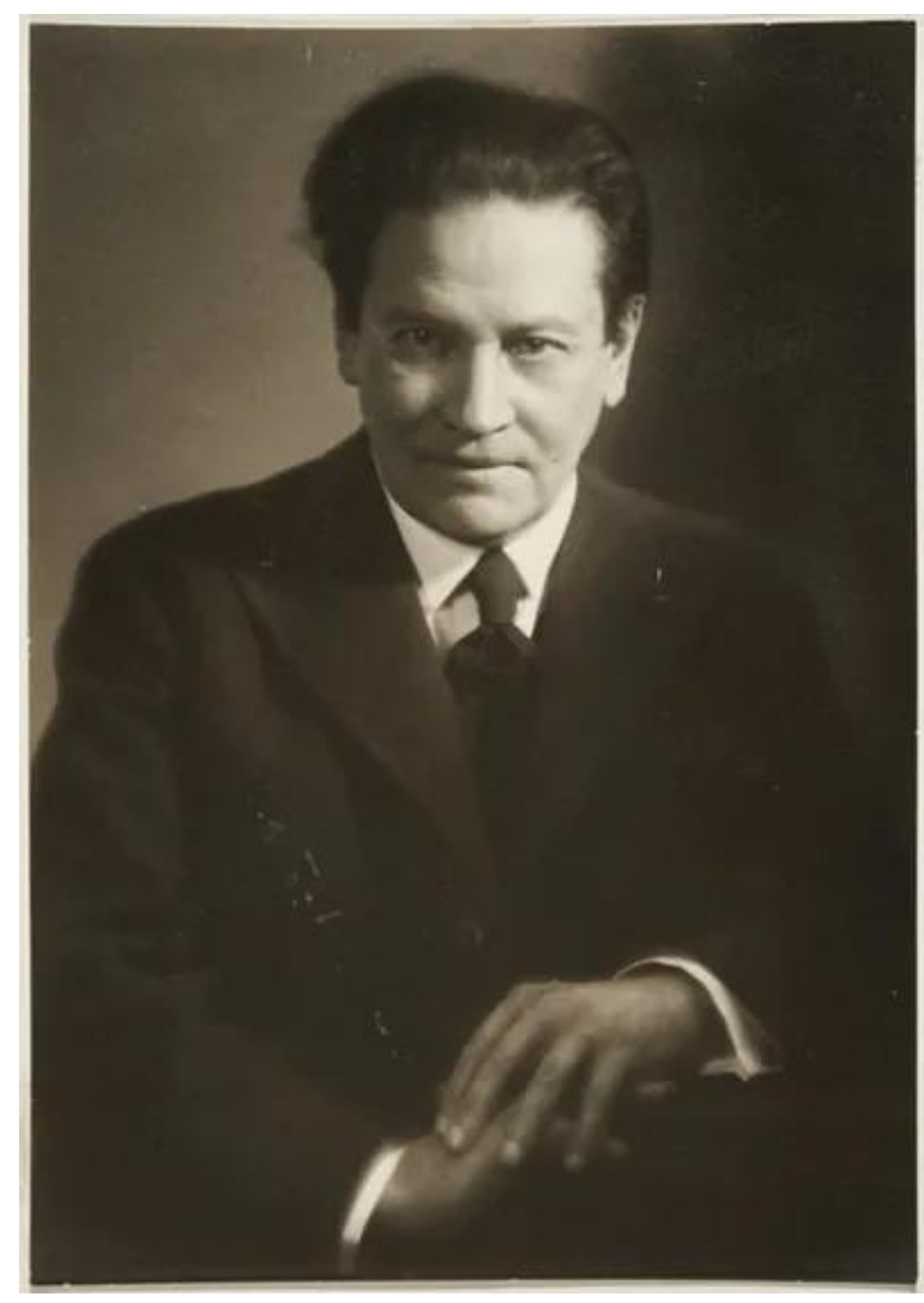

Figure 2.1 Selim Palmgren in the late 1920s. ${ }^{10}$

The diversity of Palmgren's musical and compositional skills—-his blending of different types of music into his works - is on the one hand due to the historical circumstance of his country that aroused a strong inclination to apply national musical elements into his work, and on

\footnotetext{
${ }^{10}$ Kangas, Laila, “Säveltäjä Selim Palmgrenin Lyhyt Suruaika - Musiikin Syntymäpäiväkalenteri,” accessed April 10, 2019, https://yle.fi/aihe/artikkeli/2019/02/16/saveltaja-selim-palmgrenin-lyhyt-suruaika-musiikin-syntymapaivakalenteri.
} 
the other to the experiences of his touring years, which enhanced his insight into the music of cultures that to him were exotic. Kimmo Korhonen praised Palmgren in his book Inventing Finnish Music:

Although the roots of Palmgren's music lie deep in the soil of the Romantic era, he did expand his palette towards impressionism. He used whole-tone scales, parallel chords, augmented triads and textures characteristic of Impressionist piano music. $\mathrm{He}$ is generally credited with introducing Impressionism to Finland. On occasion, Palmgren's music coalesces into a cautious sort of Modernism, for example in the form of dissonant bitonality. On the other hand, from the 1930s onwards his music shows a clear tendency towards Classicism. ${ }^{11}$

Palmgren wrote extensively for solo piano and for voice. He composed over 100 songs as well as more than 100 compositions for men's chorus. "His orchestral output was more limited and his stage music consists only of some incidental music and a single opera, Daniel Hjort."12 In the context of Finnish music at the time, Daniel Hjort is "very free in its tonality, almost unsettled, and it makes much use of the whole-tone scale."13 Besides this, there are suites of incidental music for orchestra, patriotic cantatas, a couple of military/municipal marches, a concert-fantasy for violin and orchestra, a ballade for orchestra and an unfinished clarinet concerto. $^{14}$

Twice married, each time to a famous singer, Palmgren was inspired to compose vocal music. Palmgren's first spouse, Maikki Järnefelt (1871-1929) was a Finnish opera singer (soprano) who obtained much international fame during her career. ${ }^{15}$ Palmgren undertook several

\footnotetext{
${ }^{11}$ Korhonen, Kimmo, “The Mighty Spring Tide of Finnish Music," Inventing Finnish Music. (Finnish Music Information Centre, 2003), 53-54.

12 Parsons, Charles H, "Palmgren: Daniel Hjort," The Record Connoisseur's Magazine, March/April 1998, 174-175.

${ }^{13}$ Korhonen, Kimmo, “The Mighty Spring Tide of Finnish Music," Inventing Finnish Music. (Finnish Music Information Centre, 2003), 54.

${ }^{14}$ Barnett, Rob, "Palmgren Piano Concertos," Classical Music Reviews, accessed April 10, http://www.musicwebinternational.com/classrev/2016/Aug/Palmgren_PCs_ABCD385.htm.

${ }^{15}$ Ala-Könni, Erkki, Tuula Kaurinkoski and Heidi Granholm, Otavan iso Musiikkitietosanakirja 3, (Helsinkin Otava, 1978 ), 308.
} 
extensive European tours, on some of which he was accompanied by her. ${ }^{16}$ She was also a respected pedagogue and was especially known as an interpreter of Wagner roles. In 1904-1906 she recorded about 20 albums for Gramophone ${ }^{17}$ and three in the United States, one in 1921 and two in $1929 .{ }^{18}$ Concert singer Minna Talvik-Palmgren (1902-1983) was Palmgren's second spouse. "She studied singing under the guidance of several teachers, but the most important was Maikki Järnefelt—Palmgren’s first wife."19

Palmgren's music for the piano is distinguished by a profound insight into the capabilities of the instrument, a remarkable faculty for suggesting definite and widely contrasted moods, and an agreeably proportionate mixture of melodic, harmonic and rhythmic invention. ${ }^{20}$ His piano works convey strong nationalistic elements rooted in Finnish musical tradition. As a brilliant concert pianist, he composed five piano concerti in a $19^{\text {th- }}$ century Romantic style reminiscent of Liszt and Schumann. His second piano concerto, "The River," (1913) was a huge success and brought him international renown. Palmgren is also famous for his lyrical and imaginative character pieces. He was a prolific composer, producing more than 300 piano works. His music is not as virtuosic as that of Liszt and Rachmaninoff, but it is neither puerile nor banal. His keyboard compositions are not only technically demanding, but they also require sensitivity from the pianist, to present the emotion and beauty of his works.

\footnotetext{
${ }^{16}$ Oramo, Ilkka. "Palmgren, Selim,” Grove Music Online, accessed April 10, 2019, https://doiorg.www.libproxy.wvu.edu/ 10.1093/gmo/9781561592630.article.20779.

${ }^{17}$ Gramophone is a British classical music on the magazine, which is one of the high-circulation publications in their respective fields. It was founded in 1923 by a Scottish writer Compton Mackenzie. The magazine rewards annually the best-selling art music recordings with the Gramophone Awards.

18 "Järnefelt Maikki," Database of the Finnish Record Archives, accessed April 10, 2019, http://www.aanitearkisto.fi /firs2/nimi.php?Id=J\%E4rnefelt+Maikki.

${ }^{19}$ Kangas, Laila, “Säveltäjä Selim Palmgrenin Lyhyt Suruaika-Musiikin Syntymäpäiväkalenteri,” accessed April 10, 2019, https://yle.fi/aihe/artikkeli/2019/02/16/saveltaja-selim-palmgrenin-lyhyt-suruaika-musiikin-syntymapaivakalenteri. ${ }^{20} \ldots$ "Selim Palmgren," accessed April 10, https://www.fennicagehrman.fi/composers-works/palmgren-selim/.
} 
In 2014, Heikki Poroila published Selim Palmgren's Compositions,${ }^{21}$ which listed the completed compositions of Palmgren's music. Following is a list, from Grove Music Online, of Palmgren's major compositions in various genres:

\section{Major Compositions by Selim Palmgren}

Opera

Daniel Hjort

Piano Concerti

Piano Concerto No. 1 op. 13, 1904

Piano Concerto No. 2 “The River,” op. 33, 1913

Piano Concerto No. 3 "Metamorphoses," op. 41, 1916

Piano Concerto No. 4 “April,” op. 85, 1927

Piano Concerto No. 5, op. 99, 1940

Other Orchestral works

The Seasons, op. 24, 1908

Pastorale, op. 50, 1918

Concert Fantasy, op. 104, vn, orch, 1945

Piano Solo

Sonata in d minor, op. 11, 1900

Fantasy, op. 6, 1901

En route, op. 9, 1901

Toukokuu "May,” op. 27, 1906-1907

\footnotetext{
${ }^{21}$ This book is written in Finnish. The original title is Selim Palmgrenin sävellykset.
} 
24 Preludes, op. 17, 1907

24 Etudes, op. 77, 1921-1922

Sonatine in F major, op. 93, 1935

Nearly 300 additional works for piano solo, in various genres. 


\section{Chapter 3}

\section{Analytical Study of 24 Preludes, op. 17}

Selim Palmgren's 24 Preludes, op. 17, were written in 1907. This set is said to be an homage to Chopin. ${ }^{22}$ Coincidently, there is another composer, the Russian Felix Blumenfeld (1863-1931), who also composed a set of 24 preludes (1892-1894) with the same opus number. Palmgren's preludes do not follow the key schemes of either Chopin in his 24 Preludes, op. 28 (circle of fifths with relative minors following each major key) or Bach in his Well-Tempered Klavier (beginning with $\mathrm{C}$ major and moving in ascending half-steps). However, it does cover, albeit somewhat randomly, the twelve major and twelve minor keys (see Appendix). Finnish pianist and pedagogue Timo Mikkilä (1912-2006) wrote these words for the preface to Fennica Gehrman's edition of Palmgren's 24 Preludes, op. 17:

Selim Palmgren has been called the "Chopin of the North." But he has sometimes been called the "Schumann of the North" too, Schumann having been the ideal of his youth. Since Palmgren was himself an excellent pianist, it is no wonder that these little pieces dating back to the early years of our century lend themselves admirably to performance on the piano. Many of them evoke an immediate response from the listener with their sensitively felt northern mood. In spite of the impressionistic lyrical style reflecting the period during which they were composed, the composer's personal idiom is at all times clearly recognizable. ${ }^{23}$

Palmgren's 24 Preludes, op. 17, reveal the inflections of late Romanticism, not only presenting traditional Finnish folk tunes and impressionist styles, but also displaying a wide range of types: technical studies, compositional exercises, and salon pieces. Although this set of preludes is not written for virtuosic display, its diverse, expressive, and lyrical characteristics,

\footnotetext{
${ }^{22}$ Wright, David, “Selim Palmgren," accessed April 10, 2019, https://www.wrightmusic.net/pdfs/selim-palmgren.pdf.

${ }^{23}$ Mikkilä, Timo. "Preface,” Selim Palmgren 24 Prelude Op. 17. (Fennica Gehrman, 2004), 1
} 
along with its moderate technical demands, provides an excellent pedagogical choice for intermediate-level students. This chapter will focus on analyzing Palmgren's 24 Preludes, op. 17, including discussions of structure, harmony, interesting compositional points, and pedagogical concerns.

\subsection{Prelude No.1}

The first piece of this set, Prelude No. 1 in E minor, features canonic contrapuntal writing. It is a brief piece—only 17 measures and five phrases long—and not technically demanding. It is a good example of how Palmgren composes an entire piece based on the opening theme.

The first phrase, which is the opening theme, starts with three eighth-note upbeats and lasts until the second beat of $\mathrm{m}$. 3. It contains two sections-a long legato melodic line followed, after an eighth rest, by a four-note slurred motif. The first half of the theme uses modified canonic writing, with the left hand entering a beat after the right. It is also worth noticing that the last three eighth notes in the long phrase reverse the intervals of the three eighth notes in the slur (see Figure 3.1.1).

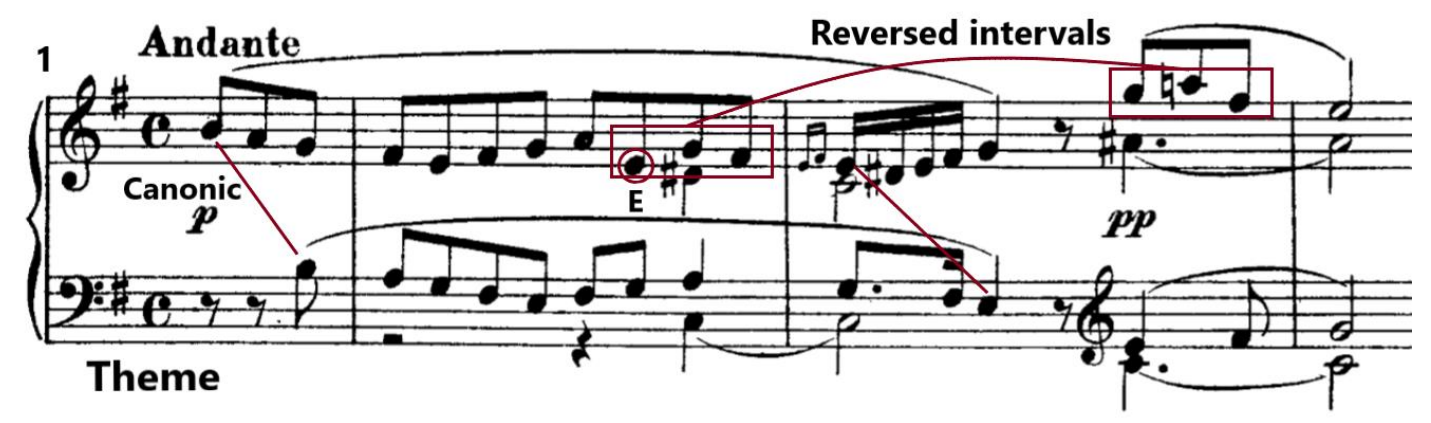

(C) 2004 by Fennica Gehrman Publisher. Used with Permission.

Figure 3.1.1 Selim Palmgren, 24 Preludes, op. 17, No. 1, mm. 1-3. 
The second phrase is a repetition of the opening theme, but with some differences: the texture becomes thicker, with the right-hand theme this time presented in octaves instead of single notes; the left-hand eighth notes in the first beat of $\mathrm{m}$. 5 change from a downward to an upward movement in the same place of the opening theme; and the intervals in the slurred section differ from those in the opening (see Figure 3.1.2).

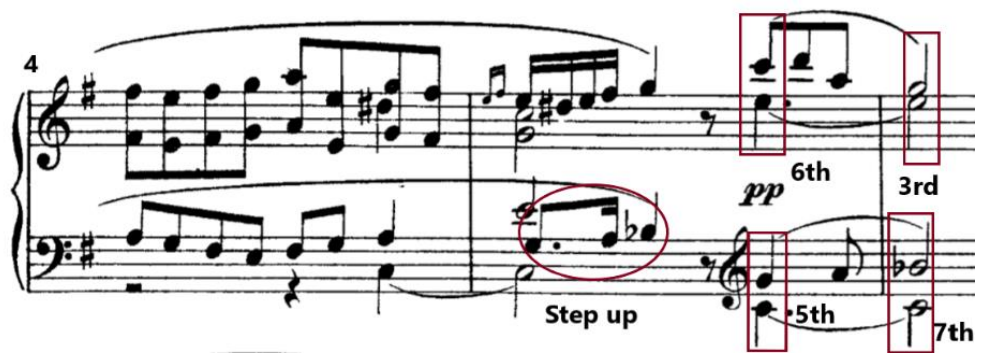

(C) 2004 by Fennica Gehrman Publisher. Used with Permission.

Figure 3.1.2 Selim Palmgren, 24 Preludes, op. 17, No. 1, mm. 4-6.

The relationship of thirds appears frequently in the third statement of the phrase. First, the legato line is a third down from that in the opening theme. Second, in m. 8, the sixteenth-note figure appears twice, the second time a third down from the first. Interestingly, there are double bars at the beginning and the end of $\mathrm{m} .9$, the only measure in the prelude with a time signature of $2 / 4$, the rest of the piece being in $4 / 4$. These two differences of the sixteenth-note figure being repeated and the added bar in $2 / 4$ render the length of the phrase the same as its first statement. However, the 2/4 measure is also the beginning of a new phrase. Thus, the two-beat bar (m. 9) causes the third and the fourth phrases to overlap: it is both the tail of the third phrase and the head of the fourth - a short episode that derives from the fragments of the theme (see Figure 3.1.3). 


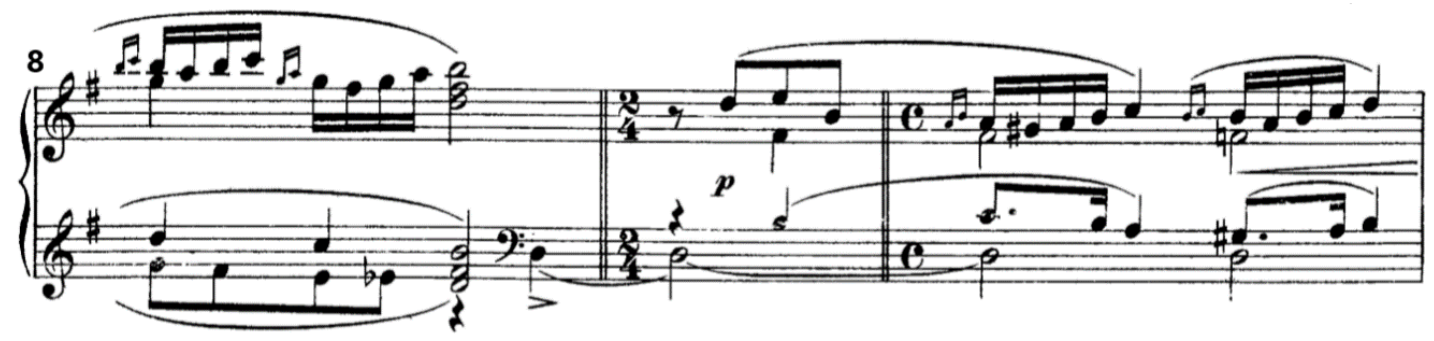

(C) 2004 by Fennica Gehrman Publisher. Used with Permission.

Figure 3.1.3 Selim Palmgren, 24 Preludes, op. 17, No. 1, mm. 8-10.

The last part of the prelude restates the opening theme's legato line twice but a step higher. The repeat consists of a series of chromatic chords that enrich the color. Throughout the coda, the left hand remains in the dominant to reinforce the E-minor tonic. After a deceptive cadence in the first beat of $\mathrm{m} .15$, the piece ends with an E-minor authentic cadence.

\section{$\underline{3.2 \text { Prelude No.2 }}$}

The second prelude is titled Im Volkston (In Folk Style), reflecting that the main theme is derived from a folk tune. The piece is in A major. It is similar to the first prelude in that the entire piece is built upon the opening theme. This prelude, containing only 16 measures, is even shorter than the previous one. Structurally, it reveals a one-part form that consists of two sections, the second derived from the first, with two symmetrical phrases each (AA'BB'). Rhythmically, this prelude consists almost entirely of the following pattern: two eighth notes followed by two quarter notes. Although it is not clear where the original folk tune comes from, the 3/4 beat and the Andante semplice tempo marking suggests the feature of an elegant dance.

The A section is divided into two four-bar phrases, each of which is subdivided into two small phrases. The second phrase is formed from the materials of the first. However, not only 
does the theme in the left hand change into octaves, but also another voice is added to thicken the texture from three voices to four.

Materials in the B section are derived from section A but with some differences: First, the rising and then falling major seconds in the second and third beats of m. 1-2 in section A become rising and falling perfect fifths in $\mathrm{m}$. 9-10 (see Figure 3.2.1). Moreover, the inner voices in the B section are more active than in the previous section, resulting in a richer and more chromatic texture than in the A section. However, the dynamics in this section are much softer compared to the opening section—-for instance, the last phrase of Section B begins $p p$ compared to $m f$ in the same place of section A.
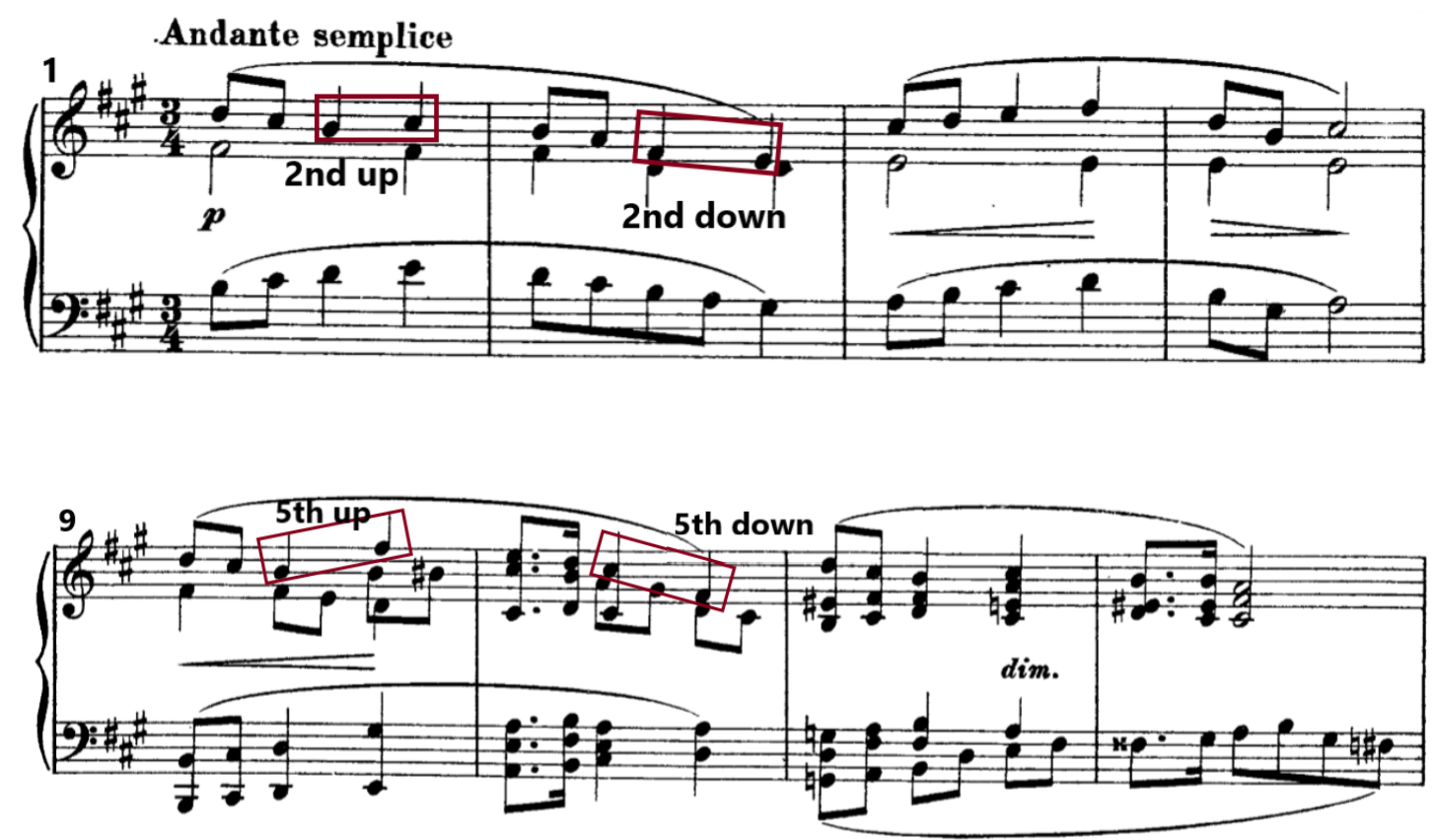

(c) 2004 by Fennica Gehrman Publisher. Used with Permission.

Figure 3.2.1 Selim Palmgren, 24 Preludes, op. 17, No. 2, mm. 1-4, 9-12.

Most parts of this prelude exhibit conjunct motion and pose little technical difficulty. However, the contrapuntal feature of this prelude demands control that not only requires the top 
melodic line to be clearly stated within the multi-voiced writing, but also simultaneously maintaining smooth and legato phrases.

\section{$\underline{3.3 \text { Prelude No. } 3}$}

Besides the relatively long duration of the piece, Prelude No. 3 differs from the previous two in many aspects. First, compared to the previous two that are based entirely upon one theme, the structure of Prelude No. 3 is in ABA form. In addition, the characteristics of the piece are more variable than with the other two. Prelude No. 3 is marked Allegretto con grazia, which means a moving tempo with a graceful flowing style. Besides this, there are many more performance instructions such as simile, dim. molto e rit., a tempo, ritenuto, as well as the frequent crescendo and decrescendo dynamics indicated in the piece. Moreover, the technical demands of this prelude are much higher. Prelude No. 3 is a fast and lively piece with many repeated chords, octaves, jumps, and staccato thirds and fourths, which require much more advanced playing skills than do the previous two.

The opening A section is in A major and extends from the beginning to $\mathrm{m}$. 29. The first three measures are the introduction and remain in the tonic. It consists of repeated chords and provides a feeling of a military horn sound. The first theme starts from $\mathrm{m} .4$ to $\mathrm{m}$. 11 . It consists of two four-bar phrases that are derived from the introduction material. The second theme extends from $\mathrm{m} .12$ to the downbeat of $\mathrm{m}$. 24. Staccato markings and constantly rising and falling figures in both hands result in a more lively and lyrical characteristic compared to the first theme. In mm. 20-21, there are three groups of four-note figures that cross the bar line in a falling sequence. The accents on the first notes of these four-note groups provide a hemiola 
effect (see figure 3.3.1). The section from m. 25 to m. 29 is a codetta-like section that refers back to the repeated-chords figure in the opening. It ends in German augmented-sixth chords and turns the $\mathrm{B}$ section into $\mathrm{G}$ major.

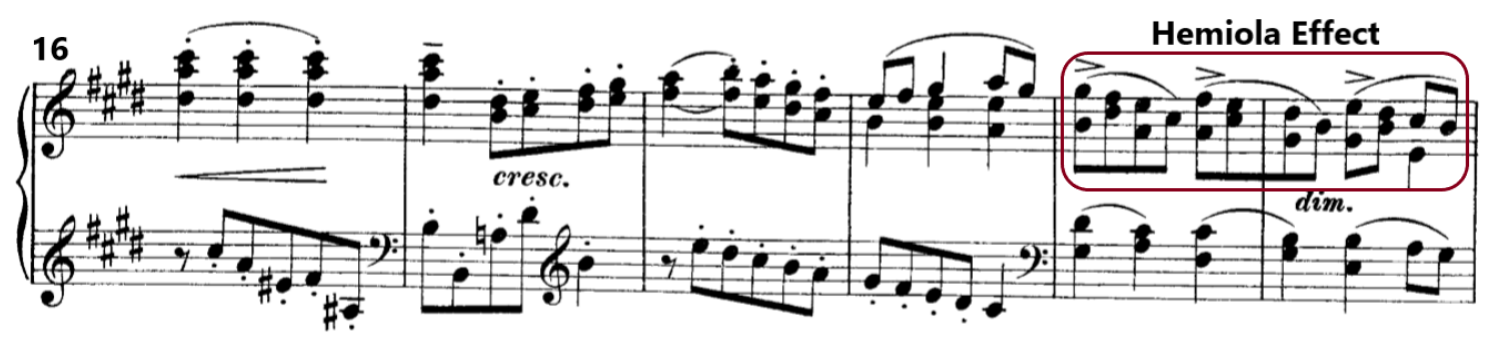

(c) 2004 by Fennica Gehrman Publisher. Used with Permission.

Figure 3.3.1 Selim Palmgren, 24 Preludes, op. 17, No. 3, mm. 16-21.

The B section is 22 measures long and consists of a repeated ten-measure section followed by a two-measure figure. Materials in this section mostly imitate the first theme. The section begins in $\mathrm{G}$ major, modulates to $\mathrm{E}$ minor in $\mathrm{m} .32$ for only two bars, and then returns to $\mathrm{G}$ major. Because of the brevity of the B section, no new materials are introduced. However, the dynamics vary often within it. After the repeat, the harmony returns to the dominant of E major, arriving finally at the tonic at the downbeat of $\mathrm{m}$. 43 , which is beginning of the section $\mathrm{A}$ '- the restatement of the opening section (See figure 3.3.2). 

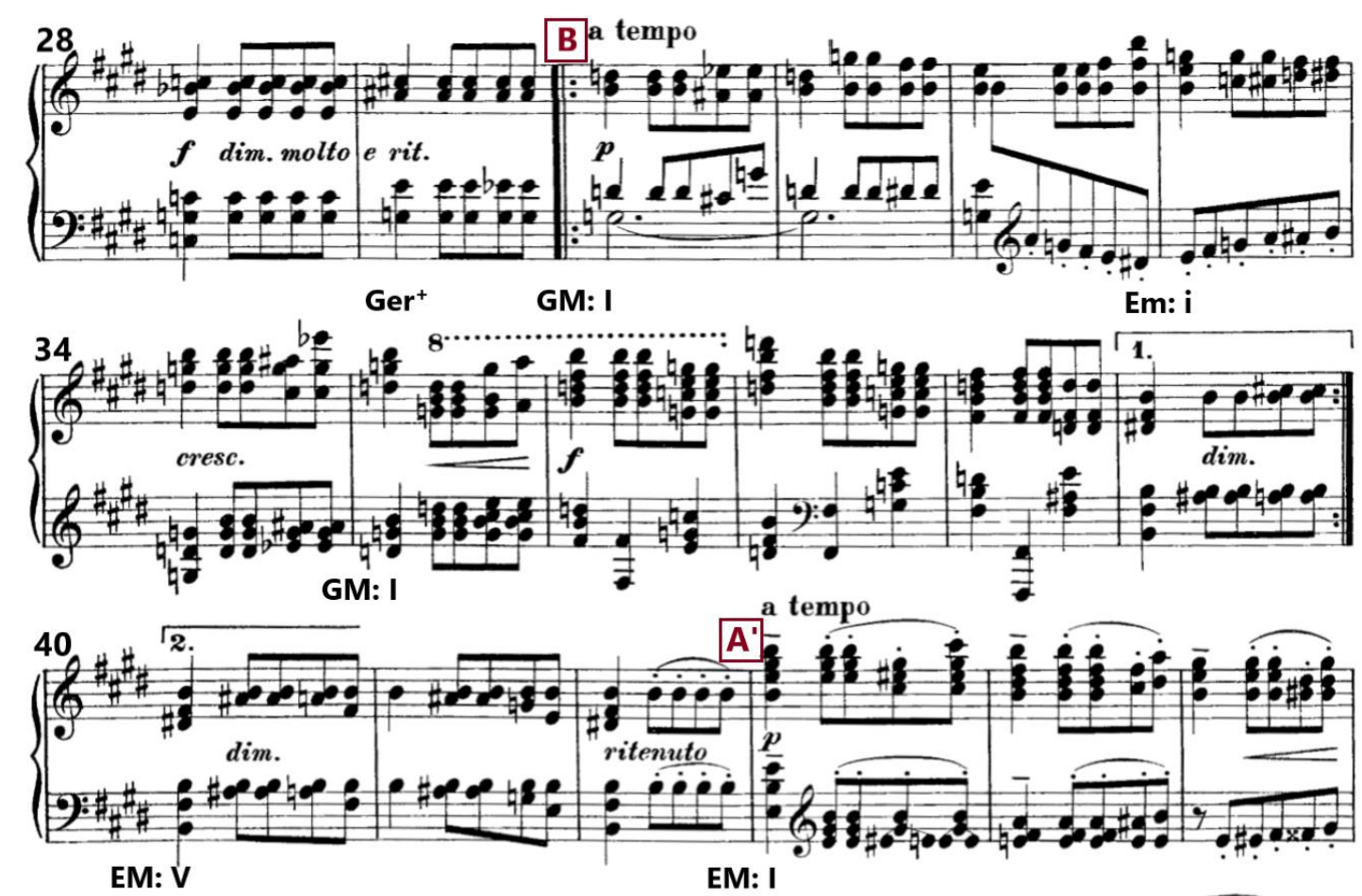

(C) 2004 by Fennica Gehrman Publisher. Used with Permission.

Figure 3.3.2 Selim Palmgren, 24 Preludes, op. 17, No. 3, mm. 28-45.

Structurally, this prelude is simple and straightforward. However, it indicates how Palmgren employs rubato and dynamic changes to make this repeated march-like rhythm into romantic expressive music.

\subsection{Prelude No. 4}

Although its key signature is four sharps, the $C^{\#}$ minor tonic of Prelude No. 4 is not introduced until the Coda. This prolongation of the presentation of the tonic renders the prelude more harmonically complicated than the previous three, which have a clear and steady key. It is a sweet waltz-like piece, reflected by its tempo marking of Tempo di Valse and the performance instruction of dolce cantando. 
The form of this prelude is ABA' with a coda. It has a traditional waltz rhythm with the accent on the downbeat. The A section extends from the beginning to $\mathrm{m}$. 28 . The melody in the top line is simple, having a rhythmic pattern consisting of three dotted half notes followed by a short slur formed by eighth notes. The portato accompaniment figure on the weak beats of both hands is reminiscent of the lightness of a waltz (see figure 3.4.1). It consists of a series of seventh chords without resolving to the tonic. Also, it contains numerous accidentals in half-step sequences that are tonally ambiguous.

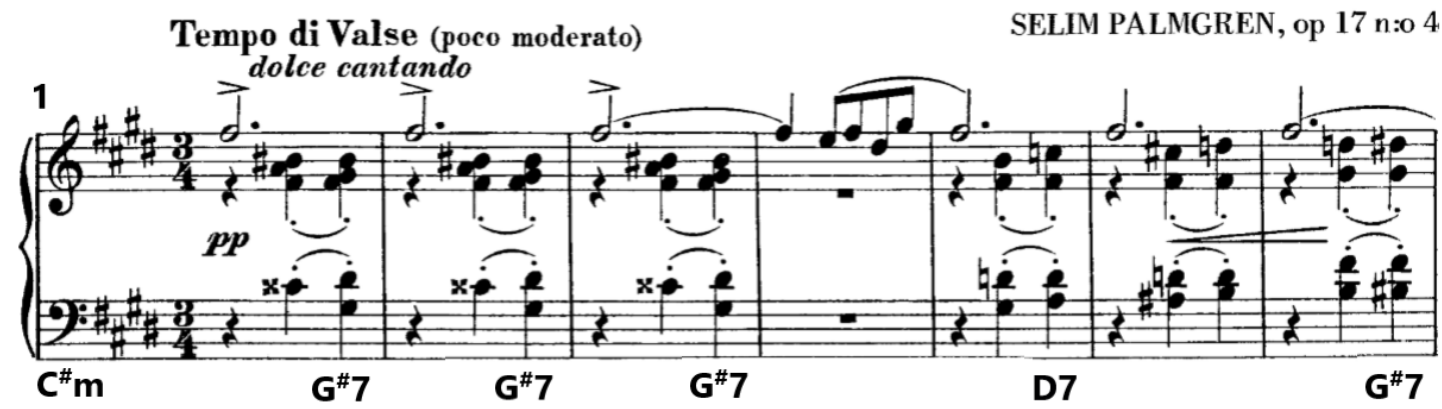

(C) 2004 by Fennica Gehrman Publisher. Used with Permission.

Figure 3.4.1 Selim Palmgren, 24 Preludes, op. 17, No. 4, mm. 1-7.

The B section, which begins at m. 29, is even more ambiguous in tonality. It imitates the opening section, but in a third-up relationship (although an octave lower). It is a short section that goes through several chord progressions from $\mathrm{D}^{7}-\mathrm{B}^{7}-\mathrm{C}^{\# 7}-\mathrm{A}^{7}-\mathrm{F}^{7}$ followed by five bars of a melodic line without accompaniment. This single voice, marked ritardando, presents a strong sense of reluctance. In m. 49 the resistance is finally overcome with the return to A' and repetition of the opening section. 
The coda extends from $\mathrm{m} .77$ through the end. At this point, the pure chord of $\mathrm{C}^{\#}$ minor makes its first appearance and remains until the end. Therefore, the key is finally established (see figure 3.4.2).
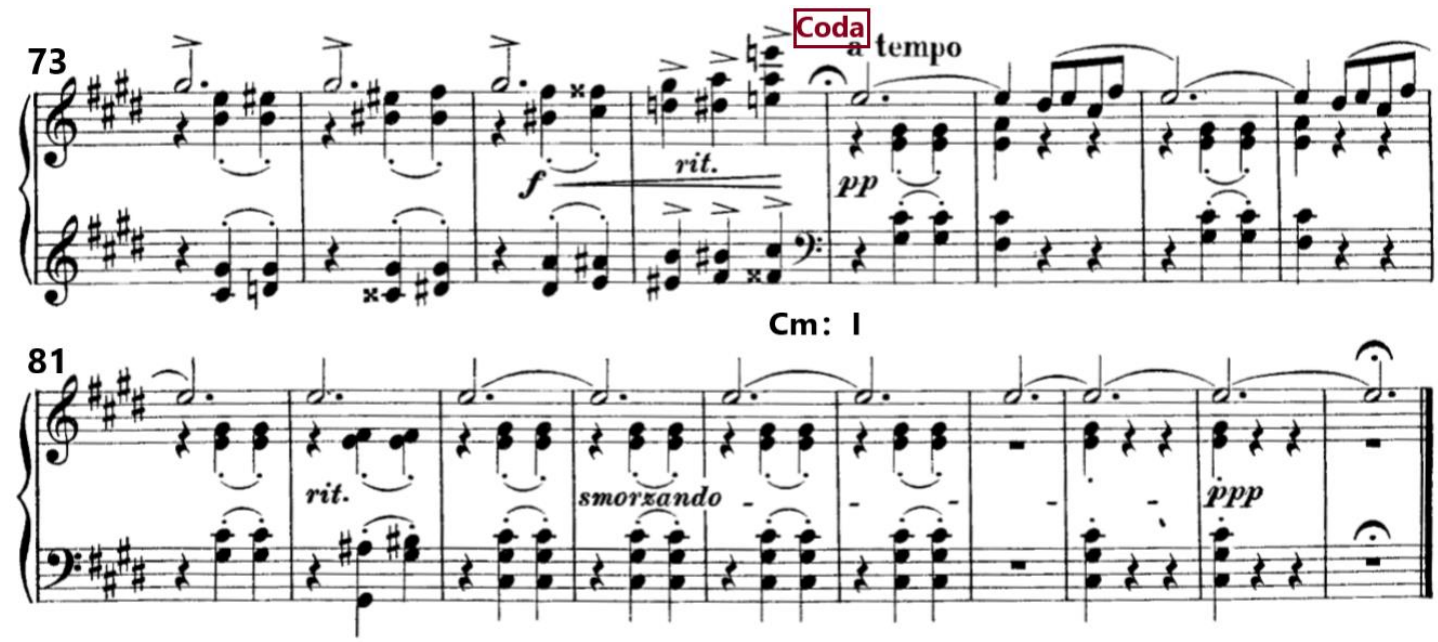

(C) 2004 by Fennica Gehrman Publisher. Used with Permission.

Figure 3.4.2 Selim Palmgren, 24 Preludes, op. 17, No. 4, mm. 73-90.

Even though the phrase structure in Prelude No. 4 is consistent, the inner section is easy to distinguish since Palmgren separates each section by an a tempo marking. Furthermore, near the end of each section, ritardando and fermata markings are added that help to create a sense of sectional change. Prelude No. 4 is a good introduction to waltz. It follows the traditional waltz rhythm and has little technical difficulty. Nonetheless, the chromaticism of this piece is a good challenge for students to practice sight-reading skills and to further an understanding of harmony. 


\section{$\underline{3.5 \text { Prelude No. } 5}$}

Since Beethoven and Schubert, intervallic relationship has become a common compositional technique. Romantic composers such as Chopin, Liszt, and Brahms often apply relations of thirds, fourths, fifths, etc. in their repertoire. And Palmgren does the same. Although the use of thirds can be found in previous preludes, Prelude No. 5 is an example of how Palmgren extensively utilizes the relationship of thirds throughout the music.

Prelude no. 5 is in G major. It is a rapid running piece with three voices. It reveals a onepart form with three sections. The first section extends from the opening to the downbeat of $\mathrm{m}$. 31. It contains two different materials. Material A is eight bars long and contains two four-bar identical phrases. The running notes in both hands show a parallel-tenth relationship, as the left hand plays an octave plus a third below the right hand. The inner voice stays on the dominant note of $\mathrm{D}$ in order to establish the key of G major (see figure 3.5.1).

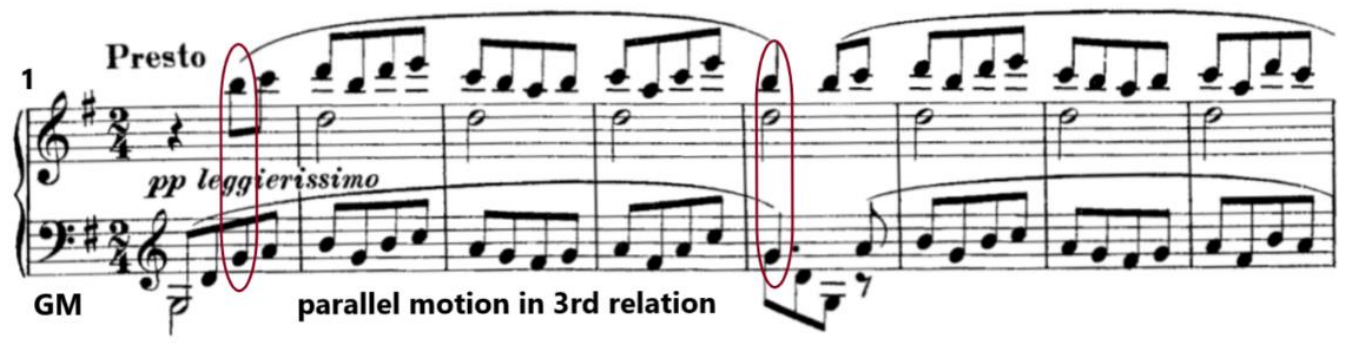

(C) 2004 by Fennica Gehrman Publisher. Used with Permission.

Figure 3.5.1 Selim Palmgren, 24 Preludes, op. 17, No. 1, mm. 1-8.

Material B starts from the second beat of $\mathrm{m} .9$ and lasts through the downbeat of m. 27 . Similarly, the second part is divided into two identical eight-bar sections, each containing a series of small phrases. The two outer voices maintain an intervallic relationship of a third. In addition to that, within the top voice, the first two legato phrases are in third relationship as well. 
Unlike the first section, the inner voice of this section displays descending motion that moves from A to C (see figure 3.5.2). Material B ends on an A-minor chord and connects with a fourbar episode that brings the passage back to the tonic of $\mathrm{G}$ major.

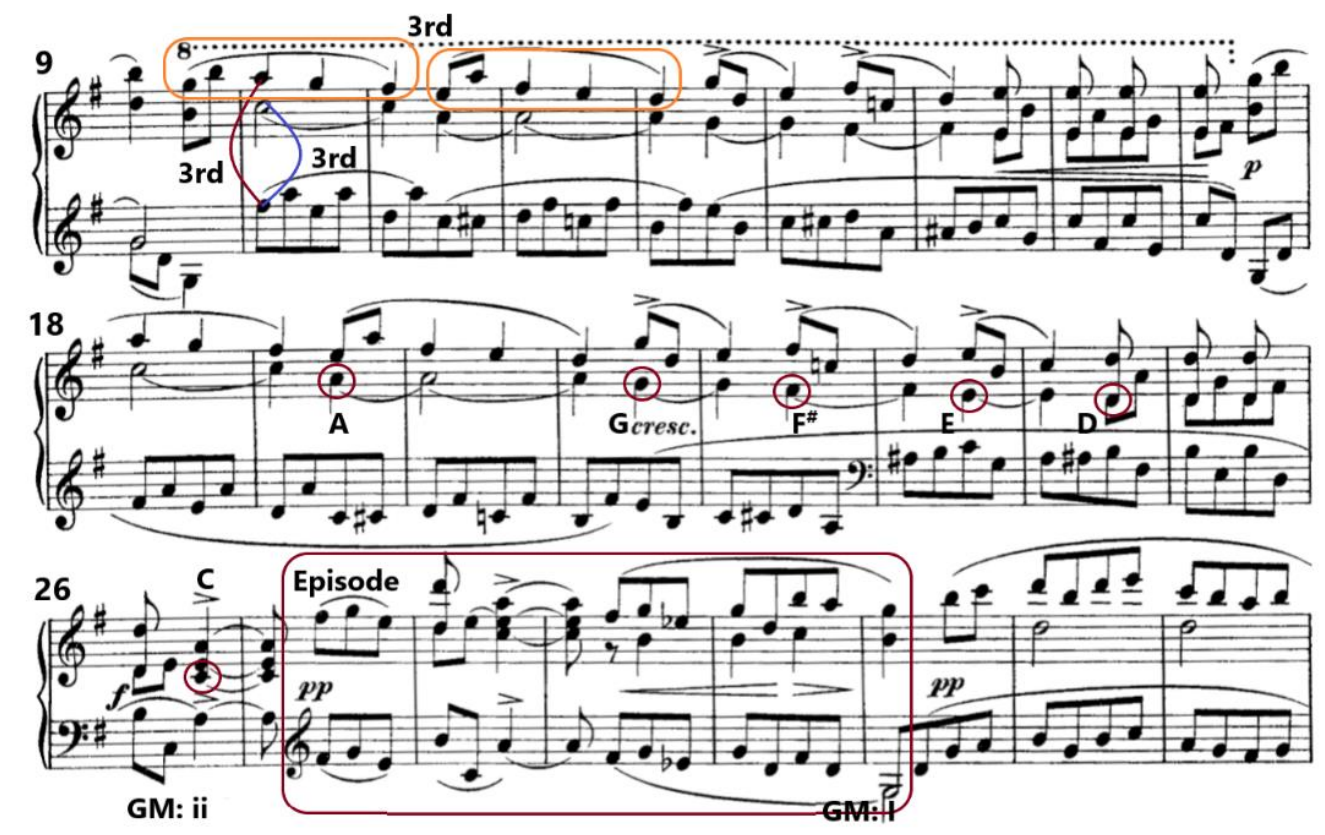

(C) 2004 by Fennica Gehrman Publisher. Used with Permission.

Figure 3.5.2 Selim Palmgren, 24 Preludes, op. 17, No. 5, mm. 9-33.

The second section lasts from the upbeats to $\mathrm{m} .32$ until the downbeat of $\mathrm{m}$. 84 . The materials in this section come mainly from the first part but modulate to different keys. We see a restatement of material $\mathrm{A}$ at the beginning and then the repetition of a fragment of it through $\mathrm{C}$ major, $\mathrm{A}^{\mathrm{b}}$ major and $\mathrm{A}$ minor. Finally, it returns to G major at $\mathrm{m}$. 64 and is followed by the restatement of material $\mathrm{B}$.

Material A is stated for the last time in the coda section from the pickup to m. 85 , reinforcing the key of $\mathrm{G}$ major. A poco accelerando instruction appears near the end of the last long phrase. It is a six-bar ascending line in a relationship of a third that resembles the pattern of 
material A (see Figure 3.5.3). The piece ends with a perfect authentic cadence with a tempo. Palmgren here uses $p p p$ for the last two chords along with portato marks, creating a feeling of fading away.

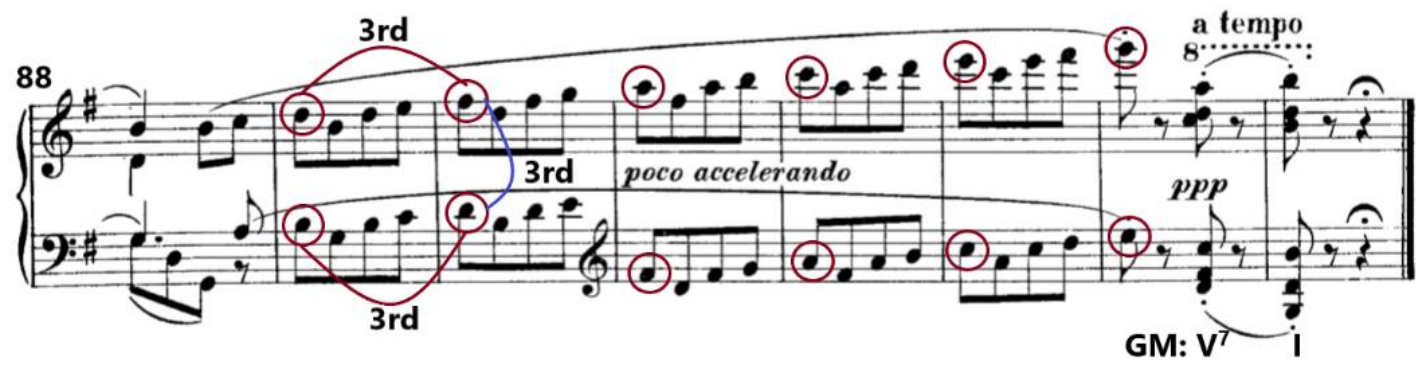

(C) 2004 by Fennica Gehrman Publisher. Used with Permission.

Figure 3.5.3 Selim Palmgren, 24 Preludes, op. 17, No. 5, mm. 88-95.

From a technical aspect, prelude No. 5 is marked Presto, which places difficult demands upon the pianist, particularly as the dynamic markings in most parts of the piece range are soft, ranging from $p$ to $p p p$. The piece provides a good exercise for students to learn to play fast and clear notes under soft dynamic circumstances.

\subsection{Prelude No. 6}

Following the Sarabande writing scheme of the Baroque era, Prelude No. 6 is written in traditional style: triple meter, Andante cantabile tempo, and contrapuntal texture. However, unlike the general binary (AB or AA'BB') form of the Baroque Sarabande, Prelude No. 6 is in ternary (ABA') form, with a brief middle section.

Beginning in G minor, Prelude No. 6 is comprised of four voices. The inner voices are chromatic, with much half-step voice leading. The opening A section mostly features conjunct 
motion and extends from the opening to the downbeat of $\mathrm{m}$. 17. It consists of two similar passages that are in call-and-response setting. For instance, passage $a$ is eight bars long and is mainly in descending motion, while passage $b$ is more likely to climb up. Figure 3.6.1 shows the comparison of the opening two passages.
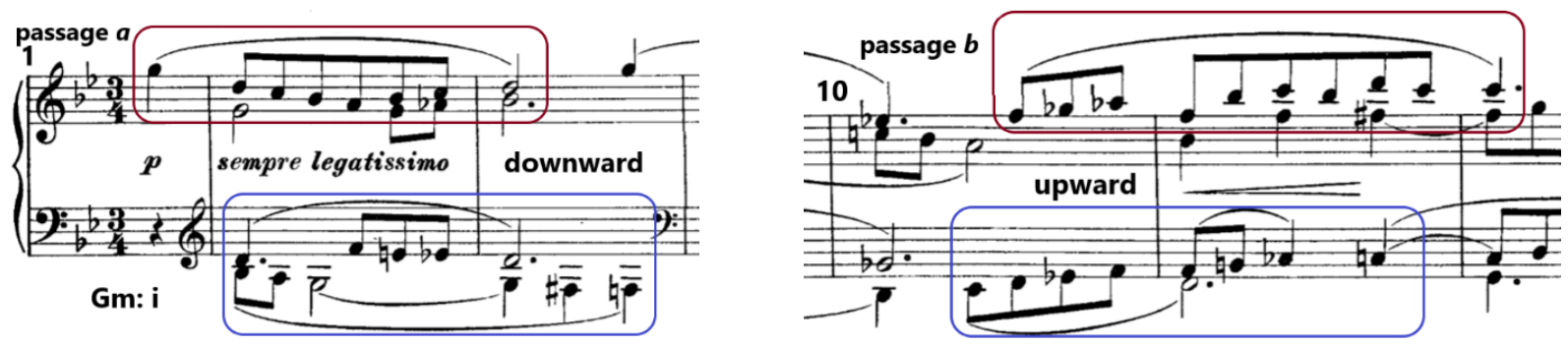

(C) 2004 by Fennica Gehrman Publisher. Used with Permission.

Figure 3.6.1 Selim Palmgren, 24 Preludes, op. 17, No. 6, mm. 1-2, 11-12.

Materials in the B section are mainly derived from the first section; however, the inner voices are more active and chromatic, arousing tonal ambiguity. This section is only eight bars long. The last section, which returns to $\mathrm{G}$ minor, begins at $\mathrm{m} .26$ and mostly restates the opening section. The last five bars of this prelude reveal two descending scales, one starting in $\mathrm{F}$ and the other in C. Palmgren indicates that the second one is to be played with an accent on each note. Both of them end with $\mathrm{G}$, thus fortifying the tonic. The tempo in the last two bars changes to Largo, creating a strong sense of cadence. In addition, the last tonic $\mathrm{G}$ chord is held for four beats, along with three inner-voice notes $\mathrm{C}, \mathrm{A}, \mathrm{B}^{\mathrm{b}}$, recalling one of the common approaches for cadences in the Baroque era (see figure 3.6.2). 


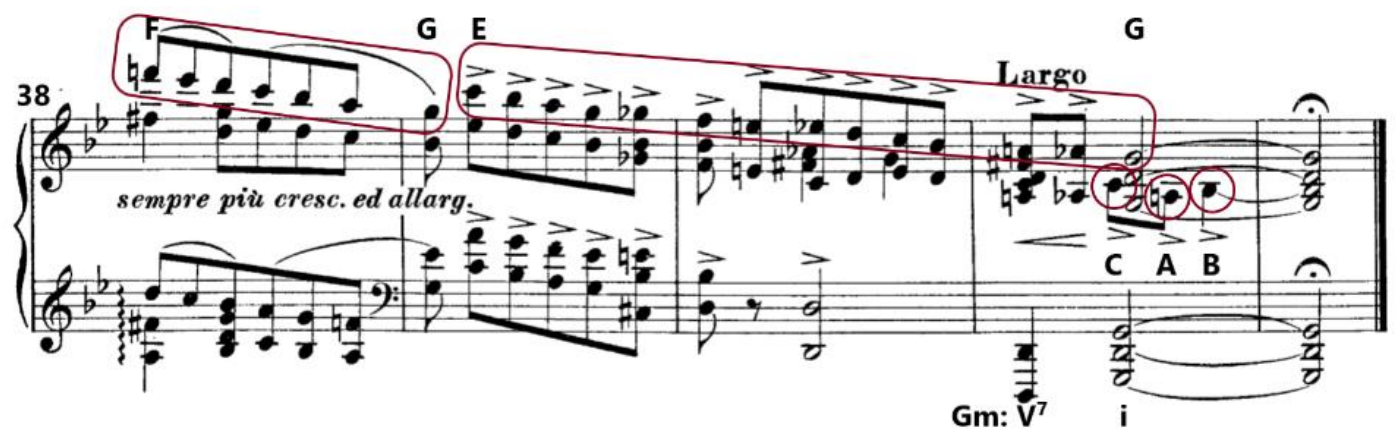

(C) 2004 by Fennica Gehrman Publisher. Used with Permission.

Figure 3.6.2 Selim Palmgren, 24 Preludes, op. 17, No. 6, mm. 38-42.

This prelude reflects Palmgren's intention of looking back to a genre created in the Baroque era. Nonetheless, he also infuses romantic elements into the piece so that it does not sound so completely "baroque." Prelude No. 6 has a romantic spirit; however, this spirit is accommodated in a baroque shell. For instance, he uses many performance expression marks such as sempre legatissimo, dim. molto e rit., and sempre piu cresc. ed allarg. to give performers more flexibility to shape the piece. For pedagogical concerns, Prelude No. 6 is a good example of introducing the genre of Sarabande. The contrapuntal texture of this prelude requires good attention to efficient fingerings in order to keep each voice connected and flowing both vertically and horizontally.

\subsection{Prelude No. 7}

Prelude No. 7 in D major returns to a one-part structure and features perpetual motion. The entire piece is built upon the opening theme. This prelude is written in four voices that are presented in a consistent rhythmic pattern - the two inner voices interlace with the outer two. The long lyrical theme appears in the outer two voices while the inner two are accompaniments that come in a half beat later than the theme, providing the piece with a syncopated feeling. 
Structurally, the piece is divided into several long legato phrases based on the opening thematic idea. It can be subdivided into three small sections plus a coda ( $\left.a b a^{\prime} \operatorname{cod} a\right)$. Section $a$ contains the first two phrases and extends from the opening to $\mathrm{m}$. 9. The outer voices are in parallel octave motion, while the inner two are in seconds - the upper voice stays on note B and lower one is in A all the way until the downbeat of m. 9, when they change into $C^{\#}$ and $B$, respectively. This feature creates a succession of consonant (octave) and dissonant (second) acoustics (see Figure 3.7.1).

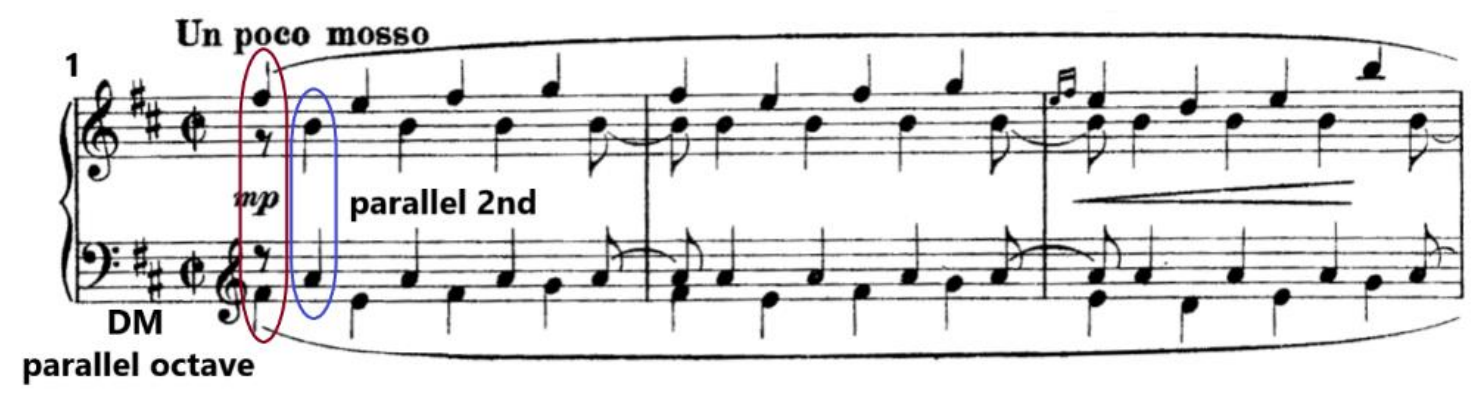

(C) 2004 by Fennica Gehrman Publisher. Used with Permission.

Figure 3.7.1 Selim Palmgren, 24 Preludes, op. 17, No. 7, mm. 1-3.

Section $b$, starting from $\mathrm{m} .10$ and extending to $\mathrm{m}$. 23, consists of thematic materials similar to those of section $a$. However, the two outer voices in this section turn into a relationship of thirds instead of octaves. In addition, compared to the opening section, the inner voices in this section alternate between intervals of seconds and thirds (see Figure 3.7.2). A two-bar single voice line is presented in the upbeat to $\mathrm{m}$. 22 which acts as an episode that transitions the piece into the next section. 

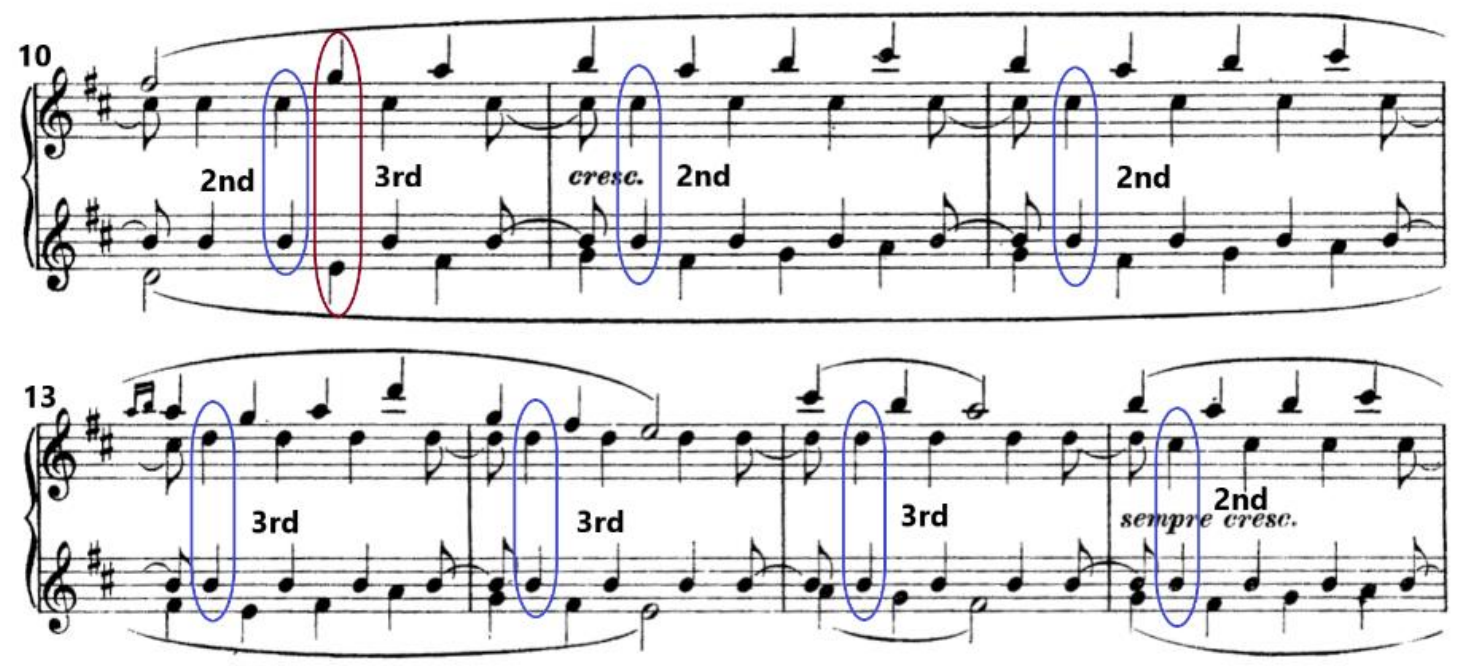

C 2004 by Fennica Gehrman Publisher. Used with Permission.

Figure 3.7.2 Selim Palmgren, 24 Preludes, op. 17, No. 7, mm. 10-16.

Section $a$ ' starts from m. 24 and mainly restates the thematic idea an octave lower than in the opening. A fermata is inserted at the end of $\mathrm{m} .30$ which splits the original phrase into two. Moreover, the texture of the second half is changed from a syncopated rhythm into vertical chords and acts as a coda-like section that presents a strong sense of closure (see Figure 3.7.3).

\section{Coda}

\section{Poco meno mosso}

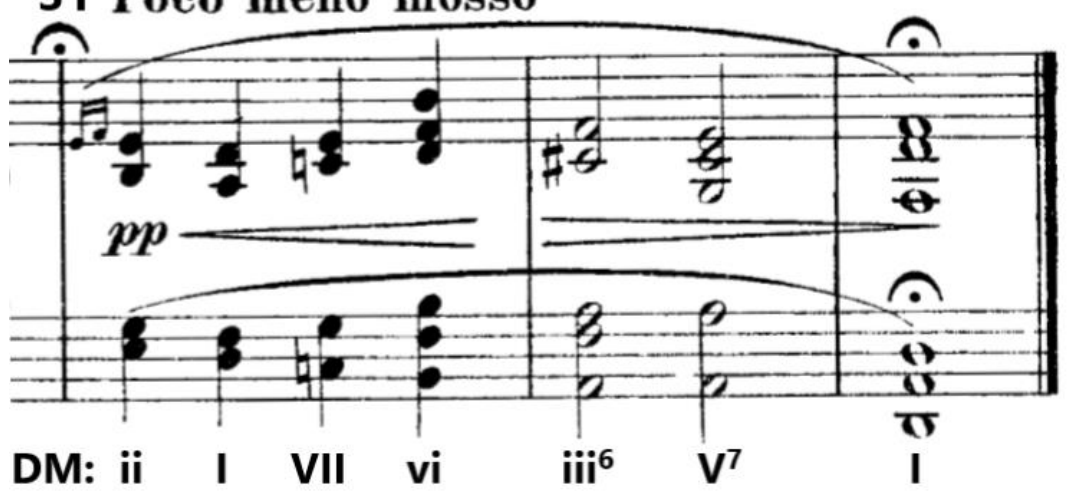

(C) 2004 by Fennica Gehrman Publisher. Used with Permission.

Figure 3.7.3 Selim Palmgren, 24 Preludes, op. 17, No.7, mm. 31-33. 
From a performance aspect, both the texture and rhythm of Prelude No. 7 are quite simple and easy to learn. However, it requires good control of balance since the accompaniments of this prelude are in the inner voices and are executed by both thumbs. It requires careful attention to control the thumbs so that the accompaniments will not be overplayed, allowing the thematic idea in the two outer voices to be clearly heard.

\section{$\underline{3.8 \text { Prelude No. } 8}$}

From a textural aspect, Prelude No. 8 resembles No. 7 in several ways that make it easy to pair them together. First, both preludes are written in four voices and in perpetual motion. In addition, the thematic idea of both preludes stays in the two outer voices while the inner two constitute the accompaniment. However, their musical characteristics are at two extremes. If Prelude No. 7 can be labeled as a tender piece, then Prelude No. 8 is its diametric opposite. The performance indication Allegro feroce makes evident the furious and violent nature of this prelude. There is no question that Prelude No. 8 requires high technical skill to manage the big jumps, restless octaves and chordal progressions that occur from beginning to end.

Prelude No. 8 is in B minor. Structurally, it exhibits binary form with a coda. Each part is delineated by its double bar signs. The A section contains two eight-bar identical phrases but in different registers (the second phrase appears an octave below the first one). The rhythmic pattern resembles Prelude No. 7, in that the outer two voices begin on the downbeats while the inner two voices come in a half beat later. Both move in a parallel-octave relationship (see Figure 3.8.1). 


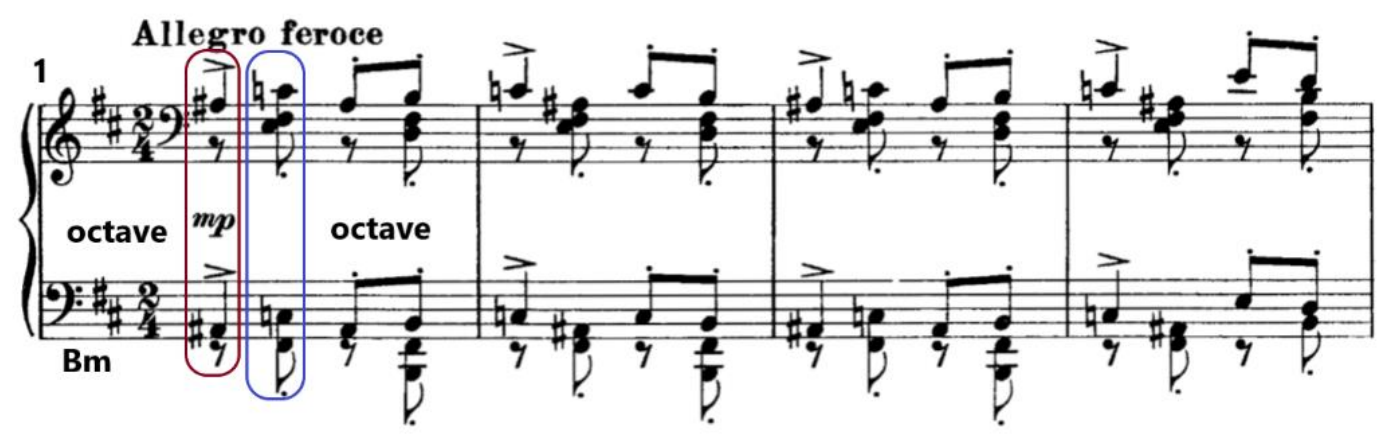

(C) 2004 by Fennica Gehrman Publisher. Used with Permission.

Figure 3.8.1 Selim Palmgren, 24 Preludes, op. 17, No. 8, mm. 1-4.

The materials in the B section derive mainly from the previous section but are presented with a thicker texture. The opening theme begins on note $\mathrm{F}^{\#}$, which is in the relationship of a third to the opening section. Also, the dynamics in this section are much heavier. In addition, many performance indications such as con strepito, sempre e furioso assai, la seconda volta sempre piu acceler. Il. tempo are added, all of which contribute to its wild and ferocious nature.

The Coda starts at m. 64, right after the repeat of section B, where the time signature changes to the extremely rare 1/2. This section is marked Presto right from the beginning. After six bars it gradually gains intensity with the instruction sempre più agitato. This section features a series of chord progressions that alternate between the right hand and the left, moving in a downward relationship of thirds, $A^{\#}-F^{\#}-D$ (see Figure 3.8.2). Seventeen measures from the end, the tempo is marked Prestissimo, and the dynamics progress from $f f$ to $f f f$, pushing the piece to its peak of strength and excitement. 

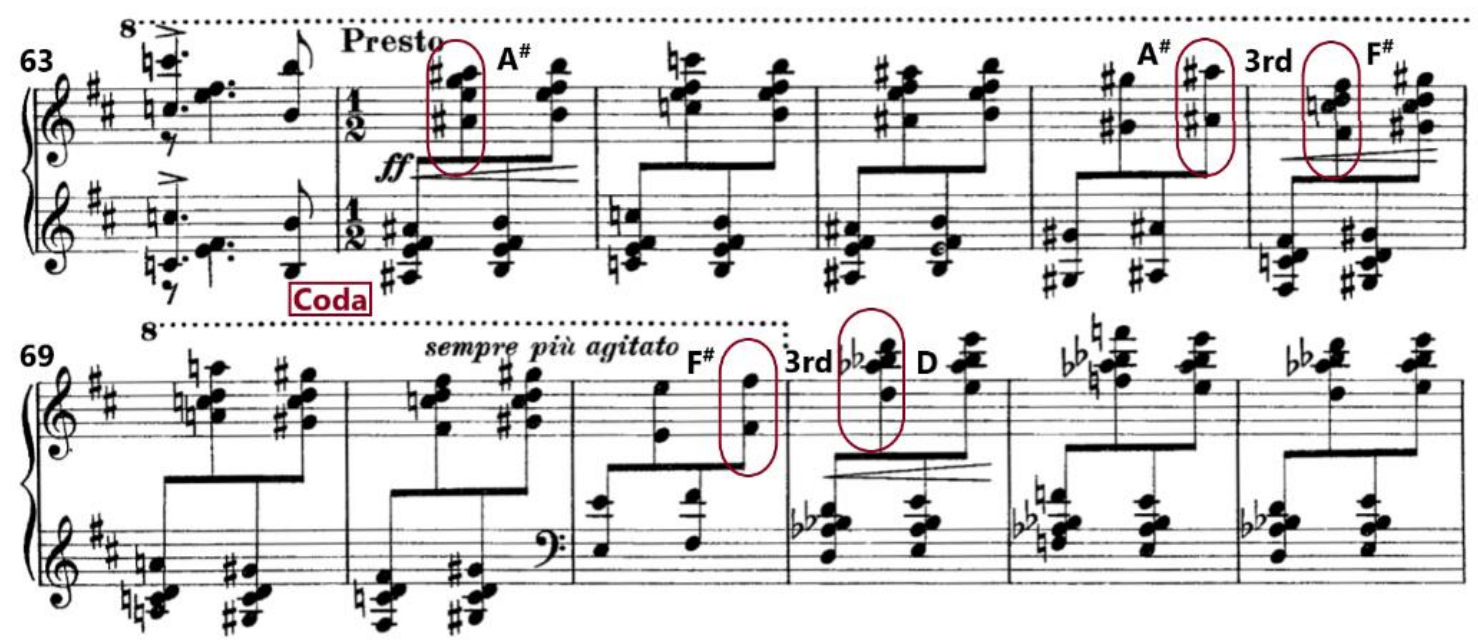

(c) 2004 by Fennica Gehrman Publisher. Used with Permission.

Figure 3.8.2 Selim Palmgren, 24 Preludes, op. 17, No. 8, mm. 63-74.

Surprisingly, the piece stays in B minor throughout until the last three chords, which are in B major (see Figure 3.8.3).

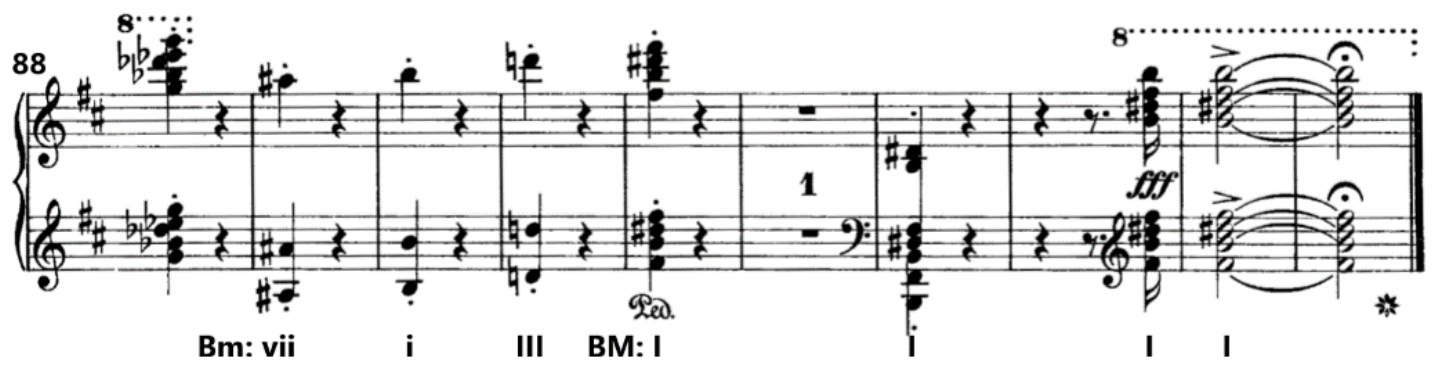

(c) 2004 by Fennica Gehrman Publisher. Used with Permission.

Figure 3.8.3 Selim Palmgren, 24 Preludes, op. 17, No. 8, m. 88-97. 


\section{$\underline{3.9 \text { Prelude No. } 9}$}

Prelude No. 9 is titled Wiegenlied, the German equivalent of the English "Lullaby" or "Cradle Song" and the French "Berceuse." Generally, a Wiegenlied is a song "designed to lull children to sleep." 24 It was originally written for voice only with no accompaniment because "there is a strong preference in infants for unaccompanied lullabies over accompanied ones." 25 Later on, composers applied the term to Lieder or to instrumental music with piano accompaniments. Gradually, it became a term that refers to a character piece for piano — notably, Chopin's Berceuse in $\mathrm{D}^{\mathrm{b}}$ major, op. $57 .^{26}$

Because of their function as an aid to sleep, lullabies commonly share structural and other similarities: quiet dynamics, tonic pedal bass, swinging or rocking accompaniment, ${ }^{27}$ intermittent repetitions, and long pauses between sections. ${ }^{28}$ These features are all evident in Prelude No. 9.

Instead of following the compound-meter scheme of the usual lullaby, Prelude No. 9 is written in 2/4 time. It is written in $\mathrm{G}^{\#}$ minor, with a Tranquillo tempo indication. There are four voices presented in this prelude. The theme appears in the top voice. The inner voices form an accompaniment that oscillates between tonic and dominant chords. The bass line remains nearly unrelentingly on a tonic $\mathrm{G}^{\#}$ pedal point throughout the entire piece, firmly establishing the key.

\footnotetext{
${ }^{24}$ Boyd, Malcolm, “Wiegenlied,” Grove Music Online, accessed April 10, 2019, https://doi-org.www.libproxy.wvu.edu/ 10.1093/gmo/9781561592630.article.30270.

${ }^{25}$ Ilari, Beatriz and Megha Sundara. "Music Listening Preferences in Early Life: Infants' Responses to Accompanied versus Unaccompanied Singing," Journal of Research in Music Education 56, no. 4 (January 2009): 357.

${ }^{26}$ Hamilton, Kenneth L, "Berceuse,” Grove Music Online. accessed April 10, 2019, https://doi-org.www.libproxy.wvu.edu/ $10.1093 / \mathrm{gmo} / 9781561592630$.article.02749.

${ }^{27}$ Perry, Nina, “The Universal Language of Lullabies,” BBC News, accessed April 10, 2019, https://www.bbc.com/ news/magazine-21035103.

${ }^{28}$ O'Neill, Colleen T., Laurel J. Trainor, Trehub and Sandra E. “Infants' Responsiveness to Fathers' Singing,” Music Perception: An Interdisciplinary Journal18, no. 4 (Summer 2001): 410.
} 
Prelude No. 9 is in ABA form with repetitive phrases. The theme of this prelude contains two motives that form a four-bar phrase in a " $1+1+2$ " structure. The A section extends from the opening through m. 24 and contains two asymmetrical parts that are formed by the two motives. The first motive demonstrates upward motion while the second motive consists of downward chord patterns. Both motives are in conjunct motions without big leaps and maintain a sedate and peaceful mood (see Figure 3.9.1).

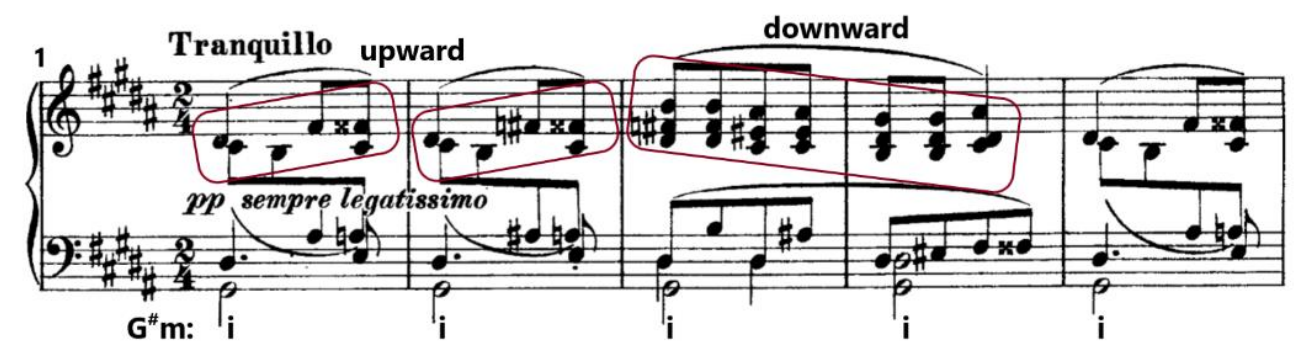

(C) 2004 by Fennica Gehrman Publisher. Used with Permission.

Figure 3.9.1 Selim Palmgren, 24 Preludes, op. 17, No. 9, mm. 1-5.

The B section contains the same motivic materials as in the A section, but in reversed direction: the first motive turns into a downward motion while the second motive now rises (see Figure 3.9.2). The A' section starts from $\mathrm{m}$. 37 and is almost identical to the A section with the exceptions of the last three bars, which replace the second motive by an authentic cadence.

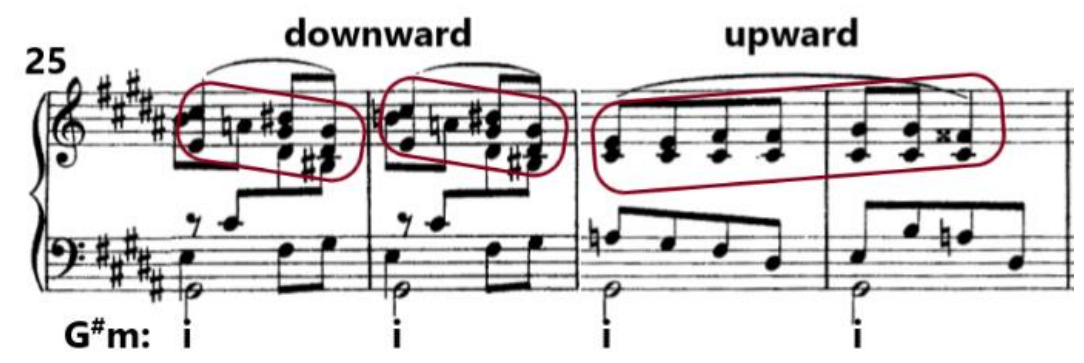

(c) 2004 by Fennica Gehrman Publisher. Used with Permission.

Figure 3.9.2 Selim Palmgren, 24 Preludes, op. 17, No. 9, mm. 25-28. 
Although the steady rhythm, moderate tempo and conjunct motion of Prelude No. 9 requires less technical skill than does Prelude No. 8, some passages of the inner voices demand good coordination between the hands to make the sound flow seamlessly. It is a good introduction to the style of a Berceuse for students unfamiliar with the genre.

\section{$\underline{3.10 \text { Prelude No. } 10}$}

Prelude No. 10 is the second one of the set (the first being No. 2) entitled "In Folk Style." Compared to the lilting dance-like character of No. 2, presented throughout in two-bar phrases, Prelude No. 10, with its constant four-bar phrases, reflects Palmgren's lyricism. Because the theme is presented in the top line throughout the piece, it is important to bring out the legato top voice while keeping the underlying chordal phrases connected.

Although the piece is in ternary (ABA') form, it is based on one thematic idea using a contrapuntal texture. The prelude consists of six symmetrical phrases. Each phrase is four measures long, and the writing is mostly in conjunct motion. Starting in $\mathrm{A}^{\mathrm{b}}$ major, the lyrical thematic line is presented on the top voice in conjunct motion, rising and falling twice. The bass line in the first two measures features chromatic descending scales moving from $A^{b}$ to $C\left(A^{b}-G-\right.$ $\left.G^{b}-F-F^{b}-E^{b}-E^{b b}-D^{b}-C\right)$. In m. 3 it changes into a chordal texture, moving in the reverse direction of the first melodic line. The first phrase is restated from $\mathrm{m}$. 5 one step higher, while the bass line changes into four groups of descending slurs instead of one continuous legato phrase (see Figure 3.10.1). 


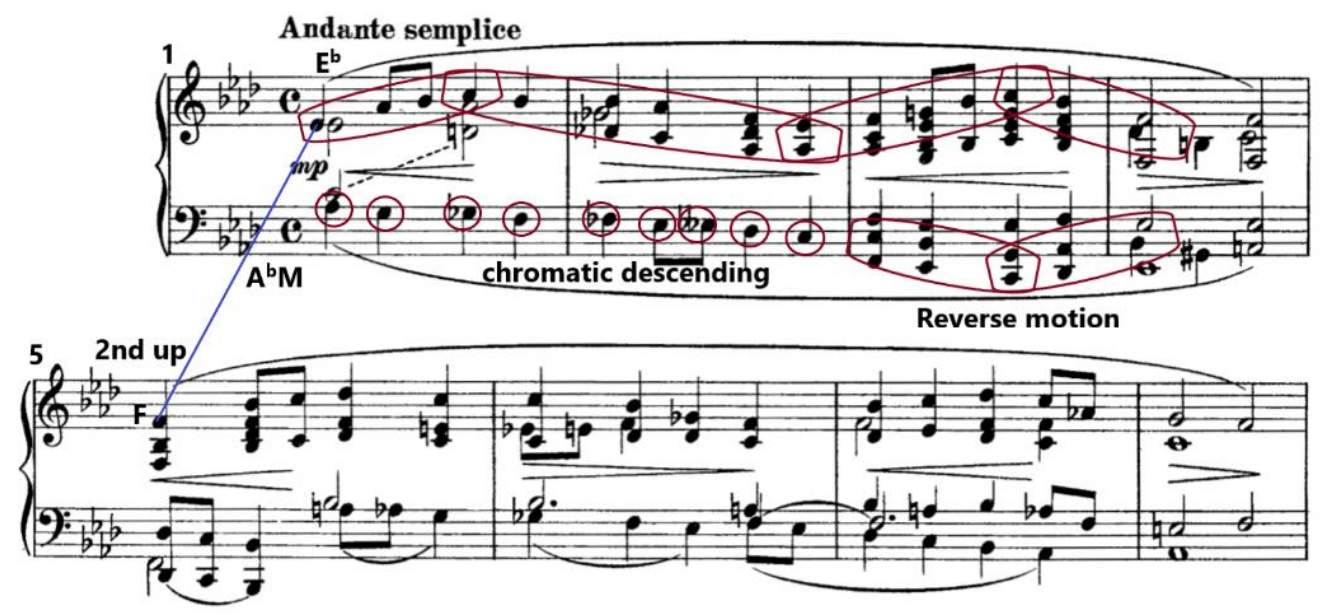

(C) 2004 by Fennica Gehrman Publisher. Used with Permission.

Figure 3.10.1 Selim Palmgren, 24 Preludes, op. 17, No. 10, mm. 1-8.

The B section begins from m. 9 and modulates to $\mathrm{D}^{\mathrm{b}}$ major. It contains two similar phrases as does section A, but this time they move in opposite directions. Mirroring is one of the common compositional techniques that Palmgren employs. In this prelude, reverse motion can be found everywhere - not only between hands, but also between sections. Starting with $\mathrm{D}^{\mathrm{b}}$, which is a step lower than the opening A section, the melodic contour of the B section is the reverse of that appearing in section A. However, the second phrase in the B section remains in $\mathrm{D}^{\mathrm{b}}$ instead of following the previous scheme that moves up a second (see Figure 3.10.2). The last section starts in $\mathrm{m} .17$ and returns to $\mathrm{A}^{\mathrm{b}}$ major. It restates materials of the A section, but Palmgren replaces its last three measures with a two-bar authentic cadence. 


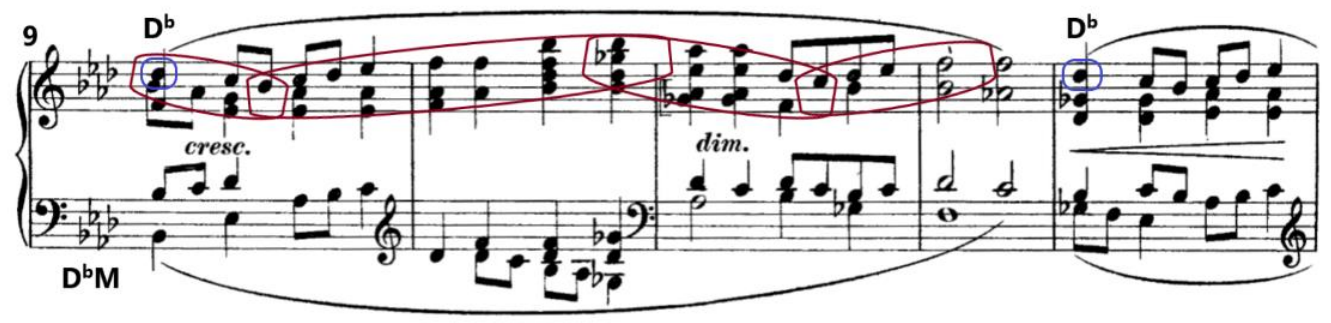

(C) 2004 by Fennica Gehrman Publisher. Used with Permission.

Figure 3.10.2 Selim Palmgren, 24 Preludes, op. 17, No. 10, mm. 9-13.

\subsection{Prelude No. 11}

Prelude No. 11 has an imaginative title Traumbild, which is German for "Dream Picture." Although Palmgren entitled some of the previous preludes based upon their genre characteristics, such as No. 6 (Sarabande) and No. 8 (Cradle Song), this is the first time he treats a prelude as program music.

Prelude No. 11 is in some ways reminiscent of Debussy's L'isle Joyeuse - a piece inspired by Watteau's painting L'embarquement pour Cythère. It was written in 1904 and received great popularity, "for it is one of Debussy's relatively few extroverted, openly virtuosic works." 29 Nevertheless, three years later, in 1907, Palmgren composed this set of preludes and gave No. 11 the descriptive title Traumbild. Although no exact evidence is indicated that Prelude No. 11 is inspired by L'isle Joyeuse, similar compositional methods can be found in both pieces. For instance, they both start with an introduction consisting of tremolos followed by ascending arpeggios figure (see Figure 3.11.1). This figure plays an important role in both pieces and is

\footnotetext{
${ }^{29}$ Gordon, Stewart, "French Keyboard Music of the Early Twentieth Century," A History of Keyboard Literature. (Schirmer, Cengage Learning, 1996), 366.
} 
presented multiple times within sections. In Prelude No. 11, besides the introduction, the tremolo figure also acts as the inner voice maintained throughout the piece.

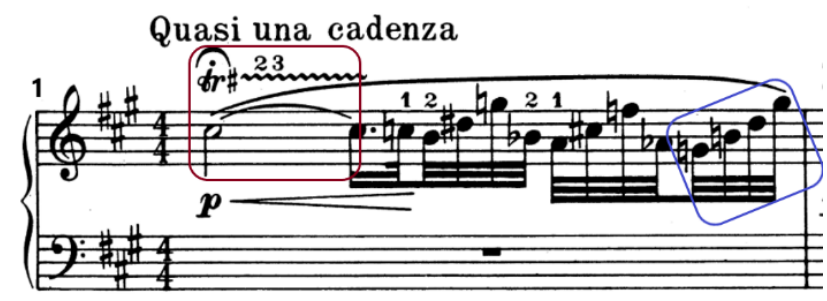

L'isle Joyeuse

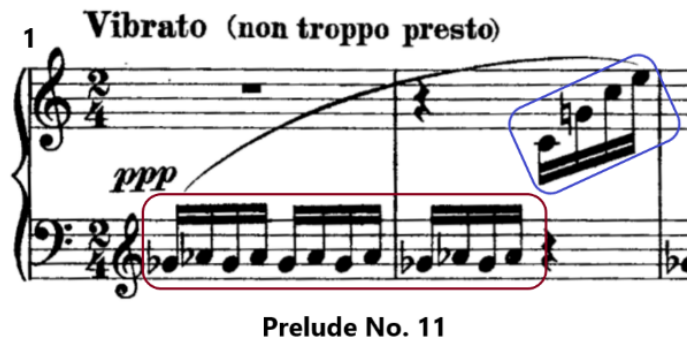

Prelude No. 11

(C) 1973 by Edition Peters Publisher. Used with Permission.

(C) 2004 by Fennica Gehrman Publisher. Used with Permission.

Figure 3.11.1 Debussy L'isle Joyeuse, m. 1, Selim Palmgren, 24 Preludes, op. 17, No. 10, mm. 1-2.

Structurally, this prelude is in one-part form with an introduction and a coda (Intro A coda). The introduction and the A section are each repeated. The last ten bars of the A section (mm. 3948) are a repetition of the Introduction. The coda repeats the tail of the introduction twice and is followed by a series of augmented $\mathrm{A}^{\mathrm{b}}$ chord progressions. Finally, it ends with a rolling $\mathrm{C}$ major chord for four bars, adding another eighth note $\mathrm{C}$ at the downbeat of m. 59 (see Figure 3.11.2).

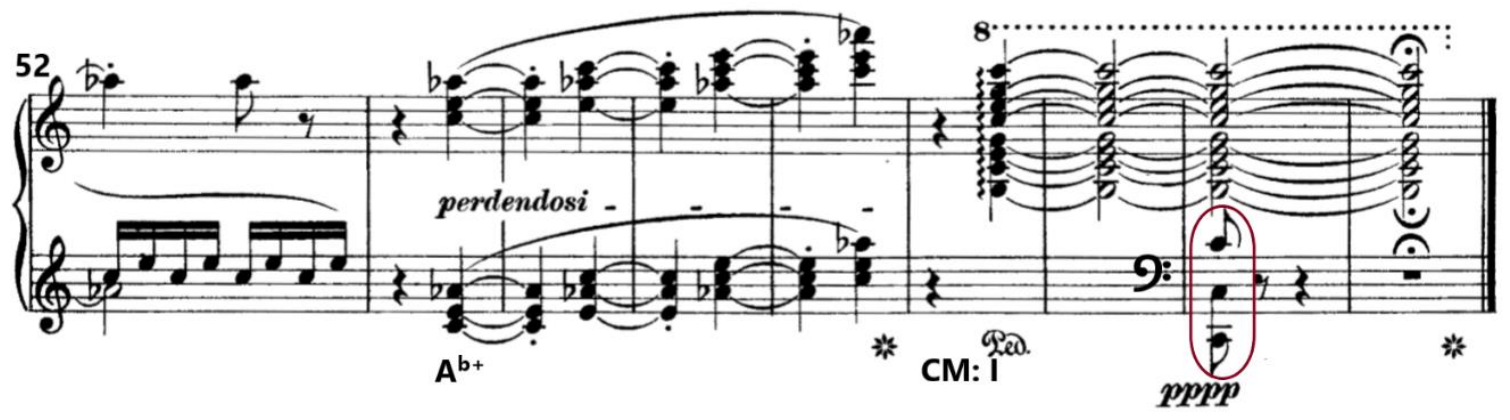

(C) 2004 by Fennica Gehrman Publisher. Used with Permission.

Figure 3.11.2 Selim Palmgren, 24 Preludes, op. 17, No. 10, m. 52-60.

One of the major features of this prelude is tonal ambiguity. The key of $\mathrm{C}$ major is not established until the last four measures. Three ascending four-note motives $\left(\mathrm{D}^{\#}-\mathrm{E}-\mathrm{F}^{\#}-\mathrm{B}\right)$ form the 
theme in the bass line and are stated three times in this section: the second statement begins a diminished fourth higher and the third a half step lower than the first. The upper two voices are accompaniments that mainly present dreamy background effects - the inner voice consists of constant tremolos while the upper voice is mostly ascending seconds (see Figure 3.11.3).
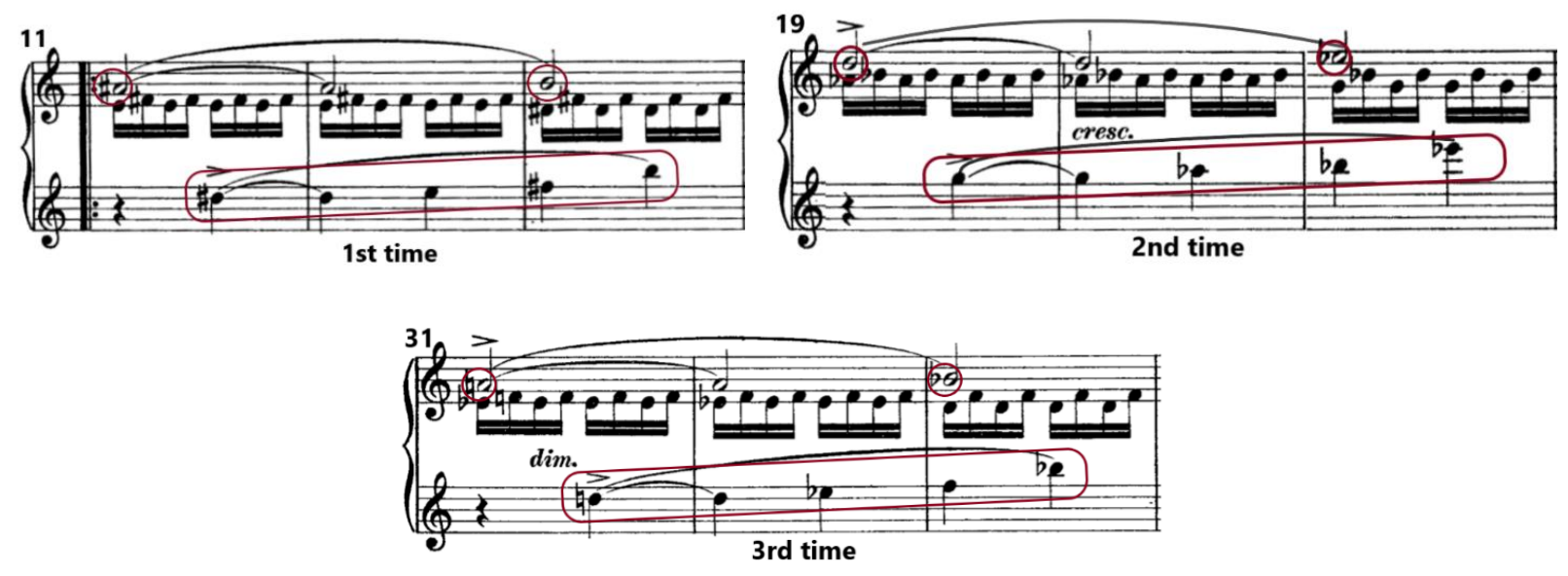

C 2004 by Fennica Gehrman Publisher. Used with Permission.

Figure 3.11.3 Selim Palmgren, 24 Preludes, op. 17, No. 11, mm. 11-13, 19-21, 31-33.

This is the first piece of this set that reveals Palmgren's impressionistic compositional style.

The vague tonality, soft dynamics, repetition of four-note ascending motives, along with its restless tremolo figures, together create a dreamlike atmosphere that fits its title well. Although the technical demands are far less than those in L'isle Joyeuse, for students Prelude No. 11 is a good introduction to the concept of impressionism.

\section{$\underline{3.12 \text { Prelude No. } 12}$}

Prelude No. 12 is one of the most famous pieces in this set and is frequently seen on recital programs. Similar to the previous one, Prelude No. 12 is written in an impressionistic style with 
a descriptive title Das Meer (The Sea), a name that recalls another famous homonymic work by Debussy_La Mer. Nevertheless, Prelude No. 12 is in scope (about one minute long) much more related to its predecessor, Prelude No. 11, than it is to Debussy's 24-minute orchestral work.

Prelude No. 12 is in A minor. The piece is divided into three parts. However, it is not in ternary form (ABA') since the second part contains the same motivic and thematic materials as the first. The prelude starts with a two-bar introduction that contains two identical running arpeggios. This arpeggio pattern is presented throughout the piece to set up the wavelike mood, and even though they are not always indicative of the key of A minor, their downbeat, always on E and always in octaves, eventually reinforces the key of A minor (see Figure 3.12.1).

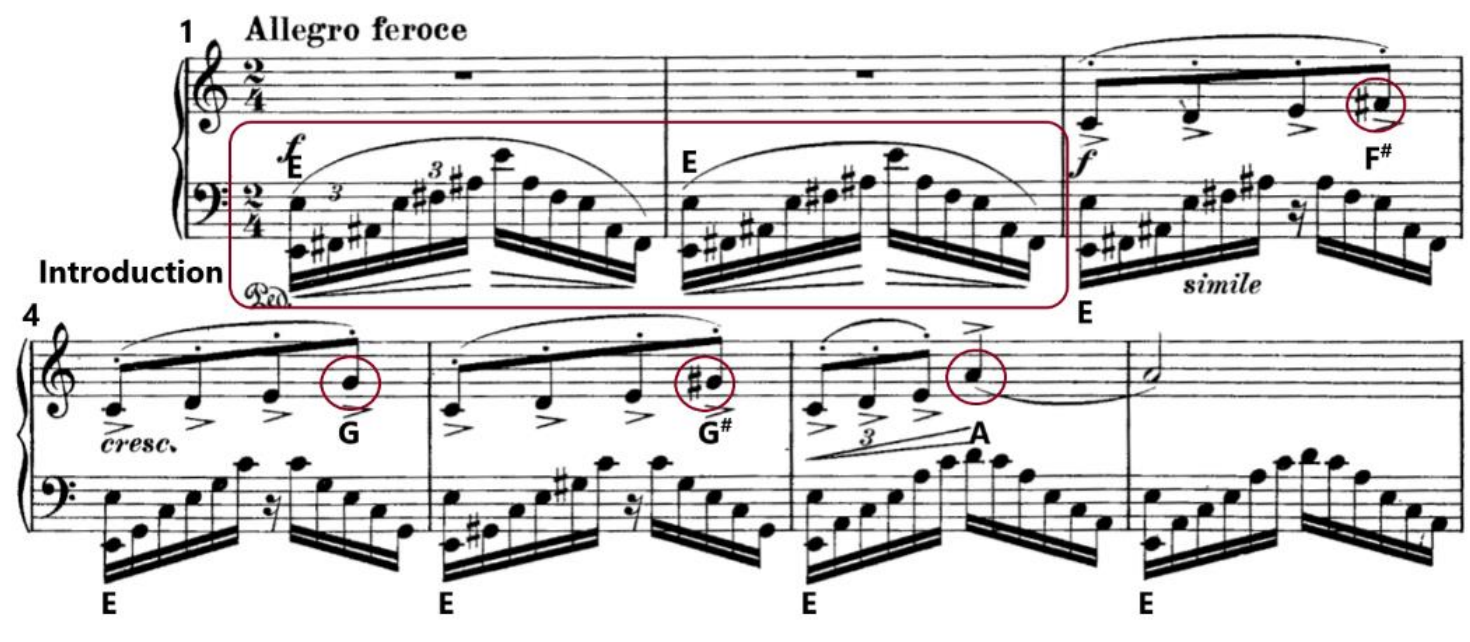

(C) 2004 by Fennica Gehrman Publisher. Used with Permission.

Figure 3.12.1 Selim Palmgren, 24 Preludes, op. 17, No. 12, mm. 1-8.

The theme is five bars long and consists of four groups of ascending four-note motives. The first three notes of each group stay the same while the last note features a chromatic ascending sequence moving from $\mathrm{F}^{\#}-\mathrm{A}\left(\mathrm{F}^{\#}-\mathrm{G}-\mathrm{G}^{\#}-\mathrm{A}\right)$ (see Figure 3.12.1). From mm. 9-12, the theme is restated an octave higher but with a denser texture. An additional two bars (mm. 13-14) of a $B^{b}$ 
chord are added, slightly departing from the key; but then the piece returns quickly to A minor at m. 15. Meanwhile, the left hand features ascending arpeggios in a chromatic sequence from $\mathrm{F}^{\#}$ to A $\left(F^{\#-G-G}-A\right)$ (see Figure 3.12.2).

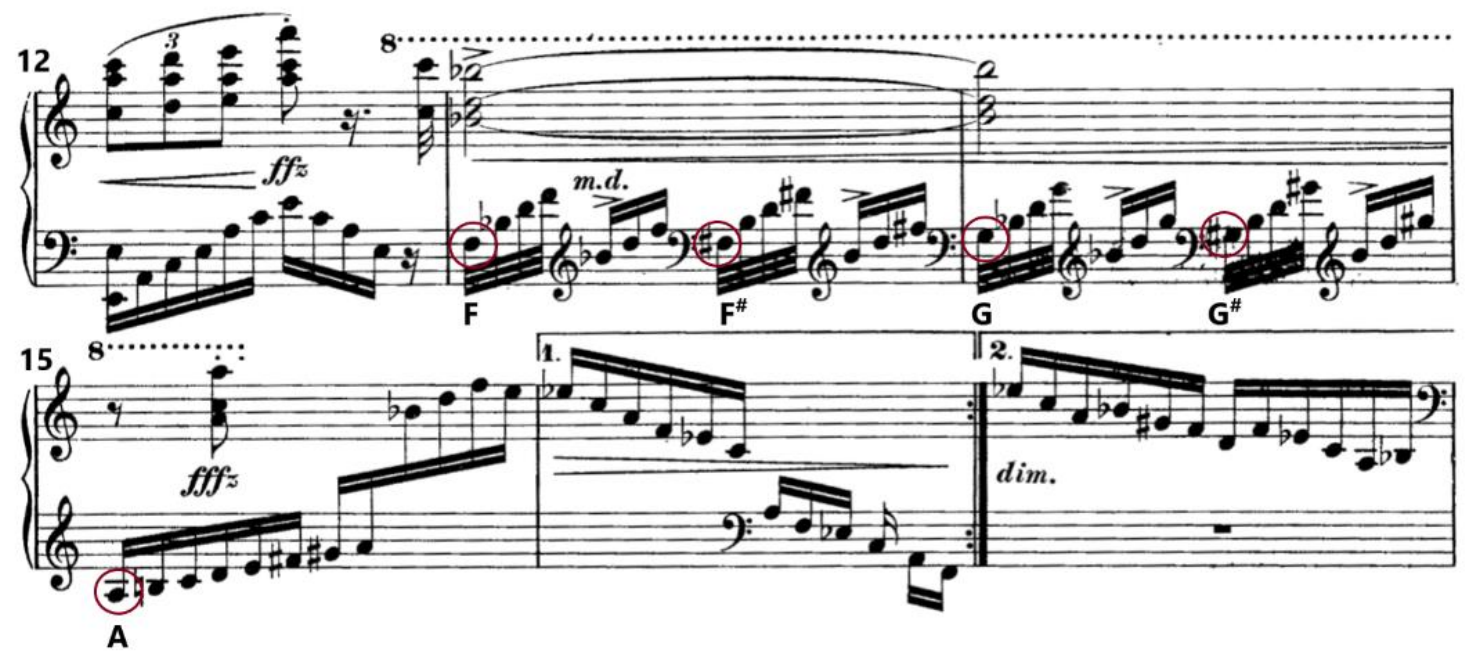

(C) 2004 by Fennica Gehrman Publisher. Used with Permission.

Figure 3.12.2 Selim Palmgren, 24 Preludes, op. 17, No. 12, mm. 12-17.

The second part is mainly borrowed from fragments of thematic materials in the first part with slight variations in texture. For instance, the ascending four-note motive in $\mathrm{mm} .30-33$ is changed into thirds instead of the single notes or octaves from the previous section. In addition, the sixteenth-note running arpeggios change into a more rapid combination of sixteenth and thirty-second notes, along with the addition of a pedal point that alternates between $\mathrm{F}^{\#}$ and $\mathrm{E}$ (see Figure 3.12.3). 


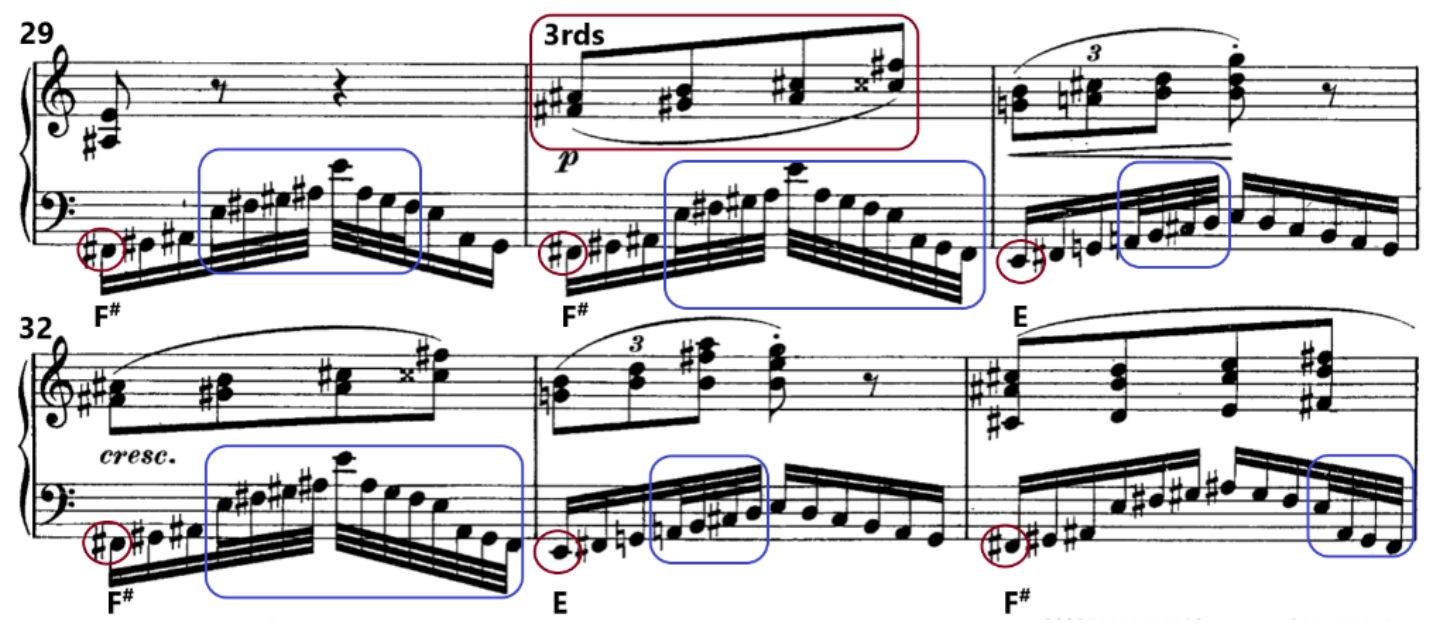

(C) 2004 by Fennica Gehrman Publisher. Used with Permission.

Figure 3.12.3 Selim Palmgren, 24 Preludes, op. 17, No. 12, mm. 29-34.

The last statement of the full theme appears in $\mathrm{m} .48$. This is the only time that the theme is presented in the bass line, while the right hand accompanies it with a running arpeggio figure until the end of the piece. It ends with a powerful augmentation in quarter notes of the four-note ascending eighth-note figure heard first at the end of the theme and later, from $\mathrm{m} .53$ until m. 57, followed by three repeated A-minor tonic chords. Interestingly, these final chords contain no thirds, only open fifths. But the tonality of A minor has been firmly established in the previous measures.

Prelude No. 12 is a challenge both technically and musically for students, not only because of its fast arpeggiated accompaniments, but also because of its wide-ranging dynamics. Although it is only three pages long, the dynamics vary from $p$ to ffff. This prelude would provide an effective method of training students to play a piece in multiple layers of colors and dynamics within a single motive. 


\section{$\underline{3.13 \text { Prelude No. } 13}$}

After two impressionistic works, Prelude No. 13 returns to pure non-programmatic music. It is more like an improvisational etude, full of freedom and chromaticism. Prelude No. 13 is written in $3 / 4$ time and is based on one theme, stated by alternate hands throughout the piece.

Structurally, it reveals a one-part form with an introduction. The opening introduction lasts for twelve bars that are in " $2+2+8$ " structure. The $p p$ dynamics, along with the cresc. $e$ string. indication help to create a hazy and mysterious atmosphere for this section. The patterns in the introduction are fairly constant: the right hand features a rapid arpeggiated ascending broken chord pattern in sixteenth notes; the left hand consists of two voices that flow in parallel motion with the right hand. Interestingly, both hands in mm. 5-7 turn into four groups of a two-beat pattern that deviate from the established pulse (see Figure 3.13.1).

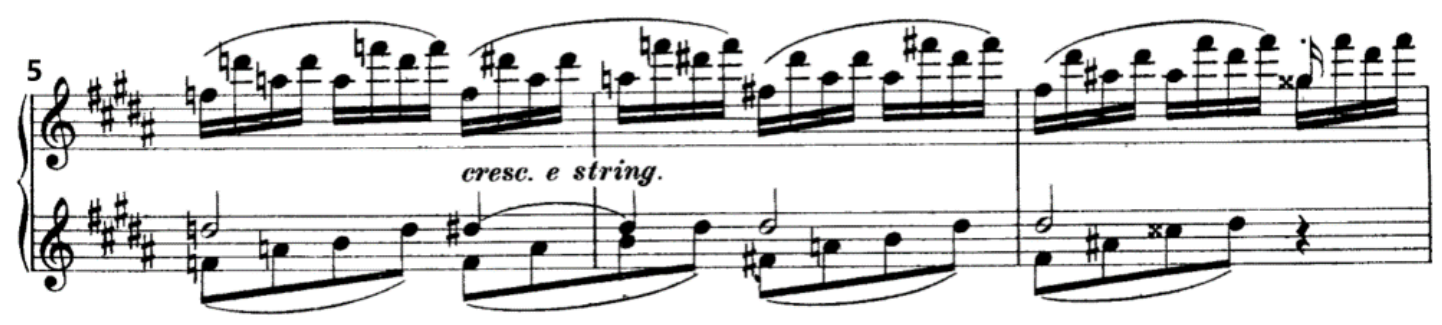

(C) 2004 by Fennica Gehrman Publisher. Used with Permission.

Figure 3.13.1 Selim Palmgren, 24 Preludes, op. 17, No. 13, mm. 5-7.

The theme enters in the upbeats to $\mathrm{m} .13$ in the right hand and lasts to $\mathrm{m}$. 18. It consists of three short phrases that display mostly conjunct motion. The accompaniment is a broken-chord pattern that is played by the left hand. Palmgren cleverly ties the theme and the accompaniment together in a way that lets them interact with each other. For instance, the hands move in reverse motion and together present all seven notes of a scale (See figure 3.13.2). 

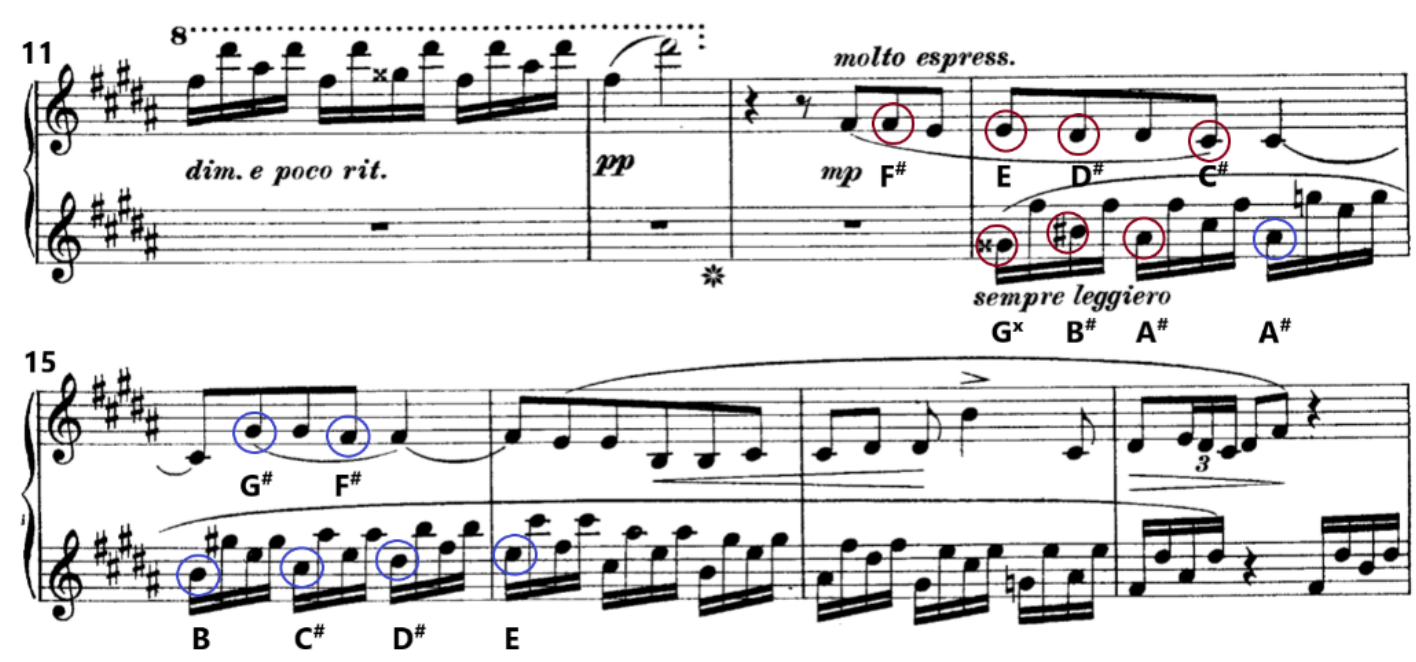

(C) 2004 by Fennica Gehrman Publisher. Used with Permission.

Figure 3.13.2 Selim Palmgren, 24 Preludes, op. 17, No. 13, mm. 11-18.

The accompaniment is transferred from the left hand to the right by an ascending arpeggiated B major chord at the last beat of $\mathrm{m}$. 24. The left hand then takes over the role of the right hand and now presents the theme. Starting from m. 25 and going until m. 37, this motive appears twice identically in E major, and the accompaniment in the right hand features a constantly ascending motion from $\mathrm{A}^{\#}$ an octave and a half up to $\mathrm{E}$, followed by a descent. (see figure 3.13.3). 

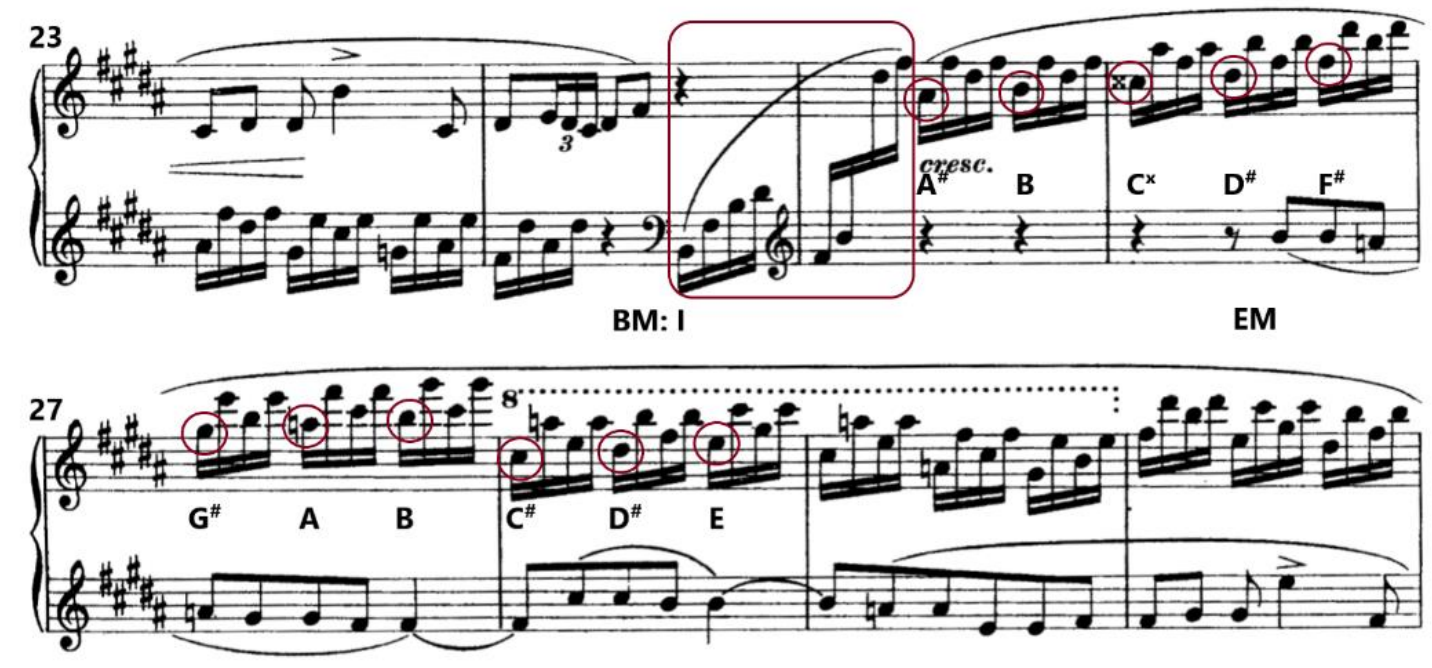

C 2004 by Fennica Gehrman Publisher. Used with Permission.

Figure 3.13.3 Selim Palmgren, 24 Preludes, op. 17, No. 13, mm. 23-30.

The theme is presented the last time by the left hand from m. 38 to m. 44 a half-step lower than its previous appearance; it also modulates into $\mathrm{D}^{\#}$ minor. The pulse is slightly varied from m. 41 to $\mathrm{m}$. 43 , when the time signature changes from $3 / 4$ to $2 / 4$. The theme switches back to the right hand and returns to B major at the pickup to $\mathrm{m}$. 46 with an extended tail that repeatedly emphasizes the subdominant note of E. After an ascending accentuated scale, it returns to B major via a dominant-ninth chord and finally resolves to the tonic (see Figure 3.13.4).

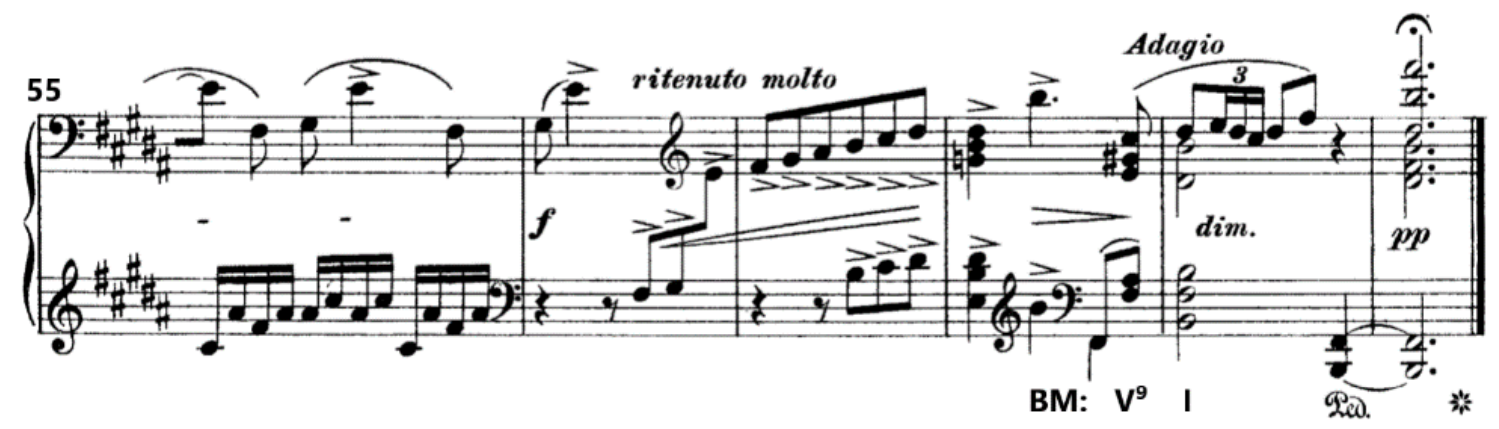

(c) 2004 by Fennica Gehrman Publisher. Used with Permission.

Figure 3.13.4 Selim Palmgren, 24 Preludes, op. 17, No. 13, mm. 55-60. 


\section{$\underline{3.14 \text { Prelude No. } 14}$}

Prelude No. 14 in D minor is a highly chromatic piece that seems, given its similarity to Chopin's Prelude in E minor, op. 28, to reflect Palmgren's esteem for the Polish composer. The structure of this piece is quite simple. It displays two-part form (AA'), instead of binary, since the materials in the second part are mainly derived from the opening section. The entire prelude is based on the opening motive that consists of left-hand octaves preceded by their same grace notes; these octaves are accompanied by repeated chords in the right hand.

The theme of this prelude is presented twice from the opening to $\mathrm{m}$. 5 . It begins with the tonic $\mathrm{D}$ and is followed by a sequence of seconds zigzagging in a downward motion to the $\mathrm{D}$ an octave lower. Meanwhile, the accompaniment is played by the right hand and consists of two groups of repeated chords. Both groups start with four repeated D-minor chords- the first group is followed by repeated chromatic descending chords from $\mathrm{B}^{\mathrm{b}}$ to $\mathrm{F}$; the second group, however, descends from $\mathrm{C}$ all the way down to $\mathrm{E}$ without the pattern of repeats (see Figure 3.14.1).
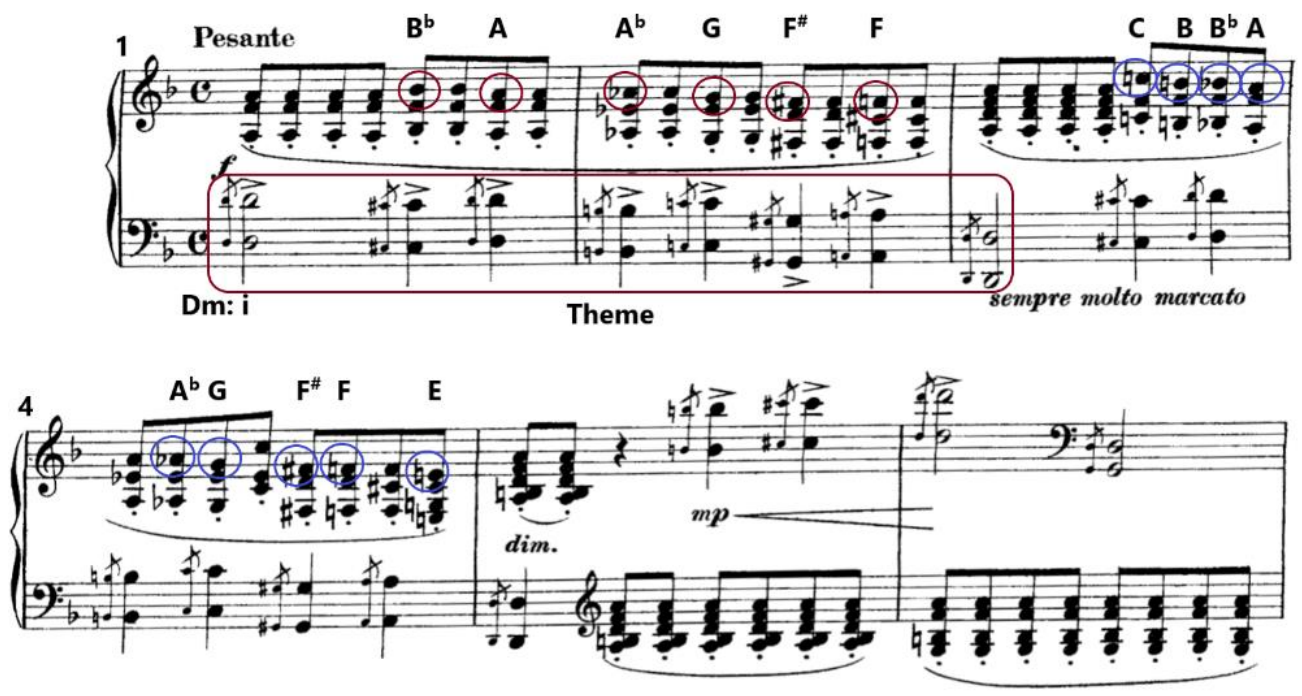

(C) 2004 by Fennica Gehrman Publisher. Used with Permission.

Figure 3.14.1 Selim Palmgren, 24 Preludes, op. 17, No. 14, mm. 1-6. 
Starting from the second beat of $\mathrm{m}$. 5 , the right and left hands switch roles: from $\mathrm{m} .5$ to $\mathrm{m}$. 12 the right hand plays four groups of the thematic motive in an ascending sequence, while the left hand plays repeated chords that remain in the dominant $\mathrm{A}$. Then, in contrast to this rising thematic contour, the thematic motive in the right hand begins to move downward from $\mathrm{m} .13$ to the downbeat of $\mathrm{m} .17$, while the accompaniment in the left hand features two chromatic ascending sequences, one from $\mathrm{B}$ to $\mathrm{D}^{\#}$ and the other from $\mathrm{E}$ all the way up to a tonic $\mathrm{D}$ that leads the piece to the A' section (see Figure 3.14.2).

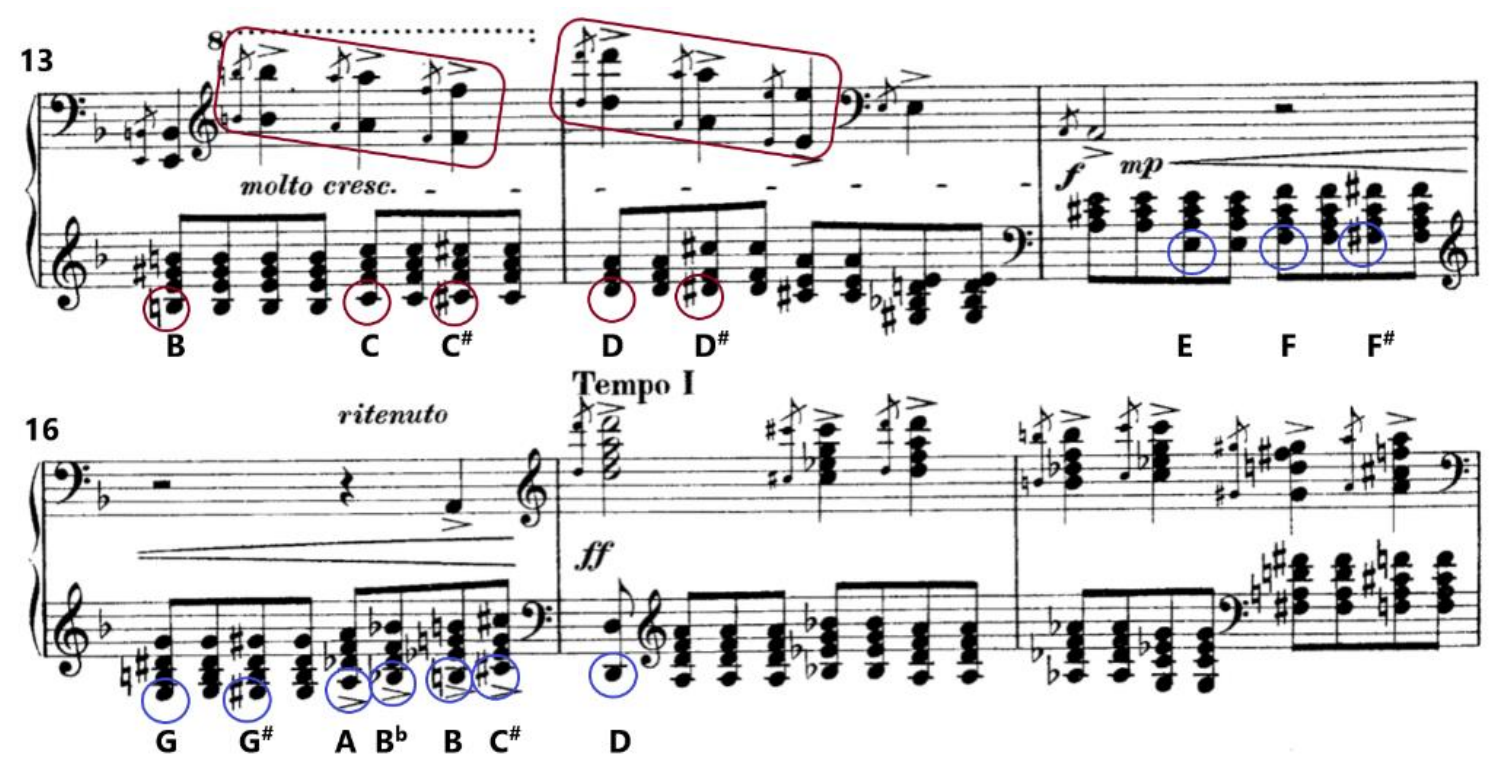

(C) 2004 by Fennica Gehrman Publisher. Used with Permission.

Figure 3.14.2 Selim Palmgren, 24 Preludes, op. 17, No. 14, mm. 13-18.

The opening theme recurs from $\mathrm{m} .17$ where there is a Tempo I indication. Unlike the beginning, the restatement of the theme is presented by the right hand and with a denser chordal texture. After a brief review of previous materials, Palmgren further expands this texture into four voices in $\mathrm{m} .24$, the top voice constantly playing an accented tonic D octave until the end. Unexpectedly, the piece modulates at $\mathrm{m} .21$ from D minor to D major and remains there until the 
end of the prelude. From a pedagogical standpoint, Prelude No. 14 contains several large chords, which will prove to be technically challenging for students who have smaller hands. For example, the left hand in the last beat of $\mathrm{m} .21$ features four repeated chords encompassing the span of a tenth. In this case, several options could help to solve this technical issue: 1 . move the top $\mathrm{G}$ note an octave lower; 2. move the bottom $\mathrm{E}$ note an octave higher; 3. omit either the top G note or the bottom E note; or 4. arpeggiate the chords (see Figure 3.14.3).

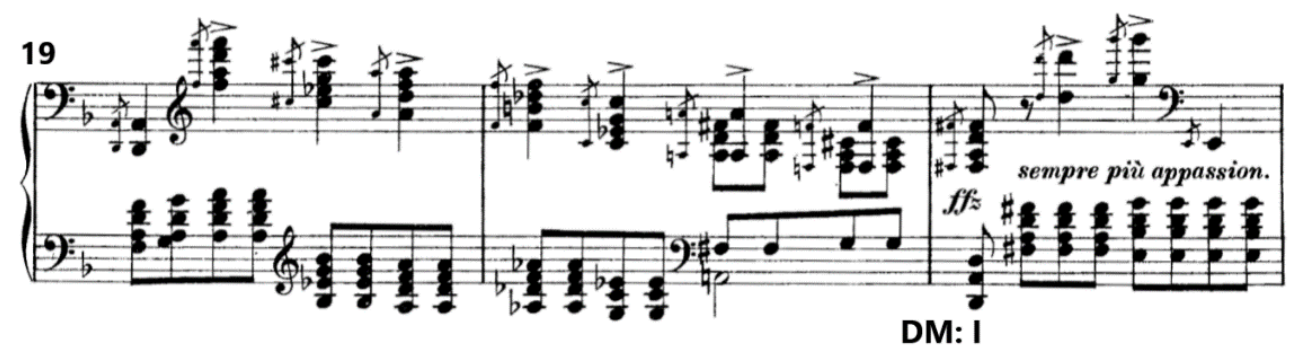

C 2004 by Fennica Gehrman Publisher. Used with Permission.

Figure 3.14.3 Selim Palmgren, 24 Preludes, op. 17, No. 14, mm. 19-21.

\section{$\underline{3.15 \text { Prelude No. } 15}$}

Prelude No. 15 is titled Reigen (Round Dance). This is the third type of dance music in the set, following Prelude No. 4 (Waltz) and No. 6 (Sarabande). A round dance is a form of social ballroom dance in which the steps are choreographed precisely to the music, as are those to the tempos and rhythms of waltzes, foxtrots, cha-chas, rumbas, etc. ${ }^{30}$ Prelude No. 15 is written in ternary (ABA') form with a traditional 3/4 dance rhythm. The tempo marking is Allegro along with a Con grazia instruction, reflecting its fast, lively, but graceful characteristics.

\footnotetext{
${ }^{30}$ Sears, Meredith, and Harold. "What is Round Dancing," Round Dancing-Choreographed Ballroom, assessed April 10, 2019, http://www.rounddancing.net/dance/articles/what.html.
} 
This piece is in $\mathrm{B}^{\mathrm{b}}$ major. The A section extends from the opening until m. 14. The left hand alone plays an open $\mathrm{B}^{\mathrm{b}}$-F fifth in the first measure to reveal the key. The right hand joins in at $\mathrm{m}$. 2 and contains two voices (see Figure 3.15.1). The bass line most often maintains either a tonic or dominant pedal point to establish the key firmly. The melody in this section appears in the top voice, which consists of three groups of phrases comprising 13 measures in a " $4+5+4$ " structure. The last phrase is identical to the first one except that it is presented an octave higher. The second phrase can be subdivided into two smaller phrases which are in " $3+2$ " structure, the second of which is a fourth above the first (see Figure 3.15.2).

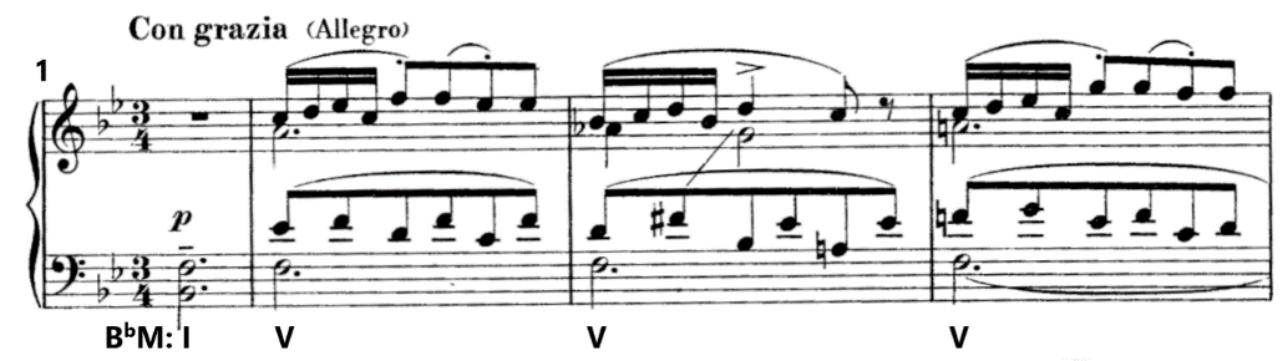

(c) 2004 by Fennica Gehrman Publisher. Used with Permission.

Figure 3.15.1 Selim Palmgren, 24 Preludes, op. 17, No. 15, mm. 1-3.

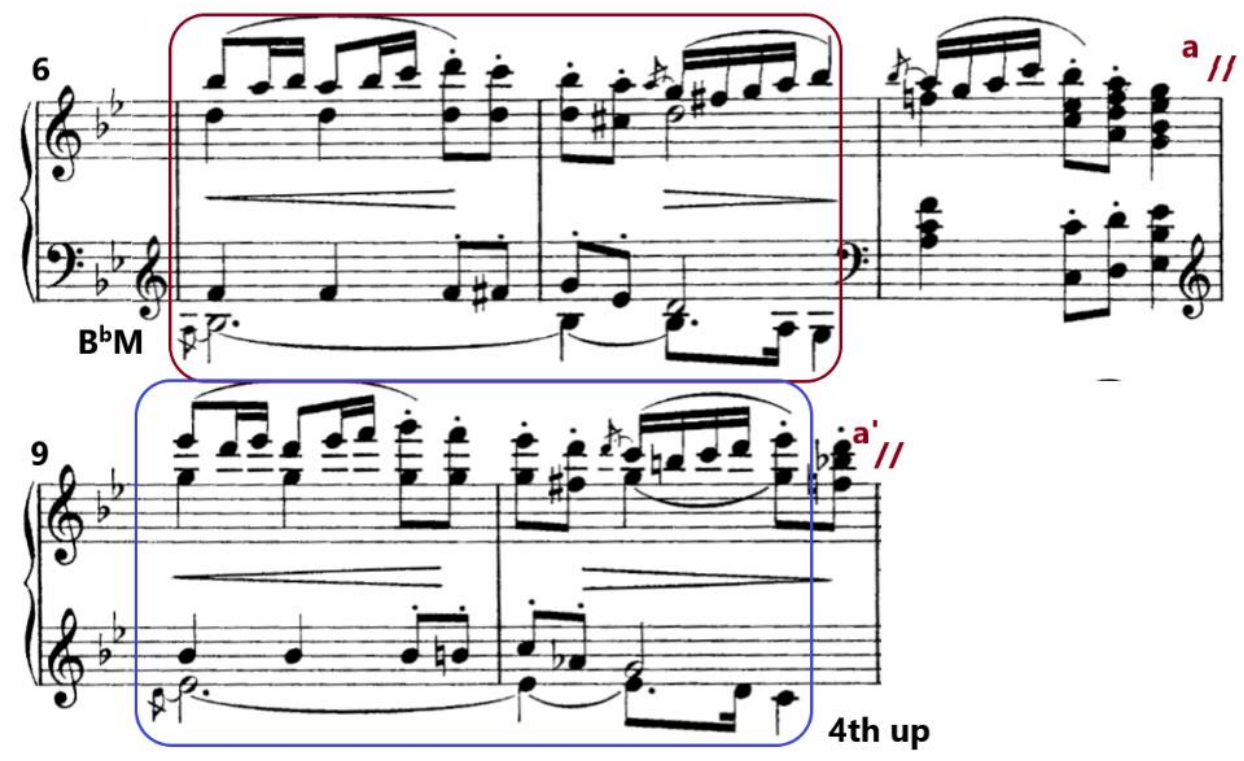


The B section starts from m. 15 and modulates to $\mathrm{D}^{\mathrm{b}}$ major. Although materials in this section are mainly borrowed from the second phrase of the A section, many of its characteristics are presented differently. For instance, the left-hand bass line changes into a staccato eighth-note ostinato throughout the B section. In addition, the right-hand melody adds a series of quintuplets that not only push the tempo rhythmically but also bring a hemiola effect to this section (see Figure 3.15.3). There is a short bridge-like passage from mm. 26-28 that brings the piece back to $\mathrm{B}^{\mathrm{b}}$ major and to the $\mathrm{A}^{\prime}$ section, the restatement of the first part.

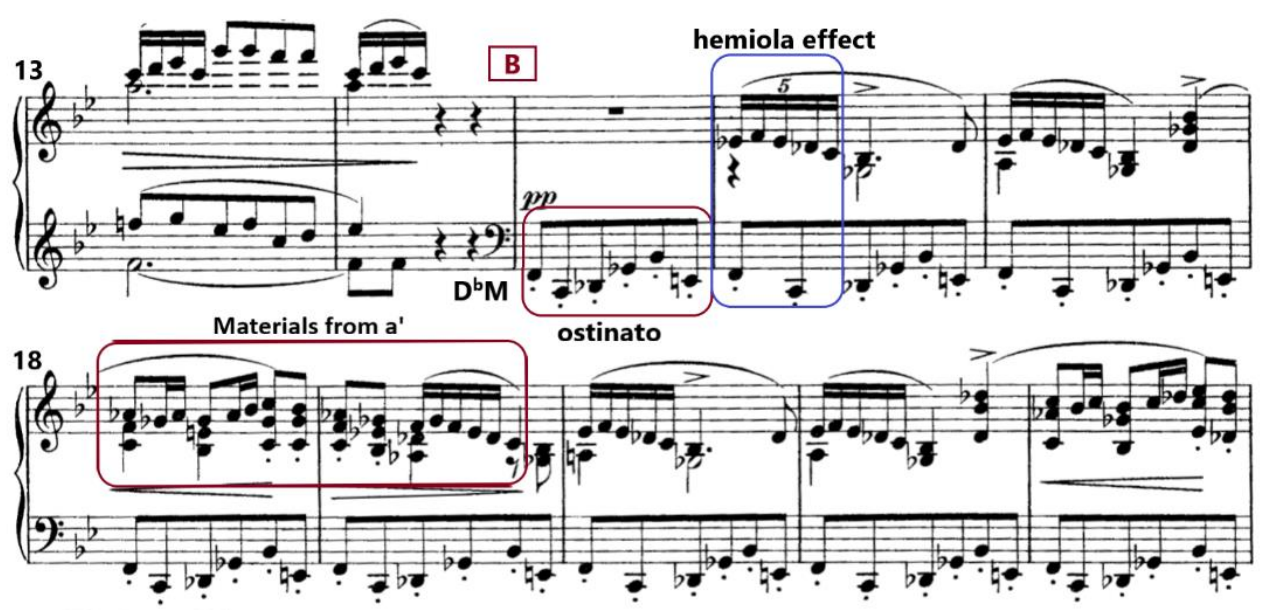

C 2004 by Fennica Gehrman Publisher. Used with Permission.

Figure 3.15.3 Selim Palmgren, 24 Preludes, op. 17, No. 15, mm. 13-22.

Prelude No. 15 follows a traditional dance setting in both structural and harmonic aspects.

The piece is moderately difficult, containing only a few rhythmical challenges such as 5 against 2 and technical difficulties such as legato against staccato. It is a good introduction for students to learn the basic concepts of a "Round Dance." 


\subsection{Prelude No. 16}

Even though the key signature indicates the key of F major, Prelude No. 16 is another highly chromatic piece. It does not begin in F; in fact, most of the prelude is ambiguous in tonality. The first 16 measures serve as an introduction, during which the right hand plays a series of three-note syncopated chords, which at $\mathrm{m} .17$ will become the accompaniment, while the left hand provides the harmonic foundation on the downbeats.

Prelude No. 16 is written in one-part form with an introduction and coda, the coda being derived from the introduction (Intro A Coda). The introduction is divided into two eight-bar phrases with the same accompaniment patterns. The opening four bars feature an ascending line in the right hand that moves from C-F (C-D-E-F), while the last four bars of the second phrase feature a chromatic descending line from $A$ down to $F^{\#}\left(A-G^{\#}-G-F^{\#}\right)$ (see Figure 3.16.1).
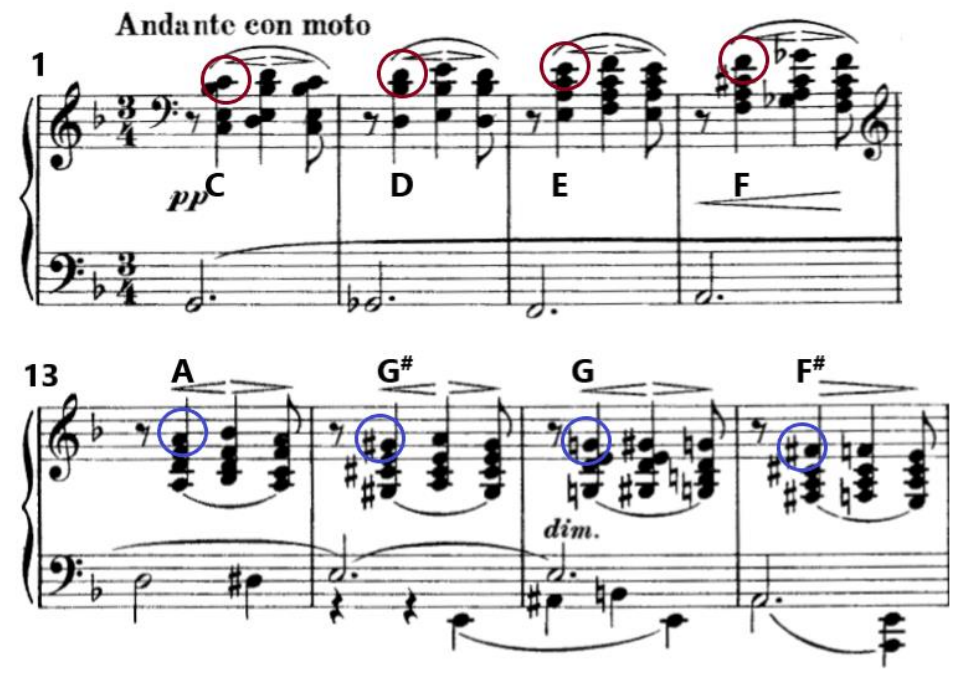

(C) 2004 by Fennica Gehrman Publisher. Used with Permission.

Figure 3.16.1 Selim Palmgren, 24 Preludes, op. 17, No. 16, mm. 1-4, 13-16. 
The main section starts from m. 17 and extends to m. 46. The texture becomes thicker, changing from two to four voices. The melody is presented in both hands in the two outer voices, and the two inner voices form the accompaniment, which interacts with the melody. Both the melody and accompaniment in the two hands are identical except that the right-hand melody is presented in octaves while the left hand is a single voice. From mm. 35-38, the melody gradually climbs from $\mathrm{A}^{\mathrm{b}}$ to $\mathrm{D}^{\mathrm{b}}\left(\mathrm{A}^{\mathrm{b}}-\mathrm{B}^{\mathrm{b}}-\mathrm{C}-\mathrm{D}^{\mathrm{b}}\right)$ and alternates between $\mathrm{C}$ and $\mathrm{D}^{\mathrm{b}}$ with accents on each melodic note during mm. 37-42, while the left hand climbs from $D^{\#}$ to $B^{b}\left(D^{\#}-E-F^{\#}-G^{\#}-A-B^{b}\right)$ before returning to $\mathrm{A}^{\mathrm{b}}$ at $\mathrm{m} .46$, the last bar of the $\mathrm{B}$ section. It then proceeds to $\mathrm{G}$ more than an octave lower, where the Coda begins, restating the material from the introduction (see Figure 3.16.2).

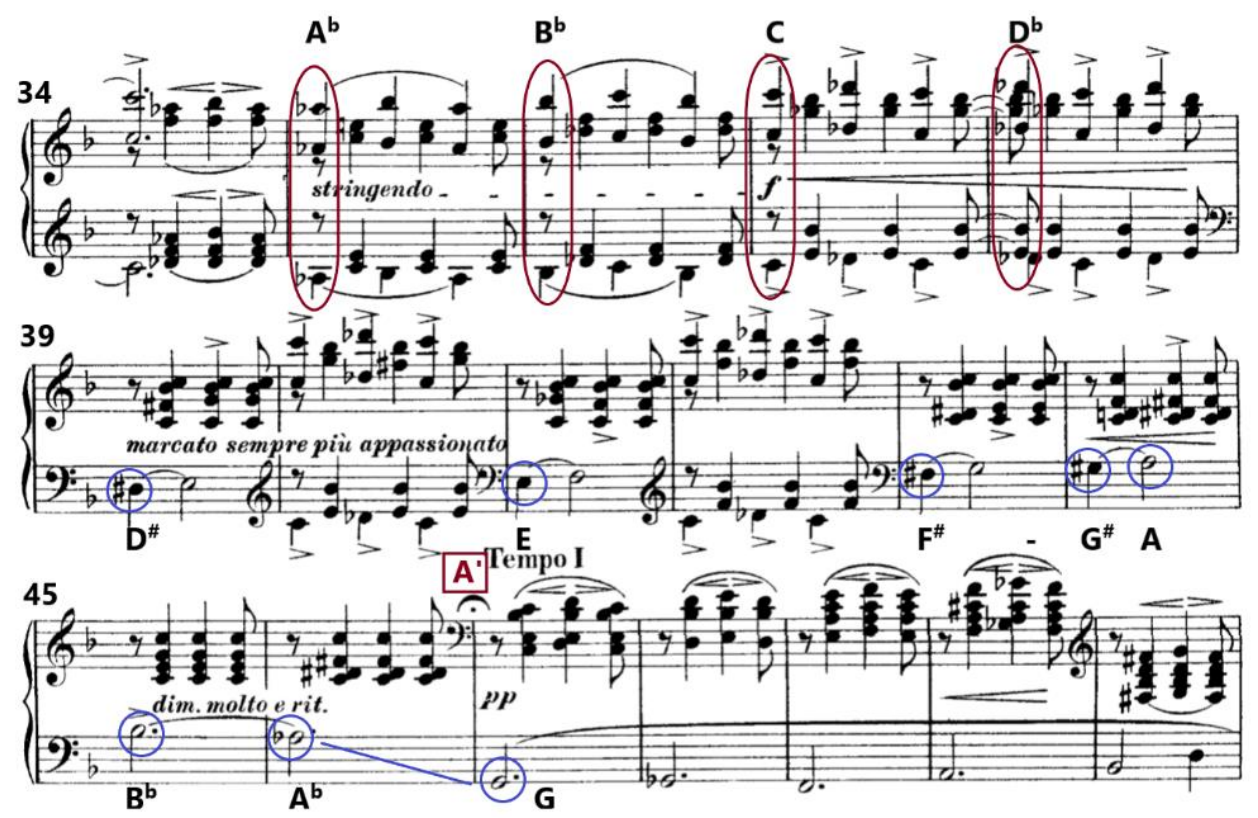

(C) 2004 by Fennica Gehrman Publisher. Used with Permission.

Figure 3.16.2 Selim Palmgren, 24 Preludes, op. 17, No. 16, mm. 34-51. 
The rhythmic pattern in this prelude is repetitive. However, the many dynamic markings added to the chords or melodic lines of either hand and between the two hands prevent the piece from becoming monotonous. In addition, a series of expressive indications such as sotto voce, stringendo, marcato sempre più appassionato, dim. molto e rit., and ritardando e dim. are applied to enrich the color and transform this piece into a lyrical movement.

\subsection{Prelude No. 17}

Prelude No. 17 is a rapid, energetic, march-like piece that is dominated by descending ostinatos and rapid ascending slurs. It is simply marked Allegro agitato, anticipating Prokofiev in its pounding rhythms. The piece is brief, containing only 20 measures and lasting just a bit more than 30 seconds. $^{31}$

The piece is written in F minor with unusual 5/4 time signature. It is divided into three sections. The A section extends from the opening to $\mathrm{m}$. 9. The left hand in this section features ostinatos of five parallel descending staccato chords moving from $\mathrm{F}$ to $\mathrm{C}$ (F-E-E $\left.\mathrm{E}^{\mathrm{b}}-\mathrm{D}-\mathrm{C}\right)$ throughout the section. The downbeat of each bar is the tonic F, played in octaves. The theme in the right hand enters a dotted-eighth rest after the tonic $\mathrm{F}$ is played so that the sound of f-minor tonic can be purely presented and fortified. The theme is an ascending line that moves from $\mathrm{E}^{\mathrm{b}}$ to $\mathrm{A}^{\mathrm{b}}$, in contrast to the descending ostinato in the left hand. (see Figure 3.17.1).

\footnotetext{
${ }^{31}$ Hurwitz, David. "Selim Palmgren: 'Chopin of the North'," Classics Today, accessed April 10, 2019, https://www. classicstoday.com/review/selim-palmgren-chopin-of-the-north/.
} 


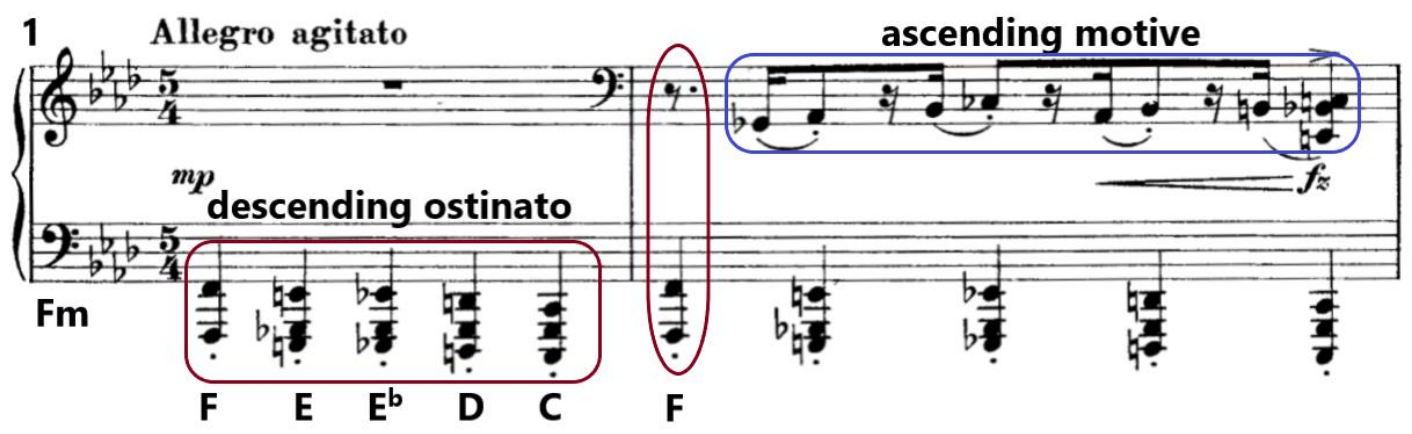

(C) 2004 by Fennica Gehrman Publisher. Used with Permission.

Figure 3.17.1 Selim Palmgren, 24 Preludes, op. 17, No. 17, mm. 1-2.

Section B contains only four measures, from m. 10 to m. 13. Both hands in the first two measures display the reverse motion of the A section: the left-hand ostinatos turn from descending to ascending motion from $\mathrm{G}$ to $\mathrm{C}\left(\mathrm{G}-\mathrm{A}^{\mathrm{b}}-\mathrm{B}^{\mathrm{b}}-\mathrm{B}-\mathrm{C}\right)$ while the right hand changes from its original ascending pattern into a descending motion from $\mathrm{C}$ to $\mathrm{G}$ (see Figure 3.17.2). After a transition bar at $\mathrm{m} .12$, both hands play the motive in parallel ascending motion from $\mathrm{E}^{\mathrm{b}}$ to tonic F, overlapping with the first beat of the last section.

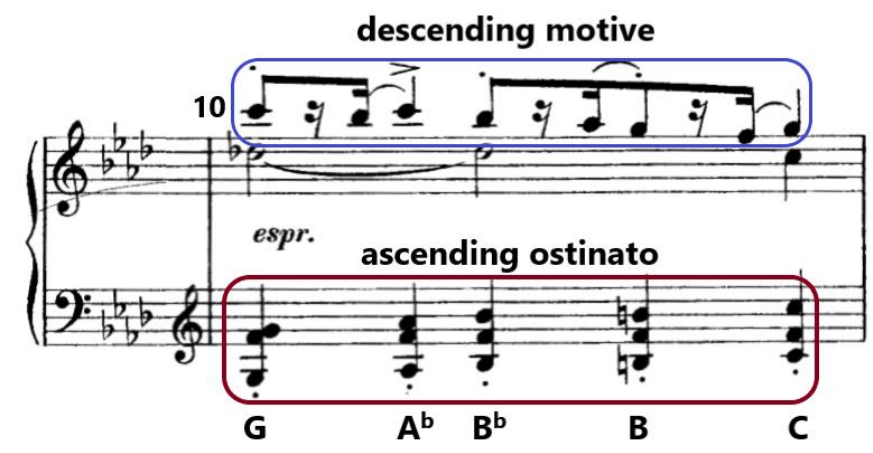

(c) 2004 by Fennica Gehrman Publisher. Used with Permission.

Figure 3.17.2 Selim Palmgren, 24 Preludes, op. 17, No. 17, m. 10. 
The last section starts with two identical thematic phrases presented an octave higher than in the opening A section. It is then repeated in mm. 16-17 with the hands switching roles: the right hand plays a descending ostinato while the left hand plays an ascending thematic motive. The ostinatos in these two bars change from staccatos into accentuated chords in order to increase the feeling of power and gravity. Nonetheless, the hands quickly switch back in m. 18 with an allargando indication, suggesting a slow rallentando, retaining a full, prominent tone. The thematic motive in this bar forms a complete scale that moves up from $G$ to the $G$ an octave above. The piece ends with three unexpected chords: a $\mathrm{G}$ dominant seventh chord containing a $\mathrm{C}$ natural, a pure $\mathrm{G}$ dominant seventh (resolving the 4-3 suspension), and a $\mathrm{C}$ major chord, surprisingly ending the prelude on a dominant chord rather than on the tonic of $\mathrm{F}$ minor (see Figure 3.17.3).

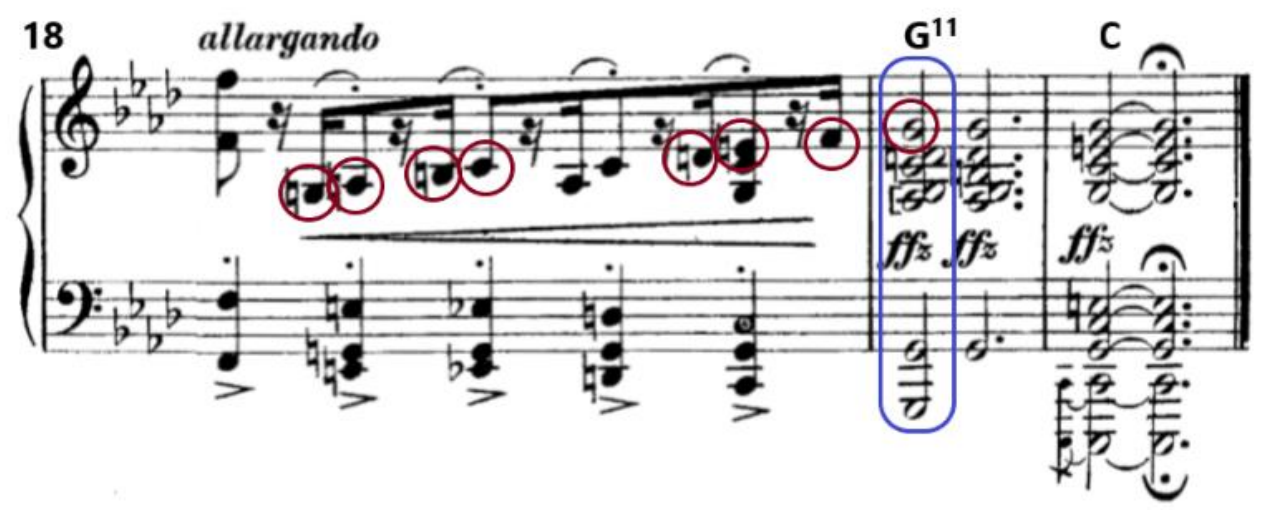

(C) 2004 by Fennica Gehrman Publisher. Used with Permission.

Figure 3.17.3 Selim Palmgren, 24 Preludes, op. 17, No. 17, mm. 18-20. 


\section{$\underline{3.18 \text { Prelude No. } 18}$}

As the title Duo indicates, Prelude No. 18 is written using an operatic bi-thematic approach. Two lyrical themes interacting with each other form this warm and lyrical prelude, the expressive qualities of which are also reflected by its Rubato marking.

Prelude No. 18 displays one-part form, divided into three sections. It is in $\mathrm{F}^{\#}$ minor; however, its key is ambiguous until the B section. Section A extends from the opening to m. 26 . Repeated chords in the right hand form the accompaniment, while the left hand expresses the two themes, one presented in the top voice (theme A) and the other (theme B) in the bass line.

The piece starts with three bars of ascending chromatic chords, the top notes of which begin on $E$ and progress to $G\left(E-E^{\#}-F^{\#}-G\right)$. In the bass, a $C^{\#}$ enters in the bass in $m .3$ and sustains for almost four bars. From a pedagogical aspect, this provides a good opportunity to introduce sostenuto pedaling to students, as the bottom $\mathrm{C}^{\#}$ must be clearly presented beneath changing harmonies. Theme A extends from m. 4 to $\mathrm{m} .7$ and features conjunct motion that flows gradually downward from $\mathrm{G}$, arriving at $\mathrm{C}^{\#}$. Theme $\mathrm{B}$, calmer and slower than theme $\mathrm{A}$, joins in m. 6. This interaction makes the left hand constantly shift between high and low registers and creates a conversational effect between the two themes. Moreover, there is also noticeable interaction between the theme and accompaniment. For instance, theme B and the accompaniment are in reverse motion in $\mathrm{mm}$. 7-9, with theme B traversing a chromatic descent (E-E $-\mathrm{D})$, while the accompaniment ascend chromatically $\left(\mathrm{F}^{\#}-\mathrm{G}-\mathrm{G}^{\#}\right)$ (see Figure 3.18.1). 

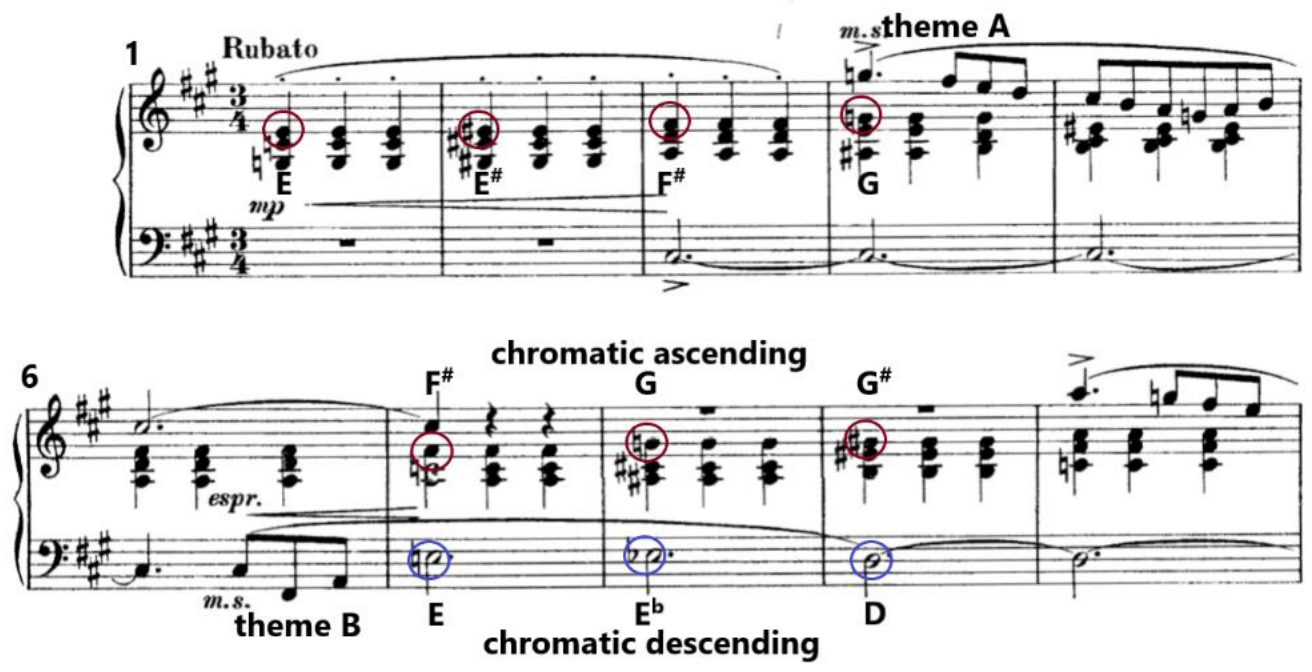

(C) 2004 by Fennica Gehrman Publisher. Used with Permission.

Figure 3.18.1 Selim Palmgren, 24 Preludes, op. 17, No. 18, mm. 1-10.

This interaction reappears twice, in mm. 13-15 and in mm. 23-25. However, at the second reappearance the reverse motion shifts into descending parallel octaves that move from $\mathrm{C}$ to $\mathrm{A}$ $\left(\mathrm{C}^{\#-B-A}\right)$ (see Figure 3.18.2).
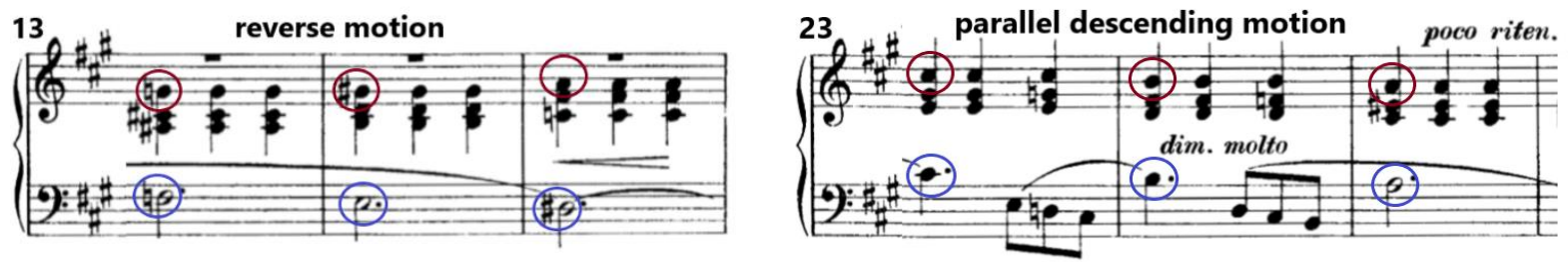

(C) 2004 by Fennica Gehrman Publisher. Used with Permission.

Figure 3.18.2 Selim Palmgren, 24 Preludes, op. 17, No. 18, mm. 13-15, 23-25.

The B section starts from $\mathrm{m} .27$ and extends to $\mathrm{m}$. 40 . The $\mathrm{F}^{\#}$ minor key is clearly established from the beginning. The texture becomes thicker, as the repeated chordal accompaniment of the previous section is split into two voices that are played by both hands. 
Materials in this section are mostly derived from theme A but in reversed motion (see Figure 3.18.3).

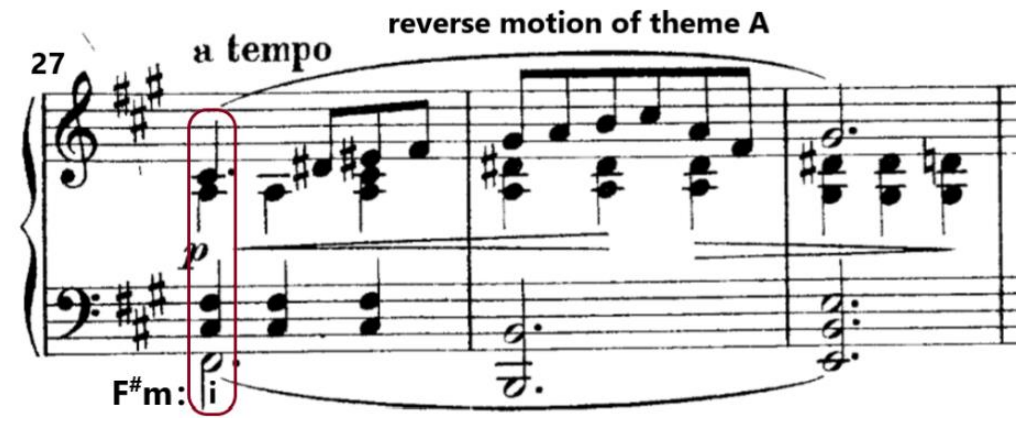

(C) 2004 by Fennica Gehrman Publisher. Used with Permission.

Figure 3.18.3 Selim Palmgren, 24 Preludes, op. 17, No. 18, mm. 27-29.

With the a tempo mark, the A' section returns to the texture of the opening. Interestingly, materials in this section are in retrograde order, compared to section A. For instance, mm. 41-46 imitates mm. 21-26; mm. $47-51$ is a shortened version of m. 6-16; and mm. $52-57$ is the restatement of the melody in $\mathrm{mm} .4-12$, but inverting the theme and accompaniment. The tonic of $\mathrm{F}^{\#}$ minor is reinforced in the final section, with constantly switching dominant and tonic chords in the final nine measures.

\subsection{Prelude No. 19}

Prelude No. 19 is probably the most famous and creative piece of this set. Palmgren entitled this piece Vogelsang (Bird Song). It is an effective miniature piece that not only requires fluent fingering techniques but also needs great imagination to capture its characteristics precisely. The fast running scales and arpeggios throughout the piece mimic the sounds of birds. The piece 
contains neither time signature nor bar lines. In the Helsinki edition, there is a note in this prelude to help identify the notes in the score:

For practical reasons, the composer here omitted the use of measures and bar lines. The provisional sharps and flats affect only the notes coming immediately after. ${ }^{32}$

The expression instruction of this prelude is "Allegro giocoso," indicating its fast, fun, and joyful spirit. The prelude is in two parts followed by a five-beat transition and a coda (AA', transition, coda). The piece lacks bar lines, but the different sections are divided by fermata marks. Each section contains several rapid running phrases that create the impression of birds singing.

Prelude No. 19 is in $\mathrm{F}^{\#}$ major. The two running phrases at the opening both start with $\mathrm{F}^{\#}$ scales to establish the key. Throughout the piece, both hands are usually in parallel octave motion. The right hand plays in a high register, imitating the sound of birds. The first two phrases in the A section are identical except that the last rolling chords are presented a major second apart (B-major triad followed by $\mathrm{C}^{\#}$-major triad). Five groups of arpeggiated phrases constitute the rest of the A section, with the last one breaking into two chromatic descending lines: one moves from $C^{\#}$ to $B\left(C^{\#}-B^{\#}-B\right)$ and the other from $A$ to $E^{\#}\left(A-G^{\#}-F^{\times}-F^{\#}-E^{\#}\right)$. Interestingly, all of these descending broken chords are made up of French augmented sixth chords-reflecting Palmgren's interest in applying impressionistic elements in his music. (see Figure 3.19.1).

${ }^{32}$ Selim Palmgren 24 Preludes Op. 17. (Fennica Gehrman, 2004): 42. 


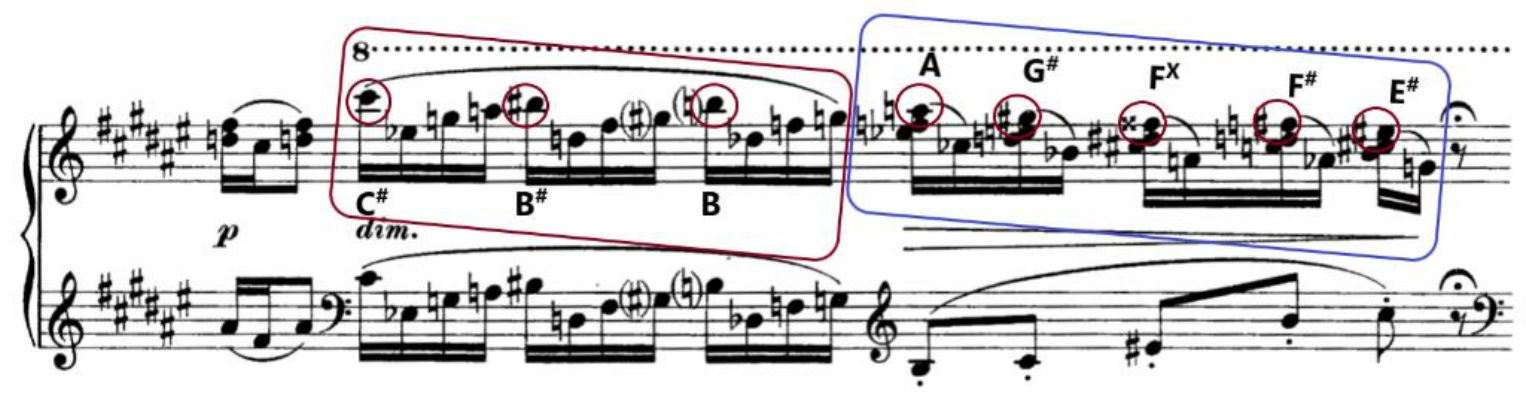

C 2004 by Fennica Gehrman Publisher. Used with Permission.

Figure 3.19.1 Selim Palmgren, 24 Preludes, op. 17, No. 19, chromatic descending passage.

The second part consists of a shortened A section because Palmgren omits two arpeggiated phrases. The chromatic descending phrase in the A section changes into a long legato curving phrase that brings the piece to its climax - it first drops down from $\mathrm{B}$ to $\mathrm{G}$ and then rises to a high A. Instead of going to either the tonic or the dominant, a sf rolling augmented-sixth chord is presented, heightening the harmonic tension. After a small ascending arpeggiated transition suggesting a $\mathrm{C}^{\#}$ dominant chord but ending on an A natural (or "sharp 5") that acts as an appoggiatura to the expected $\mathrm{G}^{\#}$, Palmgren inserts a $\mathrm{C}^{\#}$ dominant seventh chord in a lower register before resolving the A to the $\mathrm{G}^{\#}$. This resolution completes the dominant chord and (after a one-beat rest with a fermata) introduces the $\mathrm{F}^{\#}$ major coda (see Figure 19.2). 


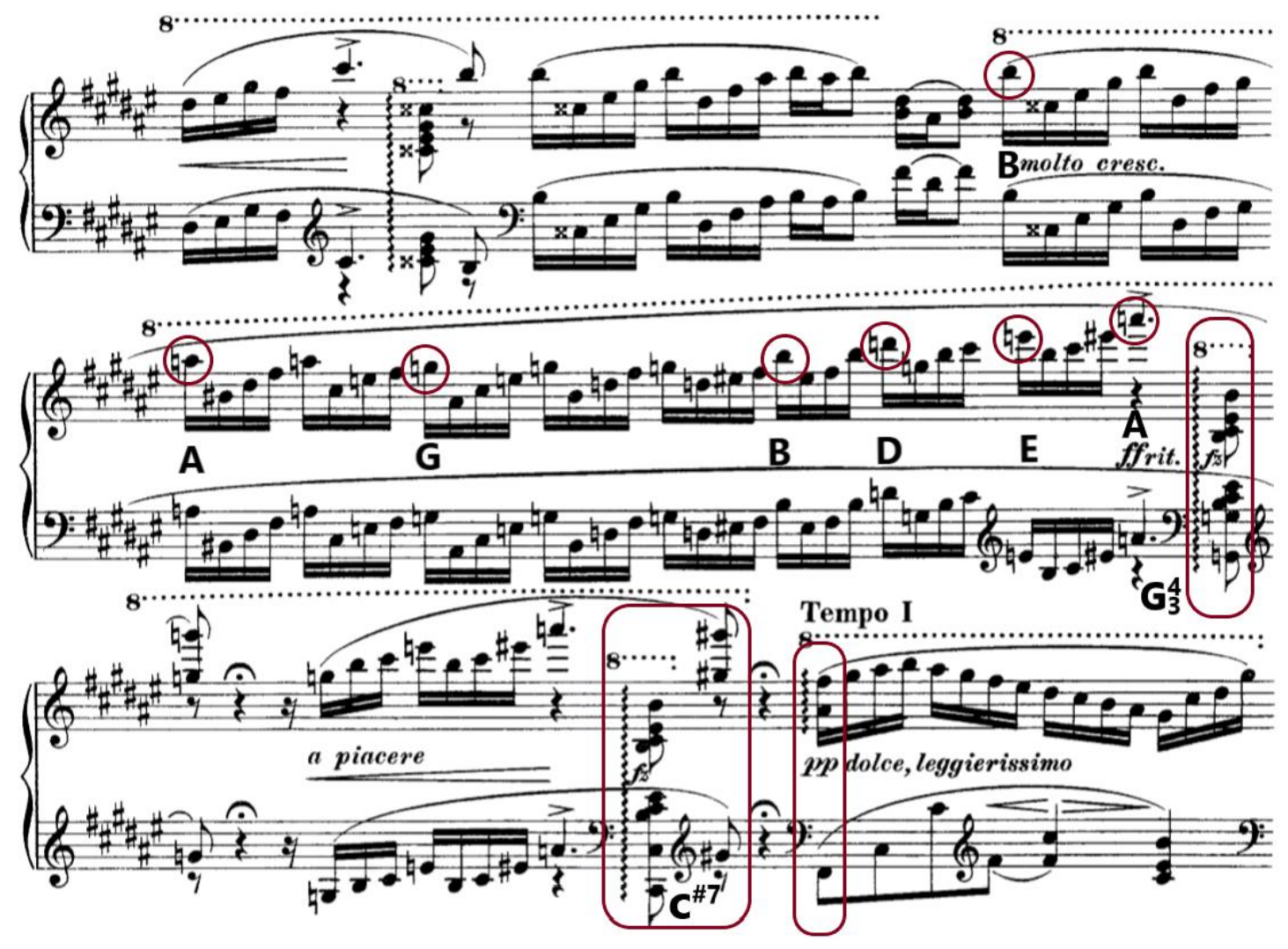

(C) 2004 by Fennica Gehrman Publisher. Used with Permission.

Figure 3.19.2 Selim Palmgren, 24 Preludes, op. 17, No. 19, ascending arpeggiated passage.

Instead of following the previous texture of parallel doubling of hands, the left hand in the coda turns into an accompaniment that shifts between the tonic and the dominant to reinforce the key. The right hand gradually descends in register, along with the expressive indications of perdendosi and rallentando, which vividly help to display a scene of the birds' singing gradually dying away in the forest.

\section{$\underline{3.20 \text { Prelude No. } 20}$}

Compared to the bright and energetic characteristics of Prelude No. 19, Prelude No. 20 is written in a completely opposite mood: dark, heavy, and gloomy. Because the piece is titled In 
Memoriam, in addition to the expression indication Lugubre, a funeral march is the first impression that this prelude conveys: this is especially true because of the minor key, like those of virtually all funeral marches (e.g., those of Chopin, Beethoven, Wagner, Mendelssohn, and Alkan).

Prelude No. 20 is one page long and contains only 19 measures. It is in one-part form that is subdivided into two sections with a coda (AA' Coda). The entire piece is based on a fixed rhythmic pattern: the motive in the right hand starts with a pickup and forms a "short-long" small slur pattern in either ascending or descending seconds; the left hand features a walking bass consisting of ascending seconds that enter on the second beat of each measure.

The first section extends from the opening until the third beat of $\mathrm{m}$. 8. It consists of two symmetrical phrases in a " $4+4$ " structure, with the first phrase alternating between rising and falling seconds, and the second in descending motion. The second section mainly imitates the previous section, but reveals a " $4+5$ " asymmetrical phrase structure that flows from the last beat of $\mathrm{m} .8$ to the third beat of $\mathrm{m} .17$. The motive in this section is written an octave higher. Moreover, the texture becomes thicker as both the motive and the walking accompaniment are doubled. The walking-bass accompaniment is doubled by the right hand in parallel octaves, while the motive is doubled, but in reversed motion, in the left hand (see Figure 3.20.1). 


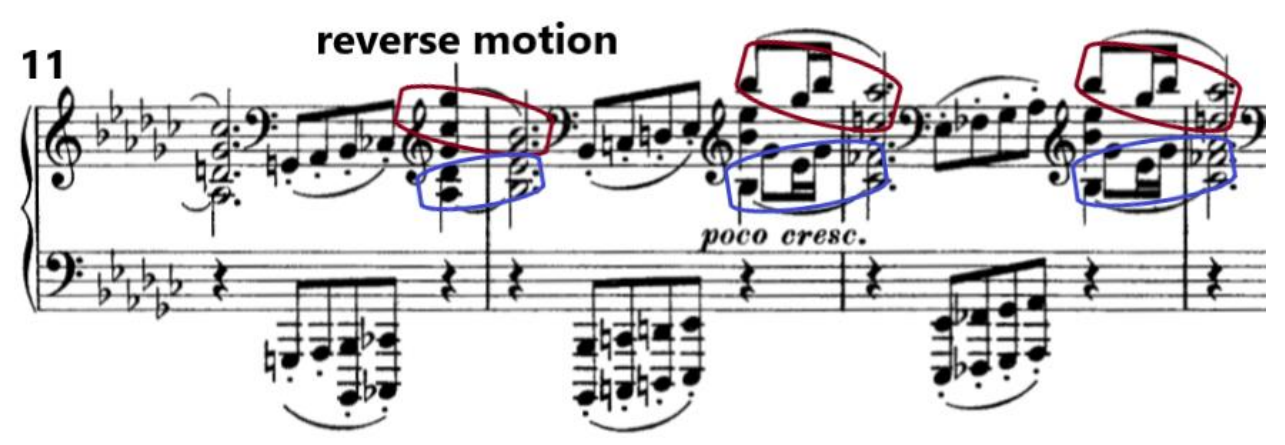

C 2004 by Fennica Gehrman Publisher. Used with Permission.

Figure 3.20.1 Selim Palmgren, 24 Preludes, op. 17, No. 20, mm. 11-13.

A series of descending accentuated half notes in mm. 15-17, shifting between tonic and dominant, provide the cadential effect. It is followed by a short two-bar coda which consists of five seventh chords that create a dark and mysterious color while finally bringing the piece home to the tonic. This progression of parallel sevenths chords recalls a common compositional technique of Debussy, displaying once more Palmgren's Impressionistic interests (see Figure 3.20.2).

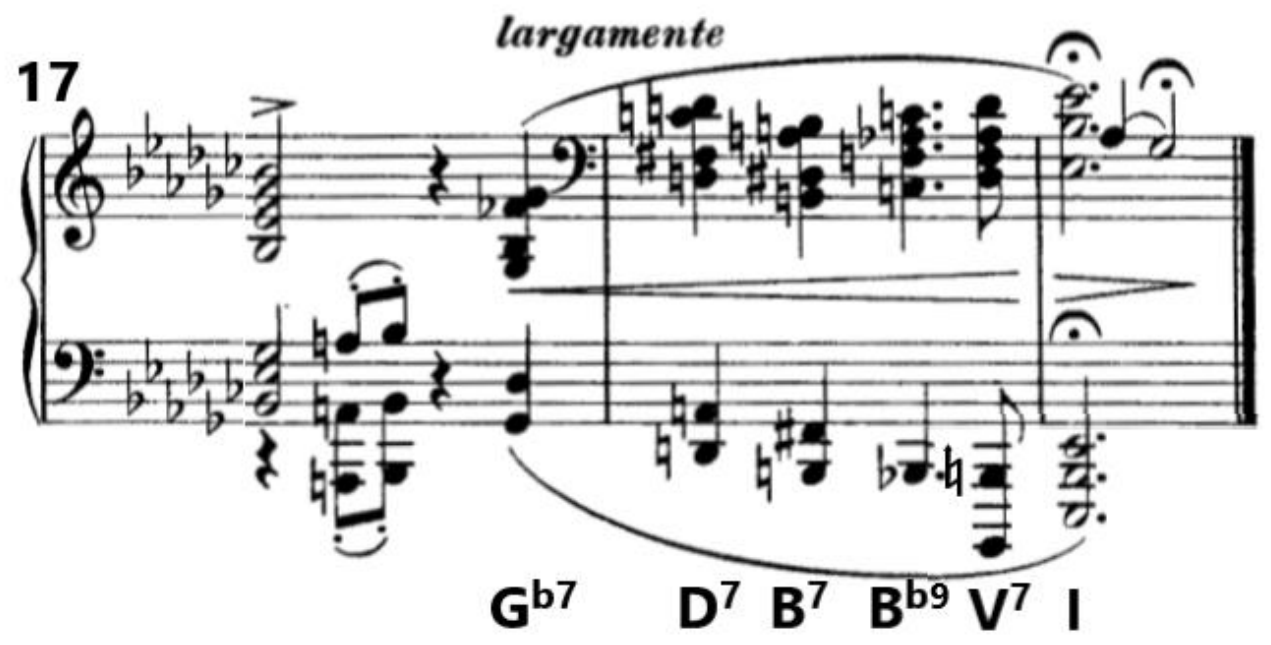

() 2004 by Fennica Gehrman Publisher. Used with Permission.

Figure 3.20.2 Selim Palmgren, 24 Preludes, op. 17, No. 20, mm. 17-19. 


\section{$\underline{3.21 \text { Prelude No. } 21}$}

In contrast to the previous sublime prelude, the characteristics of Prelude No. 21 reveal a much brisker and brighter spirit. Three repetitive voices are clearly layered, progressing horizontally without interacting with each other. The theme stated by the right hand is mainly formed by repeated notes. The left hand presents two voices: the ostinato bass line, consisting of half notes in the pattern F-E $-E^{\mathrm{b}}-\mathrm{D}-\mathrm{E}^{\mathrm{b}}-\mathrm{F}-\mathrm{E}^{\mathrm{b}}-\mathrm{D}-\mathrm{G}$; and the middle voice, featuring perpetual rocking triplets mostly in the relationship of thirds, fourths and fifths (see figure 3.21.1).
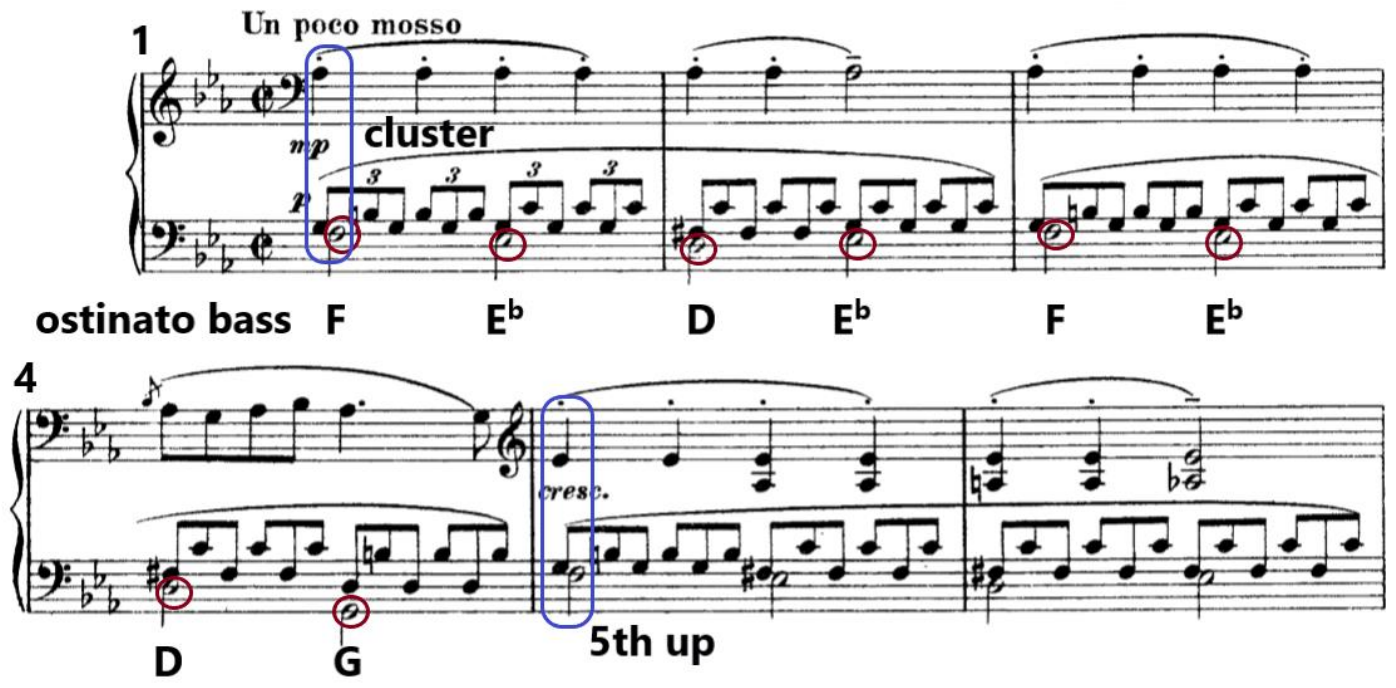

(C) 2004 by Fennica Gehrman Publisher. Used with Permission.

Figure 3.21.1 Selim Palmgren, 24 Preludes, op. 17, No. 21, mm. 1-6.

The key signature of three flats seems to indicate either $\mathrm{E}^{\mathrm{b}}$ major or $\mathrm{C}$ minor as the mode. However, the tonal sense is obscured by the opening cluster of $\mathrm{F}, \mathrm{G}, \mathrm{A}^{\mathrm{b}}$ at the downbeat and the following presence of $\mathrm{B}, \mathrm{E}^{\mathrm{b}}$ and $\mathrm{C}$ in the left-hand voices. Adding to the ambiguity is the repetitive $\mathrm{A}^{\mathrm{b}}$ in the right-hand theme, which seems to be a strong hint of its tonal area. Except for mm. 25-31, which form the coda, the entire piece consists of five repetitions of the opening 
theme, either a fifth up or in chordal texture. Figure 3.21.2 shows the relationships among the phrases.

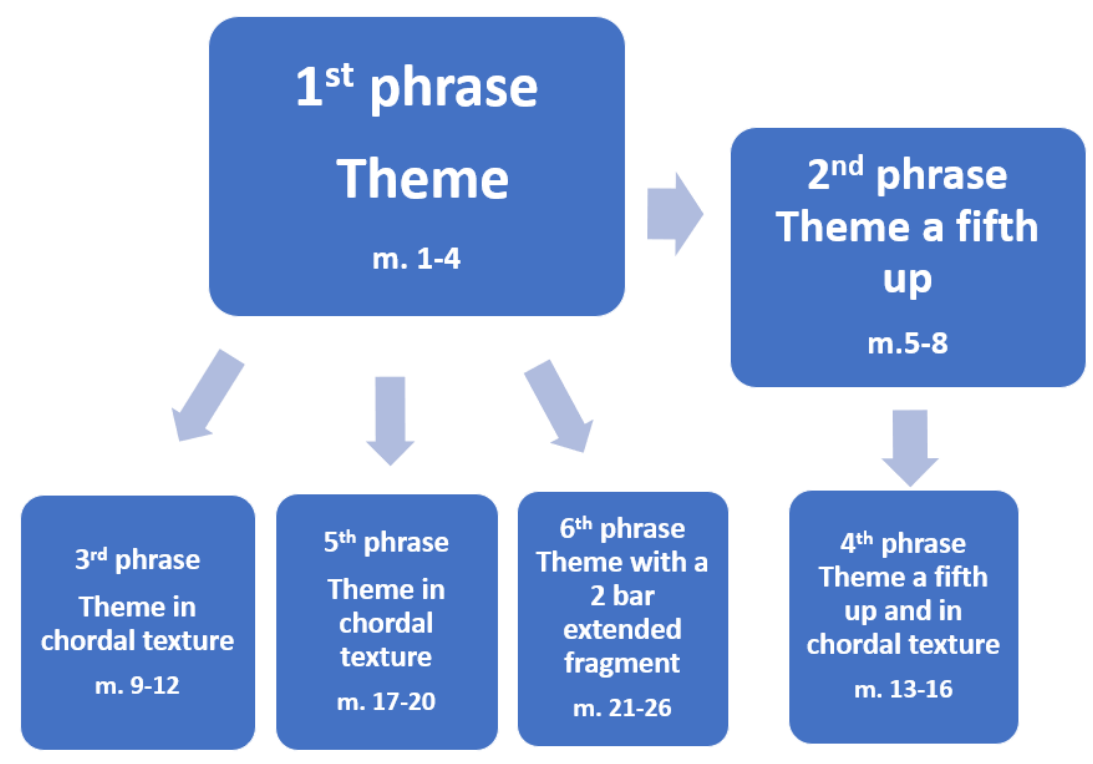

Figure 3.21.2 Selim Palmgren, 24 Preludes, op. 17, No. 21, relationship between phrases

The coda extends from m. 27 to the end and is a syncopated presentation of the beginning of the theme in open fifths $\left(\mathrm{A}^{\mathrm{b}}-\mathrm{E}^{\mathrm{b}}\right)$. These five measures contain a constant pedal point of $\mathrm{C}$, which would seem to establish the tonic key; however, this is weakened by the continuous addition of $\mathrm{A}^{\mathrm{b}}$ throughout these measures, distracting from a final sense of $\mathrm{C}$ minor (see Figure 3.21.3).

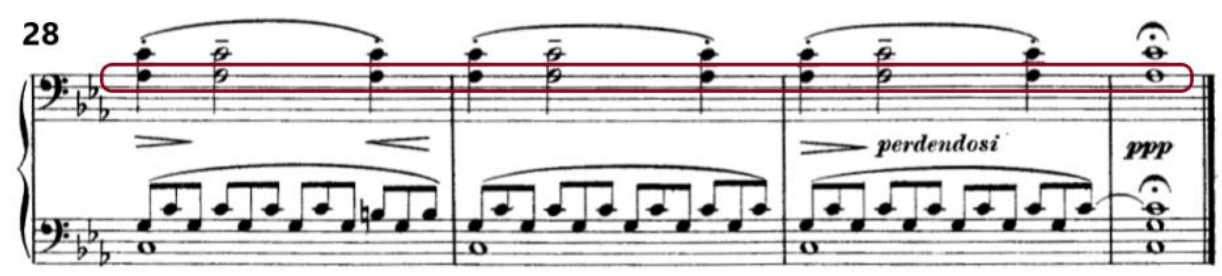

$\mathrm{Cm}$ with additional $\mathrm{A}^{\mathrm{b}}$

(c) 2004 by Fennica Gehrman Publisher. Used with Permission.

Figure 3.21.3 Selim Palmgren, 24 Preludes, op. 17, No. 21, mm. 28-31. 


\section{$\underline{3.22 \text { Prelude No. } 22}$}

Prelude No. 22 is the last of the three preludes of this set titled Im volkston (In Folk Style). The duple meter (2/4), along with the expression instruction Alla Marcia (in march style) clearly indicate the characteristics of this vigorous prelude. Compared to the tonal ambiguity of the previous prelude, Prelude No. 22, clearly written in $\mathrm{E}^{\mathrm{b}}$ Major, follows a traditional folk-music harmonic scheme. Most of the time the accompaniment stays in either the tonic or dominant to reinforce the key.

This prelude exhibits a repeated one-part form, which can be subdivided into two asymmetrical sections. The A section starts from the opening to $\mathrm{m}$. 8 . The melody in the first bar is presented by both hands, alternating with each other, requiring the performer to maintain a seamless melodic flow as the theme is passed from one hand to the other. Section A consists of two similar four-bar phrases with a steady pulse. Accents are added on the strong beats and are followed by repeated notes that are reminiscent of percussion sounds. Even the springy doubledotted rhythm in $\mathrm{m} .3$ is accompanied by the steady walking bass that retains the feeling of a march (see Figure 3.22.1).

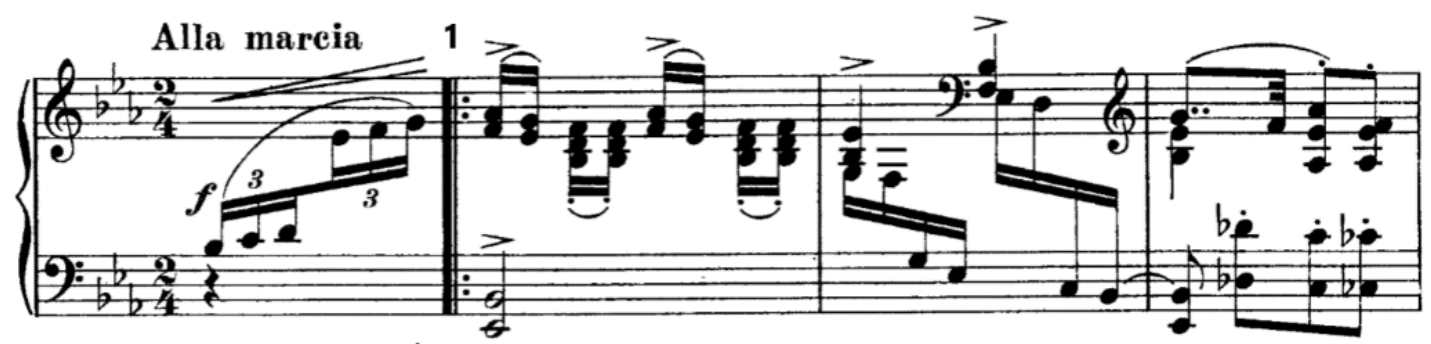

$E^{b} M:$ I

(C) 2004 by Fennica Gehrman Publisher. Used with Permission.

Figure 3.22.1 Selim Palmgren, 24 Preludes, op. 17, No. 22, mm. 1-3. 
The B section extends from m. 9 to the end. Like section A, it also contains two similar phrases, but with a more lyrical and rhythmically flowing melody. The feeling of a strict pulse is decentralized by a figure that crosses the bar line and by accents on certain weak beats. For instance, there is a one-beat cross-bar figure followed by an accent on the weak beat of $\mathrm{m} .13$ that conflicts with the larger pulse (see figure 3.22.2).

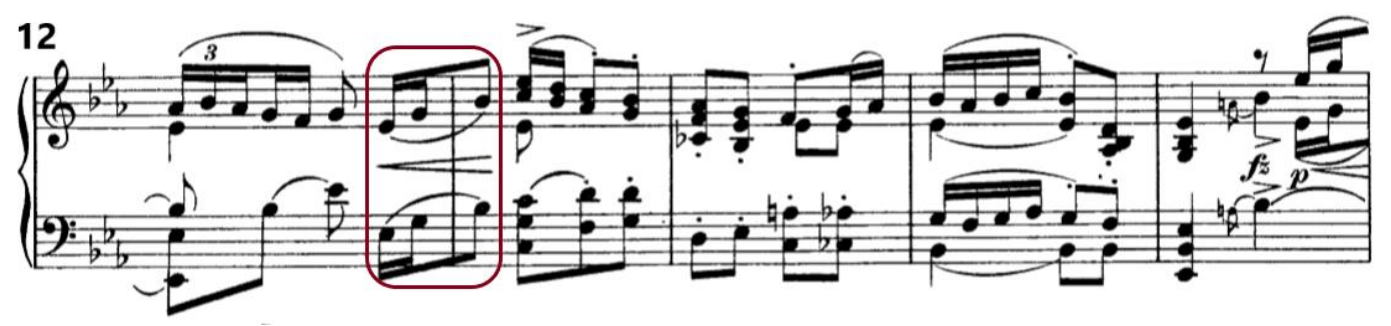

(C) 2004 by Fennica Gehrman Publisher. Used with Permission.

Figure 3.22.2 Selim Palmgren, 24 Preludes, op. 17, No. 22, mm. 12-16.

Prelude No. 22 is a brief piece that shows moderate difficulty. Some passages contain jumps and some require the voices to switch between the hands. The piece follows a traditional march setting while still infusing folk elements. Not only because of the indication of the title, but also because of the injection of some non-march elements (such as rhythmic digression from the original pulse) make it more "in folk style" than a traditional march. In addition, Palmgren marks D.C. ad libitum. at the first ending, offering performers some flexibility in the interpretation of the piece. 


\section{$\underline{3.23 \text { Prelude No. } 23}$}

The title of Prelude No. 23 is written only in Italian— "Venezia"—indicating the Italian city known in English as Venice. This title may call to mind the style of a "Barcarolle," a traditional folk melody sung by Venetian gondoliers. Indeed, this prelude resembles the style of barcarolles in many aspects. For instance, the piece is written in $\mathrm{B}^{\mathrm{b}}$ minor and in compound meter (admittedly not in the most usual compound meter)—and the expression indication Malinconico (sad, sorrowful) along with the soft dynamics and moderate tempo all fit the traditional characteristics of a Barcarolle. In addition, the low-register downbeats in the bass line are mostly in either the tonic or dominant and are followed by an ascending motion in seconds. This rhythmic figure in the style of a barcarolle is reminiscent of the gondolier's oar-stroke.

The piece is written in ternary form (ABA'). The opening section contains ten measures. It starts with two bars of introduction that resemble Felix Mendelssohn's Venetianisches Gondellied, op. 30, and Tchaikovsky's Barcarolle (June) (see Figure 3.23.1). The right hand in the introduction plays an augmented fourth at the last beat of each bar, forming with the left hand a French augmented-sixth chord, creating harmonic tension. Although the bass line stays on a $\mathrm{B}^{\mathrm{b}}$ major pedal point, which would seem to stabilize the key, the melody in the right hand varies harmonically, which lends the piece chromatic color changes.

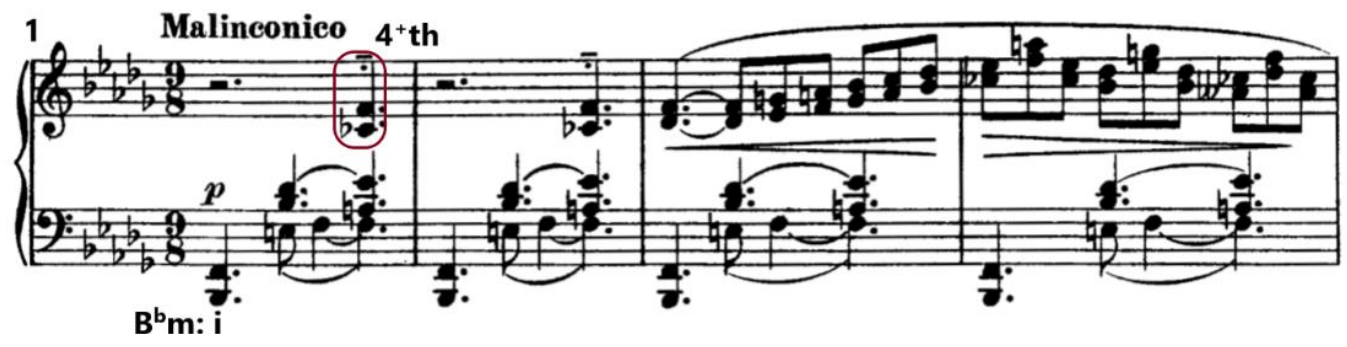

(C) 2004 by Fennica Gehrman Publisher. Used with Permission. 


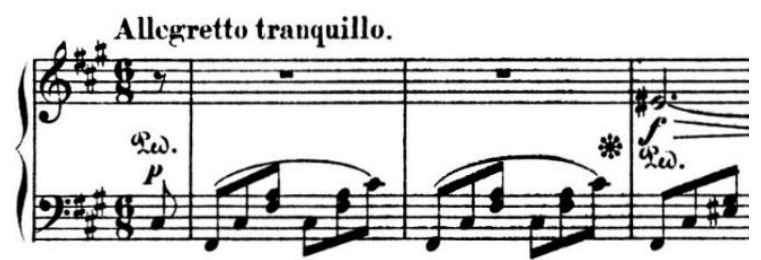

Felix Mendelssohn Venetianisches Gondellied

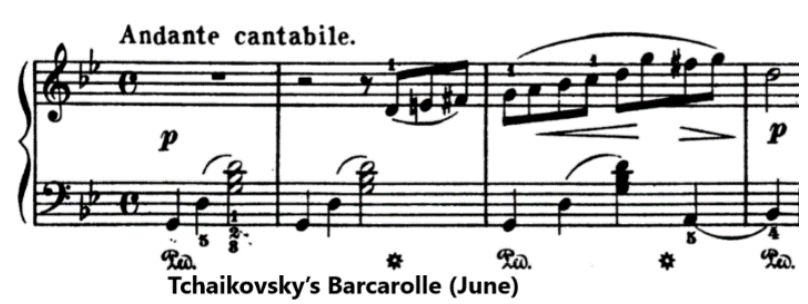

(C) 1891 by Schirmer Publisher. Used with Permission.

(C) 1874 by Breitkopf \& Härtel Publisher. Used with Permission.

Figure 3.23.1 Selim Palmgren, 24 Preludes, op. 17, No. 23, mm. 1-4, Felix Mendelssohn Venetianisches Gondellied, mm. 1-3, Tchaikovsky's Barcarolle (June), mm. 1-3.

The melodic line in the A section contains two four-bar symmetrical phrases. Each one is formed by the intervals of thirds and each features an ascending scale from $\mathrm{D}^{\mathrm{b}}$ to $\mathrm{C}^{\mathrm{b}}$ and then gradually descends to $F$ (to $G^{b}$ in the second phrase). In m. 10, the last bar of the second phrase, the melodic line is broken up into three ascending slurs that feature $\mathrm{C}^{7}-\mathrm{F}^{7}-\mathrm{C}^{7}$, which lead to the dominant $\mathrm{F}^{7}$ at the downbeat of $\mathrm{m} .11$, where the B section starts.

The B section extends from m. 11 to $\mathrm{m} .22$ and is made up of a series of small falling phrases. Each phrase from m. 11 to m. 14 is shortened to two bars, with the left hand staying mostly in the dominant, while the melodic line in the right hand begins with repeated major thirds $\left(C^{b}-E^{b}\right)$ and then features a descending motion. From mm. 15-21, the phrases are further shortened into six groups of descending lines. The first four (mm. 15-19) are each one bar long, all ending on the downbeat. The last three phrases are combined into one big descending scale from $E^{b}$ all the way down to $B^{b}\left(E^{b}-D^{b}-C-B^{b}-A^{b}-G-G^{b}-F-E^{b}-D^{b}-C^{b}-B^{b}\right)$. The $B$ section ends on a dominant-seventh chord in the last beat of $\mathrm{m} .21$ and finally resolves to the tonic of $\mathrm{B}^{\mathrm{b}}$ minor, where the A' sections starts (see Figure 3.23.2). 

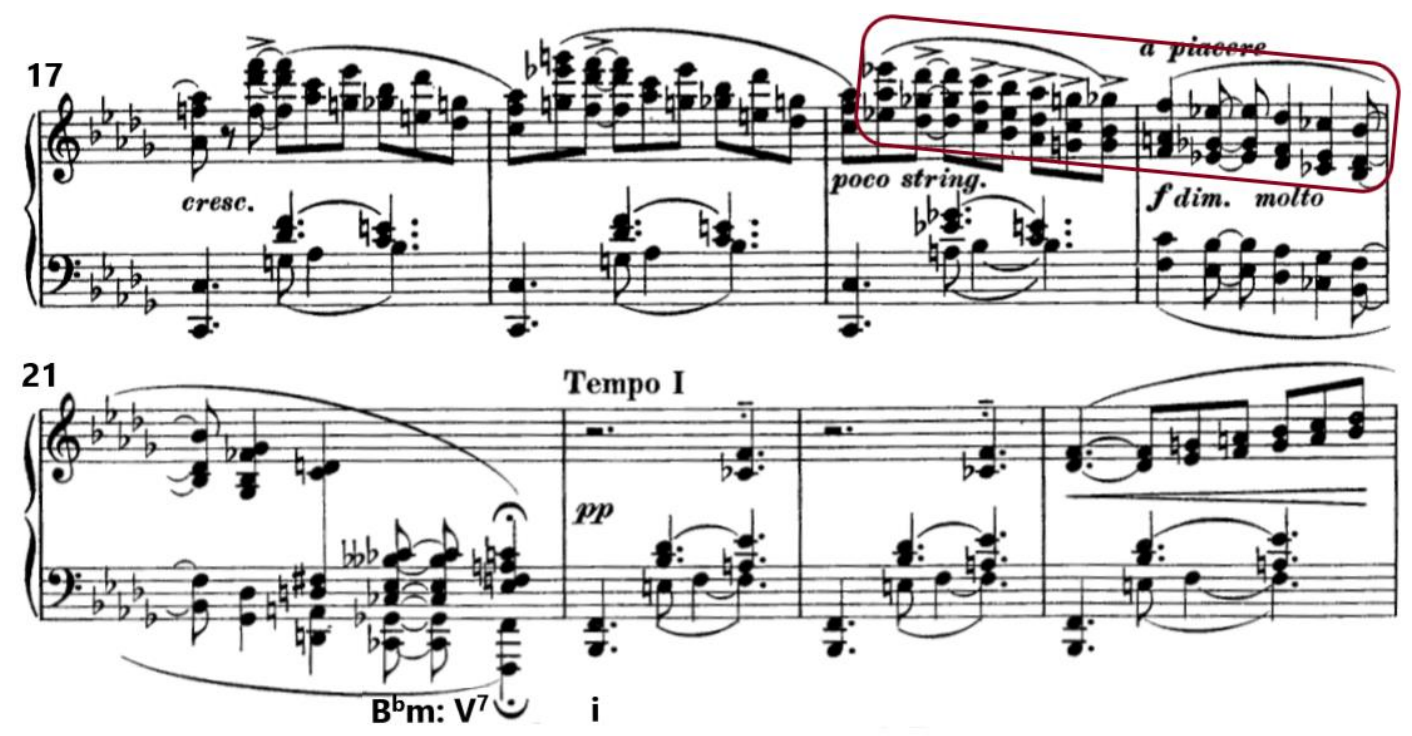

(C) 2004 by Fennica Gehrman Publisher. Used with Permission.

Figure 3.23.2 Selim Palmgren, 24 Preludes, op. 17, No. 23, mm. 17-24.

The A' section starts with a restatement of the introductory bars and is derived mainly from material presented in the opening section. The downbeats of the bass line in this section stay in the tonic through the end, strengthening the key. The right hand begins by restating the complete theme of the opening section and then gradually breaks the phrase into smaller fragments, quoting first the rising pattern from the opening few bars and then the descending motive that follows. It then leads to the final cadence, an unusual tonic minor with an added major sixth (see Figure 3.23.3). The dynamics in this section gradually recede from $p p$ to $p p p p$. The instruction of perdendosi (dying away) is added near the end to help promote an atmosphere of calmness after the boat's departure. 


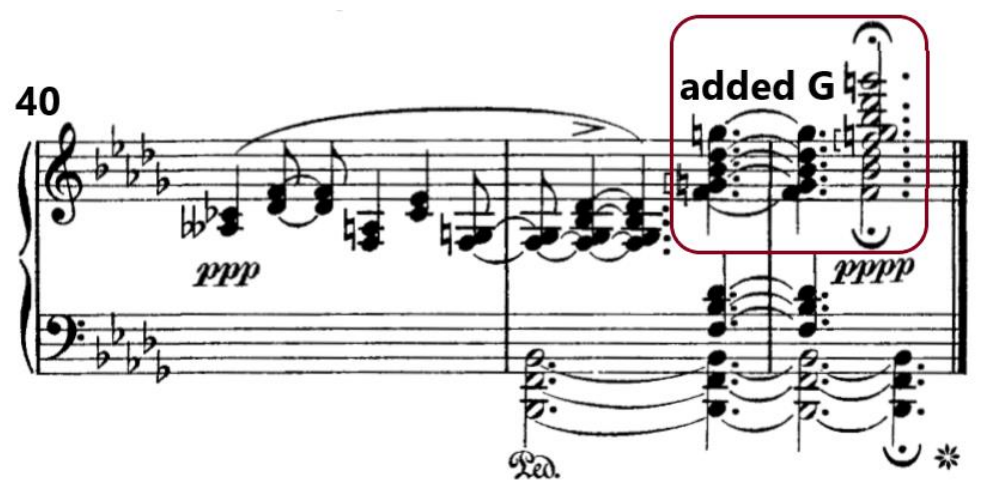

C 2004 by Fennica Gehrman Publisher. Used with Permission.

Figure 3.23.3 Selim Palmgren, 24 Preludes, op. 17, No. 23, mm. 40-42.

Prelude No. 23 is the second-last piece in the set. Commonly the movement before the last is written in a soft and gentle nature in order to provide great contrast to the magnificent finale. Palmgren follows this scheme, composing this prelude in as sedate and peaceful a character as possible, in order to showcase the rhythmically inexorable and aggressive nature of the final prelude.

\section{$\underline{3.24 \text { Prelude No. } 24}$}

The last piece of the set, Prelude No. 24, indubitably possesses the characteristics of a finale - this is a splendid march full of power and energy. It is not only the most technically and rhythmically challenging prelude of this set, but is also a great example of Palmgren's ability to employ interaction among voices.

Textually, the entire piece is written in three distinctive parts: the motive, made up of six single notes; the accompaniment, consisting of fast and powerful repeated chords; and the bass 
line, comprised of percussive octaves stated in the low register. These three parts are closely linked to each other and provide the glue that links the piece as a whole.

Prelude No. 24 is in $\mathrm{D}^{\mathrm{b}}$ major. It starts with a two-bar introduction of repeated tonic chords. The bass line comes in on the tonic at the downbeat of the second bar, reinforcing the key. Structurally, the piece reveals ternary form with a coda (ABA' Coda). The opening section extends to m. 13. The motive enters in $\mathrm{m} .3$ and contains six notes in conjunct motion (A-B $-\mathrm{B}-$ C-G- $\left.\mathrm{A}^{\mathrm{b}}\right)$ while the accompaniment in the right hand reveals a mirrored shape $\left(\mathrm{C}^{\mathrm{b}}-\mathrm{B}^{\mathrm{b}}-\mathrm{B}^{\mathrm{bb}}-\mathrm{A}^{\mathrm{b}}-\mathrm{C}^{\mathrm{b}}-\right.$ $\mathrm{D}^{\mathrm{b}}$ ). This reverse approach is largely used in this prelude. For instance, the left-hand motive in m. 9 is in the reverse motion of m. 3 (see Figure 3.24.1). Interestingly, after the first octave at the downbeat of m. 2, the strong and always accented octaves in the bass appear on the second or third beats of the bars. This not only creates a percussive feeling, but also serves as a strong foundation to fortify the tonalities, which modulate from $\mathrm{D}^{\mathrm{b}}$ major to $\mathrm{A}$ major and back to $\mathrm{D}^{\mathrm{b}}$ major.
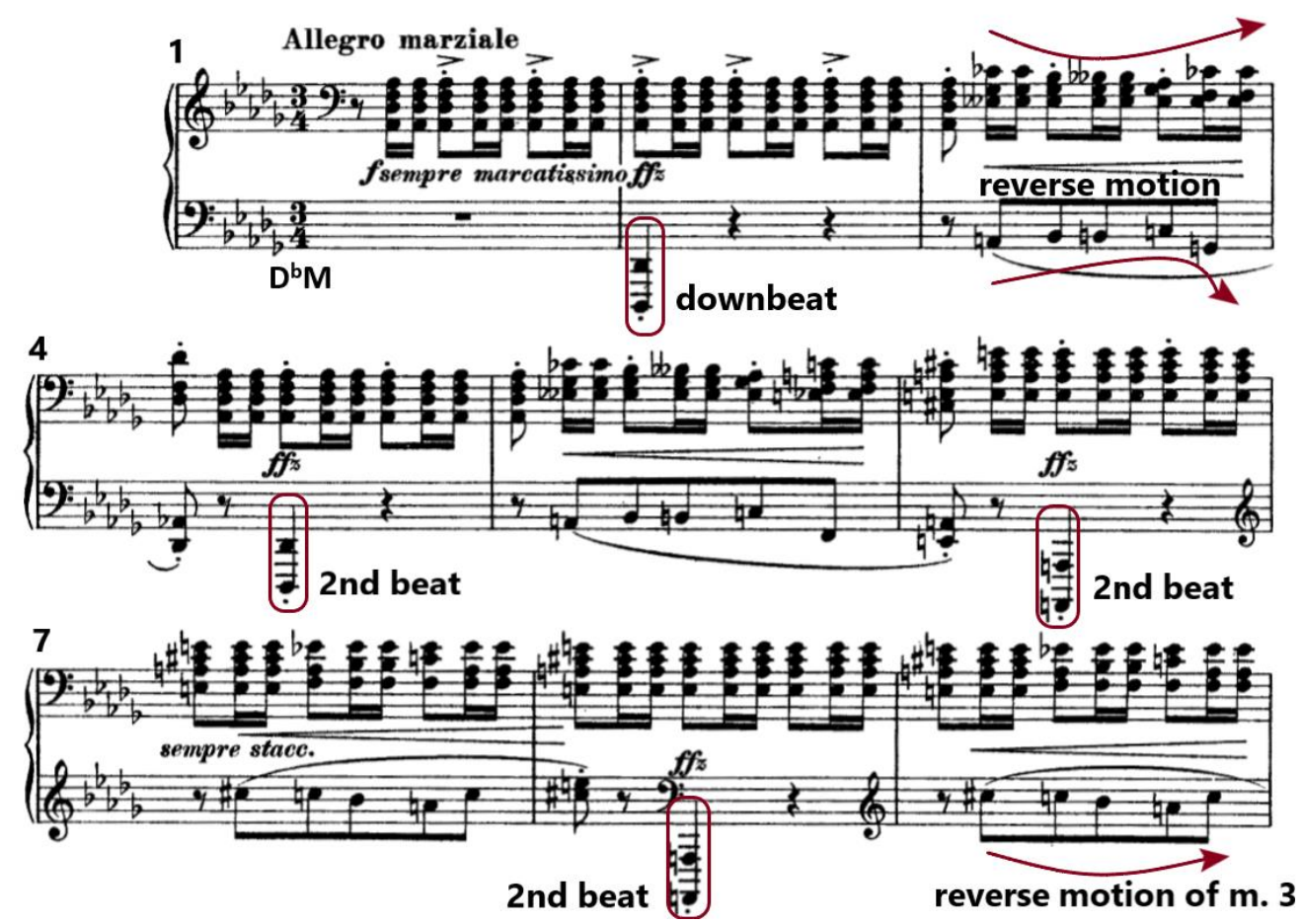
(C) 2004 by Fennica Gehrman Publisher. Used with Permission.

Figure 3.24.1 Selim Palmgren, 24 Preludes, op. 17, No. 24, mm. 1-9.

The last phrase in the A section (mm. 10-13) is a transition, with the right hand featuring a series of chromatic ascending chords in which the top notes rise from $E-A^{b}\left(E-F-F^{\#}-G-A^{b}\right)$. The bass octaves in the left hand, previously heard on the second beats, shift to the third and last beats to give way to the newly added accented voice in the treble.

The B section extends from mm. 14-32, imitating the opening section but with a thicker motivic texture. From m. 19 the accompaniment shifts to the left hand and the right hand features four groups of descending patterns in a gradual rhythmic diminution. This rhythmic change ends with a three-note slur and repeats four times in the right hand from mm. 28-29 to create a hemiola effect (3+2) (see Figure 3.24.2). The original pulse is finally restored in $\mathrm{m} .30$ and stays in the dominant for two measures. After three chromatic ascending chords whose topmost notes go from $\mathrm{F}$ to $\mathrm{G}$ (F-F\#-G) with accents and with the expression indication ten., it arrives at $\mathrm{A}^{\mathrm{b}}$ and the tonic of $\mathrm{D}^{\mathrm{b}}$ major at the downbeat of $\mathrm{m} .33$, where the $\mathrm{A}^{\prime}$ section starts.

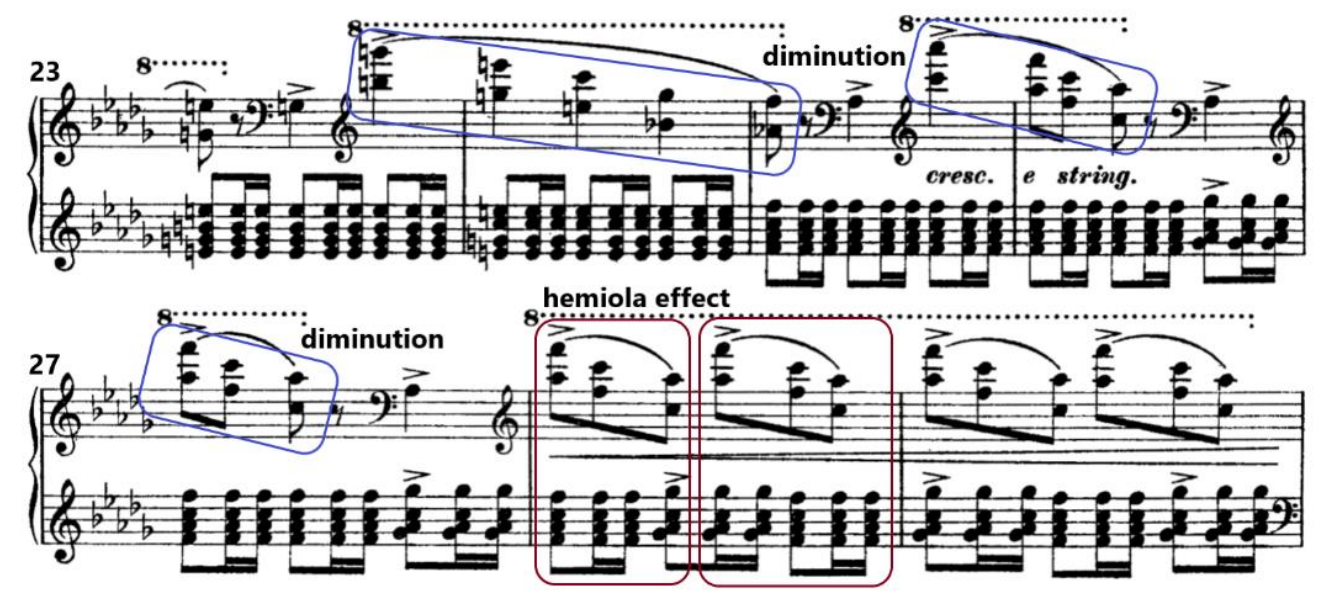

(C) 2004 by Fennica Gehrman Publisher. Used with Permission.

Figure 3.24.2 Selim Palmgren, 24 Preludes, op. 17, No. 24, mm. 23-29. 
Section A' is the combination of the previous two sections. The first 12 measures (mm. 3344) restate the materials of the A section, and $\mathrm{mm}$. 44-51 imitate the descending-slur figures of the B section. However, this time the materials of the hands are switched and the last slur is in augmentation instead of diminution

The Coda starts at $\mathrm{m}$. 51. This is not only the last section of this prelude, but the final part of this entire set. Dynamics in this section are raised to fff and, in the percussive bass octaves, even fffz. The prelude ends with an accentuated descending bass line from $\mathrm{D}^{\mathrm{b}}$ to an octave below (see Figure 24.3), which supports a triumphal and rhythmic chordal statement in the right hand derived from the introduction.

Prelude No. 24 is a powerful and magnificent piece and serves as an apt ending to the set. Its Allegro marziale performance indication effectively embodies the characteristic of this piece, which Palmgren titled "The War." 

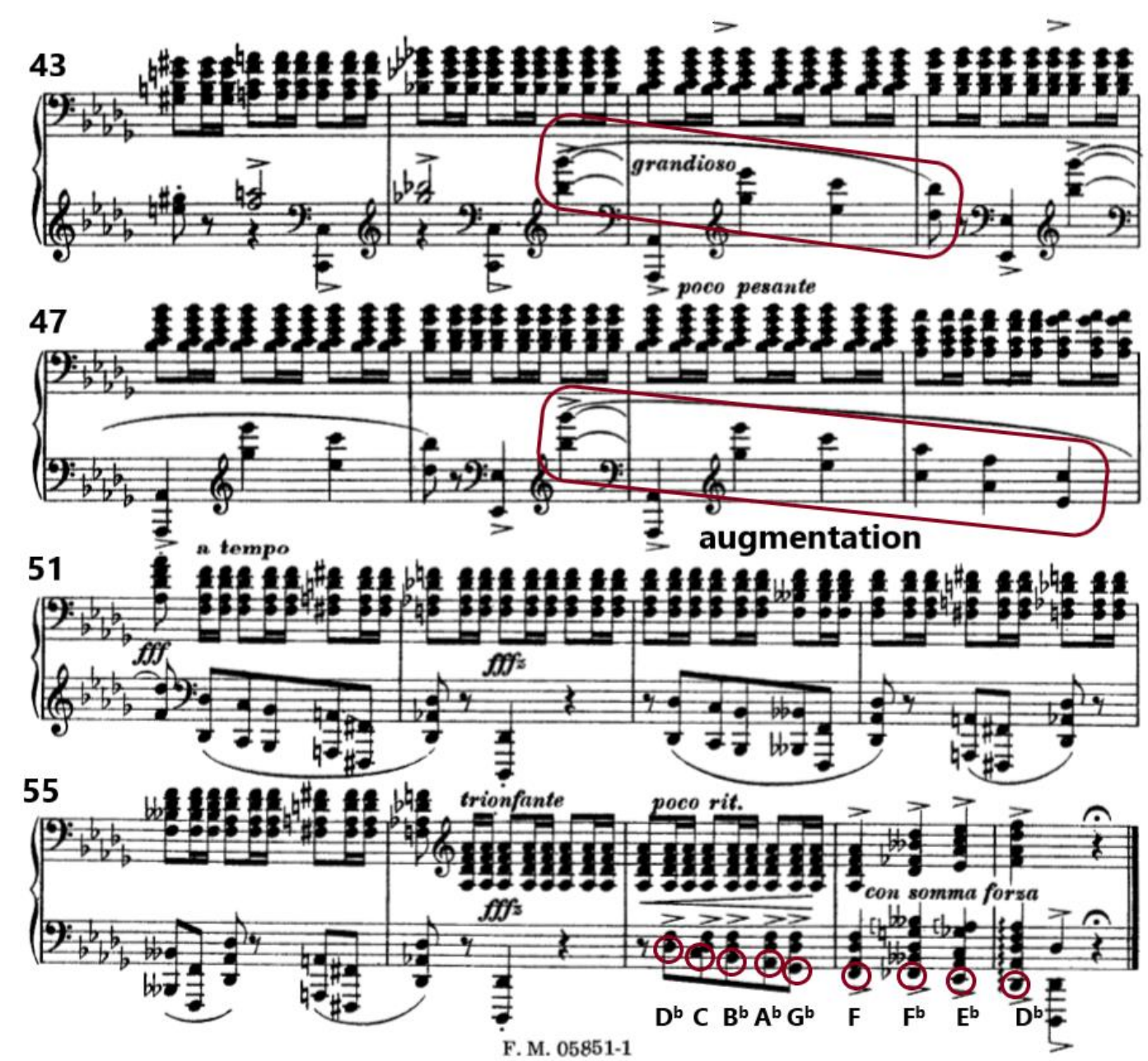

(C) 2004 by Fennica Gehrman Publisher. Used with Permission.

Figure 3.24.3 Selim Palmgren, 24 Preludes, op. 17, No. 24, mm. 43-59. 


\section{Chapter 4}

\section{Analytical Study of Tres Piezas para Piano, op. 54}

\section{About Tres Piezas para Piano, op. 54}

Tres Piezas para Piano, op. 54, was composed in 1916. The first performance of this suite was by Palmgren himself at a concert held in the Helsinki University Hall on 11/14/1916, according to its concert program Rain Drops-For the First time. ${ }^{33}$ Each of the three movements has a descriptive title:

1. Gotas de agua "Raindrops"

2. Vals el mignon "Mignonne Waltz"

\section{Luz de luna "Moonlight"}

Robert Layton states in his article Palmgren Early and Middle Period: ${ }^{34}$

In his insert-note Kimmo Karhonen speaks of his reaching "a kind of protoimpressionism in the pieces where he evokes impressions of nature" and the musical language has a simplicity of texture and pallid melancholy that is appealing. His palette is that of gouache rather than oils. Though he was a fine pianist, these miniatures do not use a particularly extensive repertory of pianistic devices (in fact it is distinctly limited) and tend to inhabit a circumscribed emotional range. Some, like the "Valse mignonne" from op. 54, are close to gentility and even salon music.

\footnotetext{
${ }^{33}$ Poroila, Heikki., Selim Palmgren Work Catalogue. (Helsinki, 2014), accessed April 10, 2019, https://www.musiikkikirjastot.fi /wp-content/uploads/2016/11/Palmgren_luettelo.pdf.

${ }^{34}$ Layton, Robert. "Palmgren's Early and Middle Period Piano Pieces," Gramophone, accessed April 10, 2019, https://www. gramophone.co.uk/review/palmgren-early-middle-period-piano-pieces.
} 
This chapter will concentrate on analyzing each movement, including its general structure, harmony and compositional techniques, with the aim of providing useful information for instructors or performers who are interested in this beautiful suite.

\subsection{Gotas de agua "Raindrops"}

The first movement of this suite is called Raindrops. Its title calls to mind one of Chopin's most well-known pieces, the "Raindrop" Prelude, op. 28, No. 15, and the two pieces are also similar in texture. Both pieces apply an ostinato pattern to suggest the drops of rain. However, the two composers interpret raindrops from a different spatial aspect. For instance, Chopin uses repeated notes in the bass line to imitate rain falling on the ground, while in Palmgren's piece, the raindrop figure is presented by falling and rising staccato eighth notes in the right hand and in a high register, mimicking raindrops dripping from different heights of eaves and resulting in different pitches upon contact with the puddles on the ground. Figure 4.1.1 shows the different raindrop figures composed by Palmgren and Chopin.

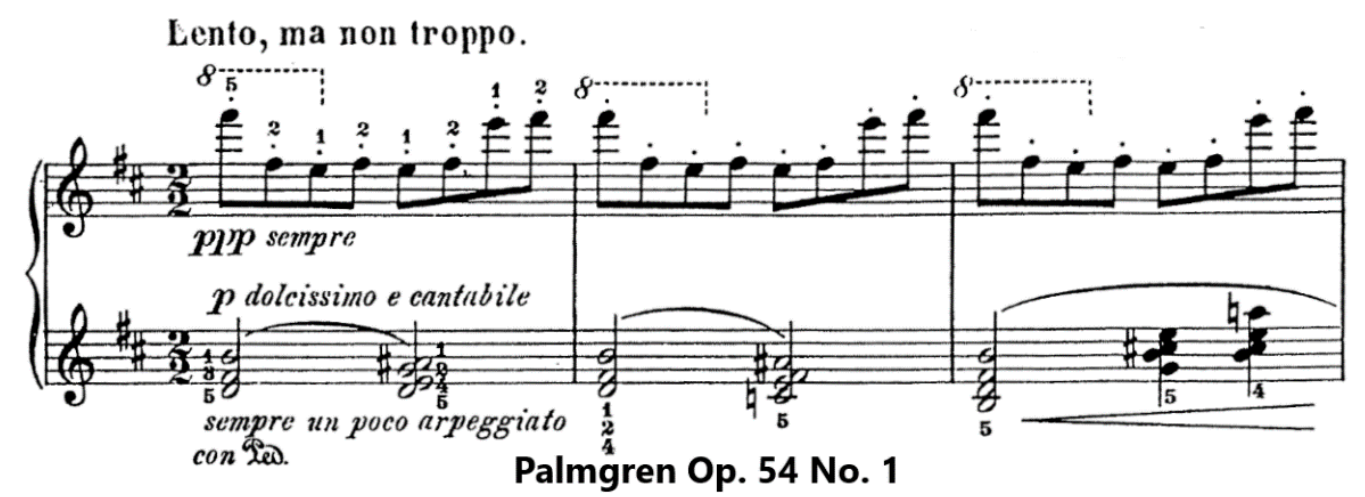

(C) 2002 by Wilhelm Hansen Publisher. Used with Permission. 


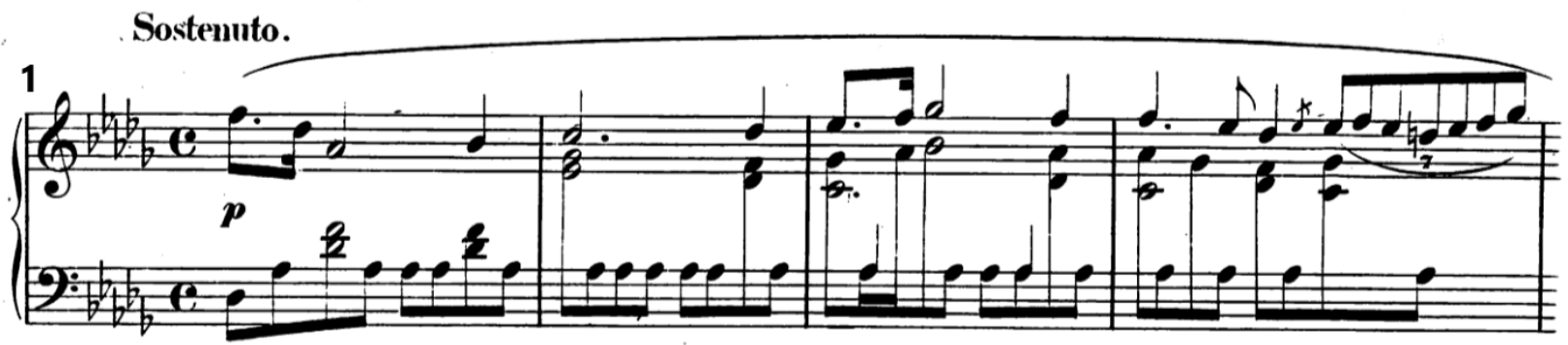

Chopin Prelude Op. 28, No. 15

(C) 1943 by G. Schirmer Publisher. Used with Permission.

Figure 4.1.1 Selim Palmgren, Tres Piezas para Piano, op. 54, “Raindrops,” mm. 1-3,

Chopin Prelude op. 28, No. 15, mm. 1-4.

Palmgren's Raindrops is in B minor, as the minor key conveys a melancholy and sorrowful mood that perfectly fits the atmosphere of this piece. Structurally, it reveals one-part form and can be divided into three sections (ABA'). The right hand consists only of the raindrops ostinato, creating a consistent atmosphere throughout the piece. It is worth noting that this ostinato figure contains only two notes, $\mathrm{F}^{\#}$ and $\mathrm{E}$, oscillating between them. It starts from the top $\mathrm{F}^{\#}$ on the keyboard, and is followed by the $\mathrm{F}^{\#}$ beneath it, the $\mathrm{E}$ a second below that, and then the $\mathrm{F}^{\#}$ and $\mathrm{E}$ below them. Then the notes are repeated in reverse order to get back to the top $\mathrm{F}^{\#}$, after which the pattern repeats. This pattern strongly emphasizes the dominant $\mathrm{F}^{\#}$ note, firmly establishing the key of B minor. Compared to the right hand, in which the ostinato consists of single notes, the left-hand material is chordal, with the theme presented as the top note of each chord and played without exception by the left thumb. Palmgren adds the performance instruction sempre un poco arpeggiato, indicating that the left hand plays in a rolling chord pattern while bringing out the theme.

The A section extends from the opening to $\mathrm{m}$. 16. It consists of four asymmetrical phrases in a " $1+1+2 "$ structure. Each two-phrase pair features a call-and-response setting. Interestingly, 
each downbeat in the "call" phrase stays in the tonic, while in the "response" phrase features a series of seventh-chord progressions in which the top notes employ anadiplosis rhetoric devices. ${ }^{35}$ Figure 4.1 .2 reflects how the anadiplosis approach is applied in the piece.

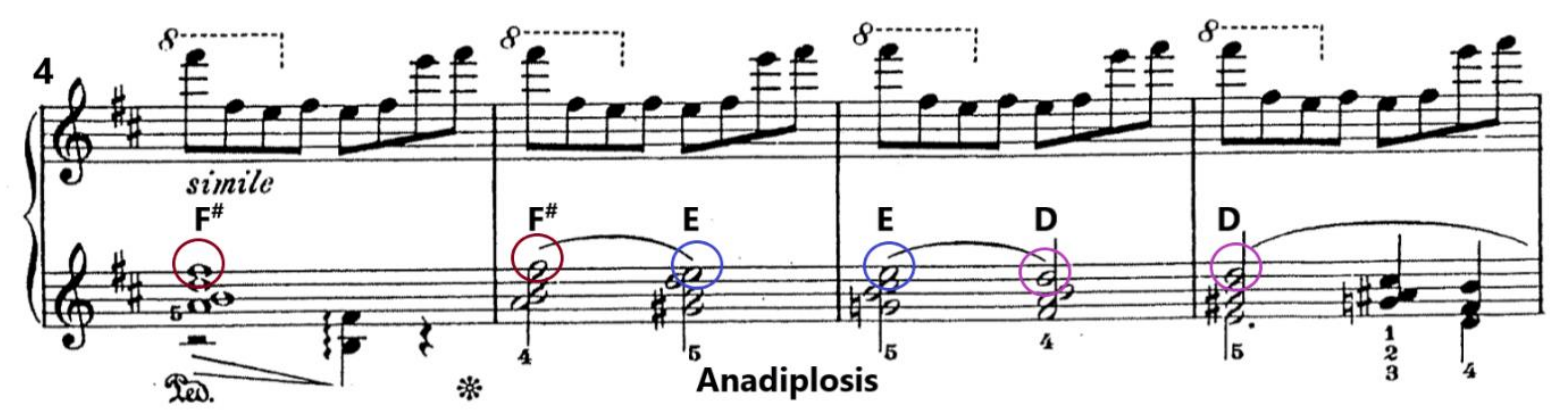

(C) 2002 by Wilhelm Hansen Publisher. Used with Permission.

Figure 4.1.2 Selim Palmgren, Tres Piezas para Piano, op. 54, “Raindrops,” mm. 4-7.

The B section contains only eight bars, lasting from $\mathrm{m}$. 17 to $\mathrm{m}$. 24. It consists of two fourmeasure phrases, both in sequences of seconds. The first phrase can be subdivided into two sequential phrases and the second phrase consists of four groups of descending sixth chords (Figure 4.1.3).

\footnotetext{
35 "Anadiplosis is a Greek word that refers to the repetition of a word or words in successive clauses in such a way that the second clause starts with the same word that marks the end of the previous clause." Literary Devices, Accessed April 10, https://literarydevices.net/anadiplosis/.
} 

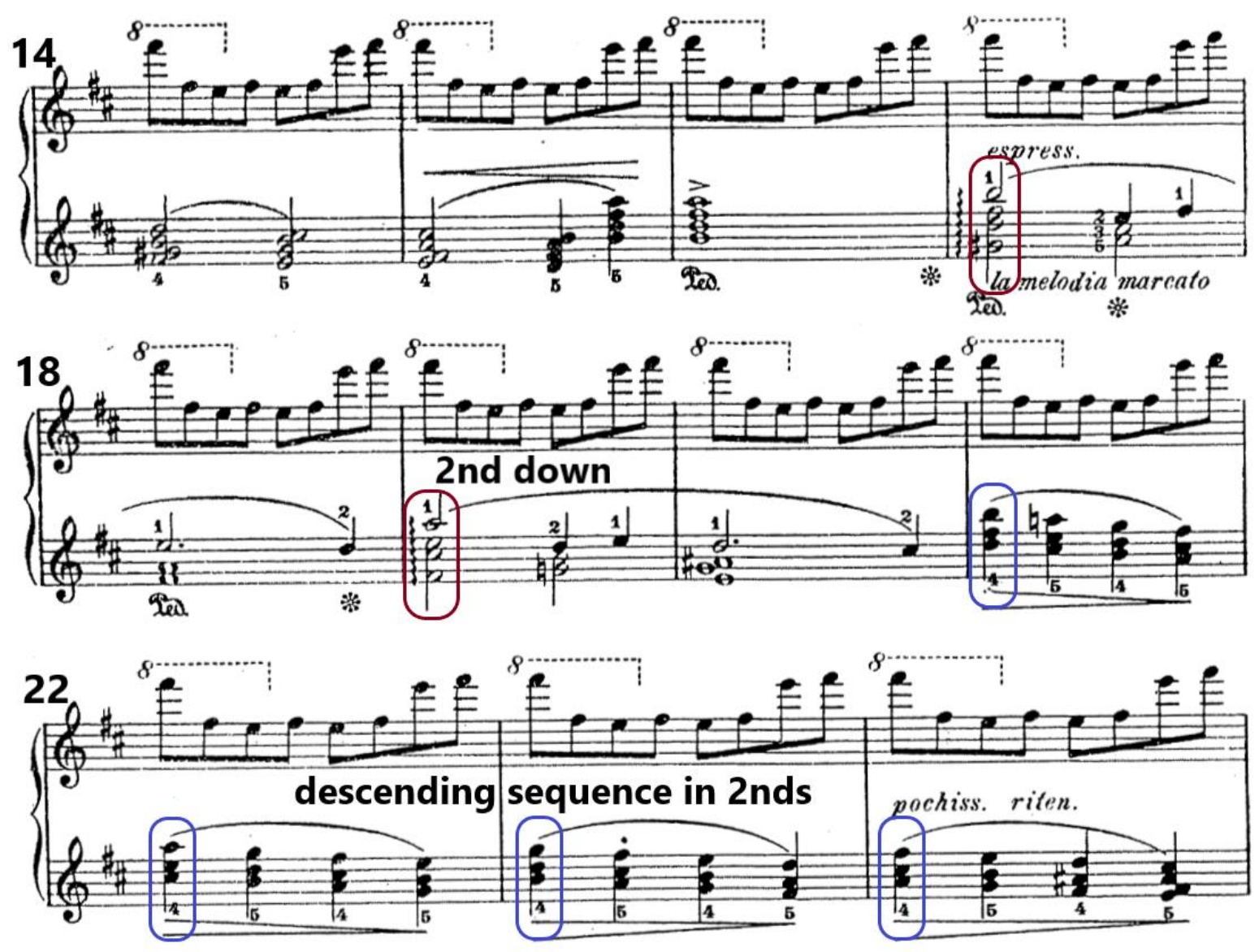

ㄷ 2002 by Wilhelm Hansen Publisher. Used with Permission.

Figure 4.1.3 Selim Palmgren, Tres Piezas para Piano, op. 54, “Raindrops,” mm. 14-24.

The last section starts in m. 25 and mainly restates the opening theme. A bass note $\mathrm{F}^{\#}$ is added into the second beat of each bar till $\mathrm{m} .32$ in the left hand, forming a tonic-dominant harmony that further emphasizes the key. The same scheme appears in mm. 33-40, but with the $\mathrm{F}^{\#}$ becoming a fifth $\left(\mathrm{B}-\mathrm{F}^{\#}\right)$ and with the $\mathrm{B}$ minor tonality suddenly and beautifully turning into B major. This is followed by a nine-measure phrase that stays in the tonic until the end, with the second beat gradually moving down from $\mathrm{F}^{\#}-\mathrm{D}^{\#}-\mathrm{B}-\mathrm{F}^{\#}$, ending pppp. The expression instructions Poco a poco perdendosi and rallent. are added to create an atmosphere of the raindrops gradually weakening and finally ceasing. 


\subsection{Vals el mignon "Mignonne Waltz"}

Unlike the first movement, which has an impressionistic atmosphere, the second movement is written with a fairly romantic approach. Compared to the other two movements of this set, the second movement is relatively lengthy and full of structural and textural variety. Palmgren entitled this piece Vals el mignon, meaning a small but charming waltz.

Structurally, this piece can be defined as multi-sectional form that is divided by different themes. Nonetheless, it also can be treated as ternary form with an introduction and a coda (Intro ABA Coda) due to the repetition of the first and last section. Diagram 1 below shows the structural scheme of this piece:

B

\begin{tabular}{|c|c|c|c|c|c|c|c|c|c|c|}
\hline & Introduction & A & & B & $\mathrm{C}$ & $\mathrm{D}$ & $\mathrm{C}$ & Transition & $A^{\prime}$ & Coda \\
\hline Theme & & & $a^{\prime}$ & $\|: b:\|$ & $\mathrm{c}$ & $\|: d:\|$ & $\mathrm{c}$ & $a^{\prime \prime}$ & $\mathrm{a} \quad \mathrm{a}^{\prime}$ & D \\
\hline Tonality & $\mathrm{D}^{\mathrm{b}} \mathrm{M}$ & & & & $\mathrm{Fm}$ & $\mathrm{A}^{\mathrm{b}} \mathrm{M}$ & $\mathrm{Fm}$ & $\mathrm{Fm}-\mathrm{D}^{\mathrm{b}} \mathrm{M}$ & $\mathrm{D}^{\mathrm{b}} \mathrm{M}$ & \\
\hline Measure & 1 & 13 & 29 & 46 & 67 & 87 & 104 & 121 & 130146 & \\
\hline
\end{tabular}

Diagram 1 Formal Structure of Selim Palmgren's Tres Piezas para Piano, op. 54, "Mignonne Waltz."

The piece is written in $\mathrm{D}^{\mathrm{b}}$ major and starts with a 16-bar introduction that features a repeated rhythmic pattern, a rolling seventh chord followed by an ascending two-note slur. Instead of starting in the tonic, it begins with the repetition of rolling $\mathrm{C}^{7}$ and $\mathrm{F}^{7}$ patterns in two registers and then features a chromatic descending sequence, guiding the passage to the dominant $\mathrm{A}^{\mathrm{b}}$ at the end of the section (see Figure 4.2.1). 

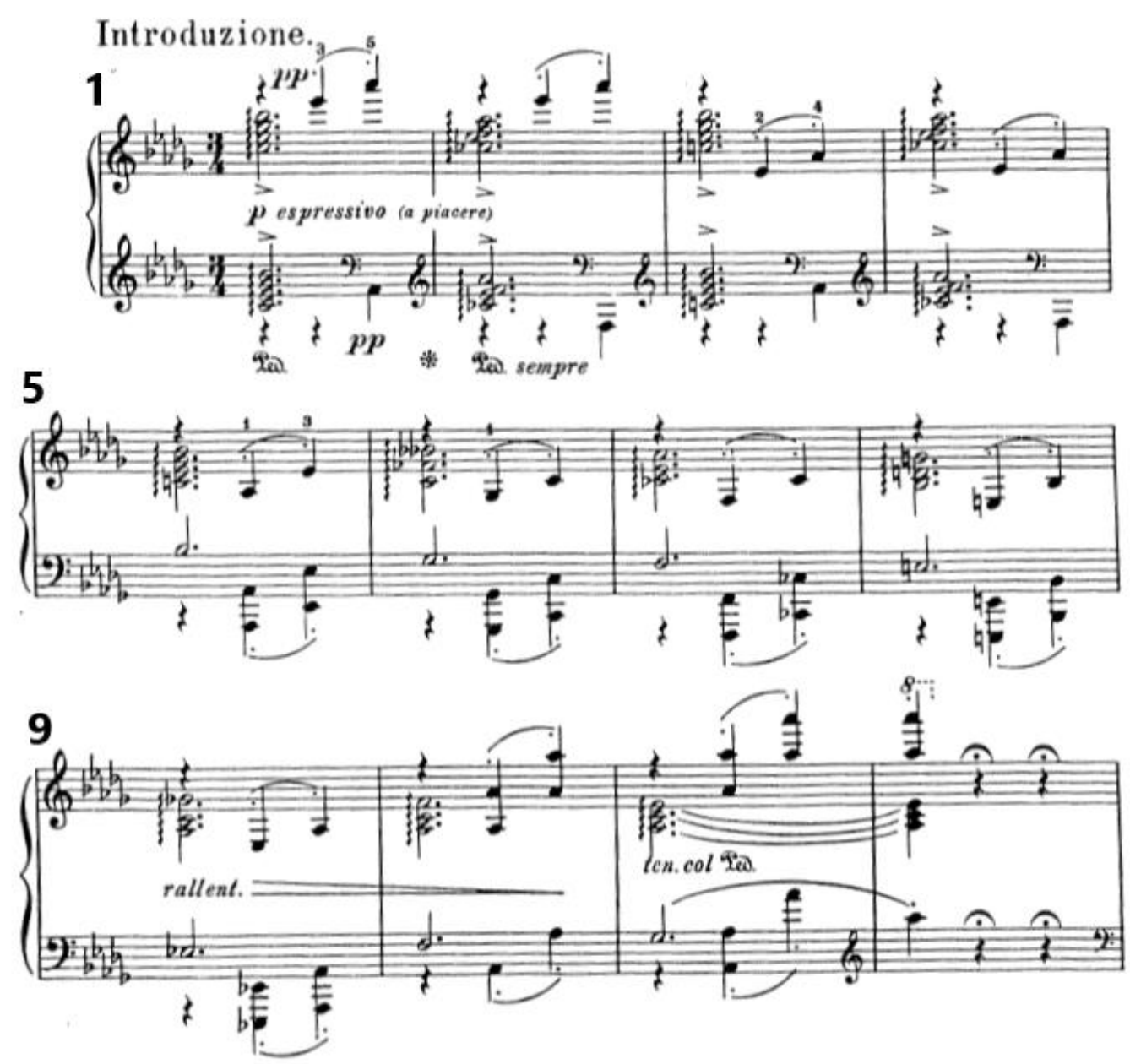

(C) 2002 by Wilhelm Hansen Publisher. Used with Permission.

Figure 4.2.1 Selim Palmgren, Tres Piezas para Piano, op. 54, “Mignonne Waltz,” mm. 1-12.

After the introduction, the tempo instruction Tempo di valse appears at the beginning of the first section, indicating the opening of the waltz itself. The sectional structure of the waltz is mainly built using four themes. Each section carries a single theme that provides its individual characteristics. Section A extends from m. 13 to m. 45 , staying in $\mathrm{D}^{\mathrm{b}}$ major throughout. It states theme $a$ twice, the second time using a triplet figure in the accompaniment (see Figure 4.2.2). It is an elegant and lyrical theme in a " $2+2+4$ " phrase structure, with a $p$ ma molto cantabile 
expression indication. The two-bar phrase features a similar rhythmic pattern, three ascending quarter notes followed by an accented half note and a quarter note.
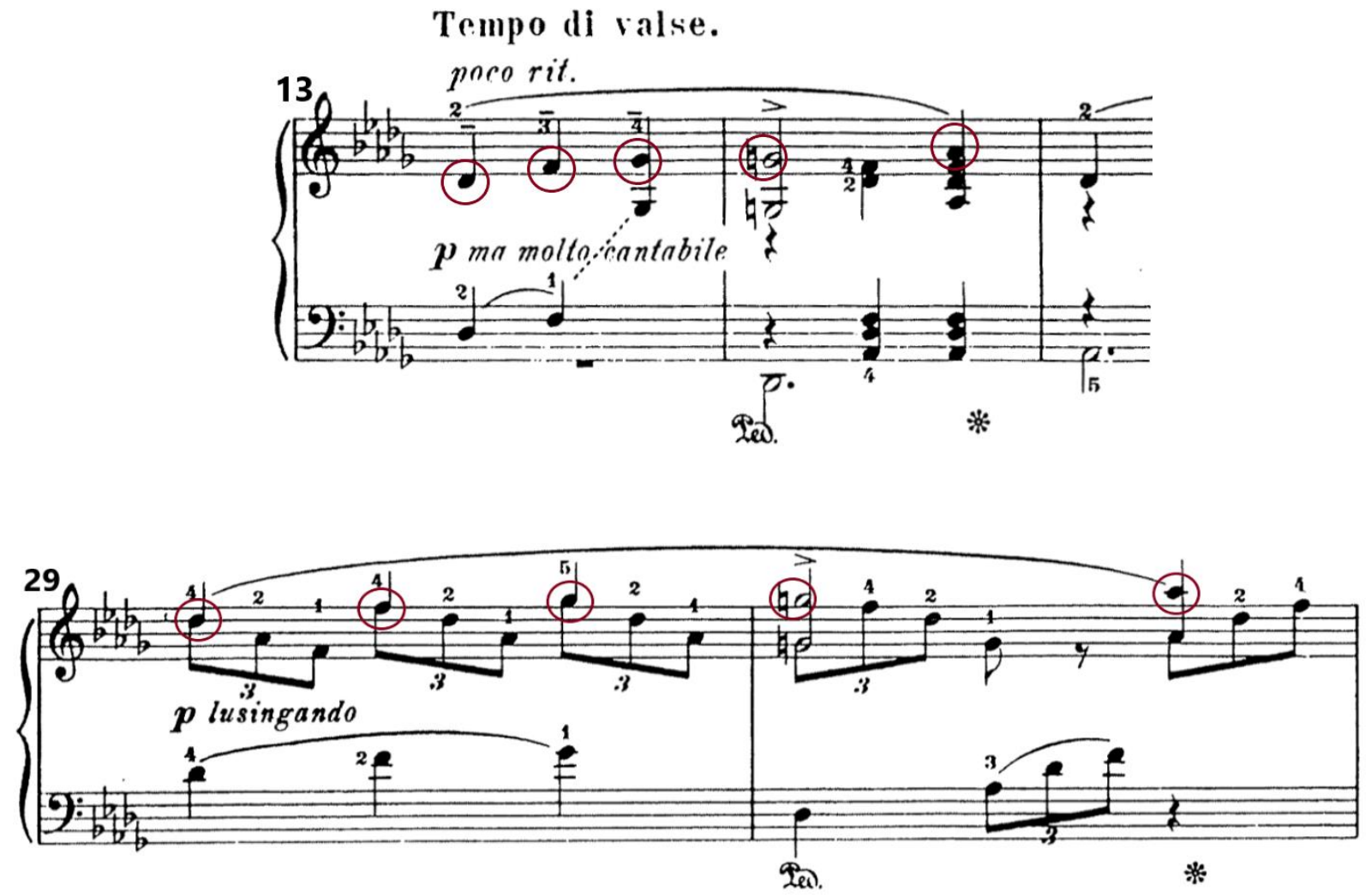

(c) 2002 by Wilhelm Hansen Publisher. Used with Permission.

Figure 4.2.2 Selim Palmgren, Tres Piezas para Piano, op. 54, “Mignonne Waltz," mm. 13-14, 29-30.

Section B enters in m. 46, repeats the $b$ theme twice and presents a brighter and more active impression than does the previous section. Compared to the legato lyrical line of theme $a$, theme $b$ in this section is comprised of staccato notes and short slurs. Also, the expression instruction un poco animato in this section clearly differentiates the characteristics between theme $b$ and theme $a$ (see Figure 4.2.3). 

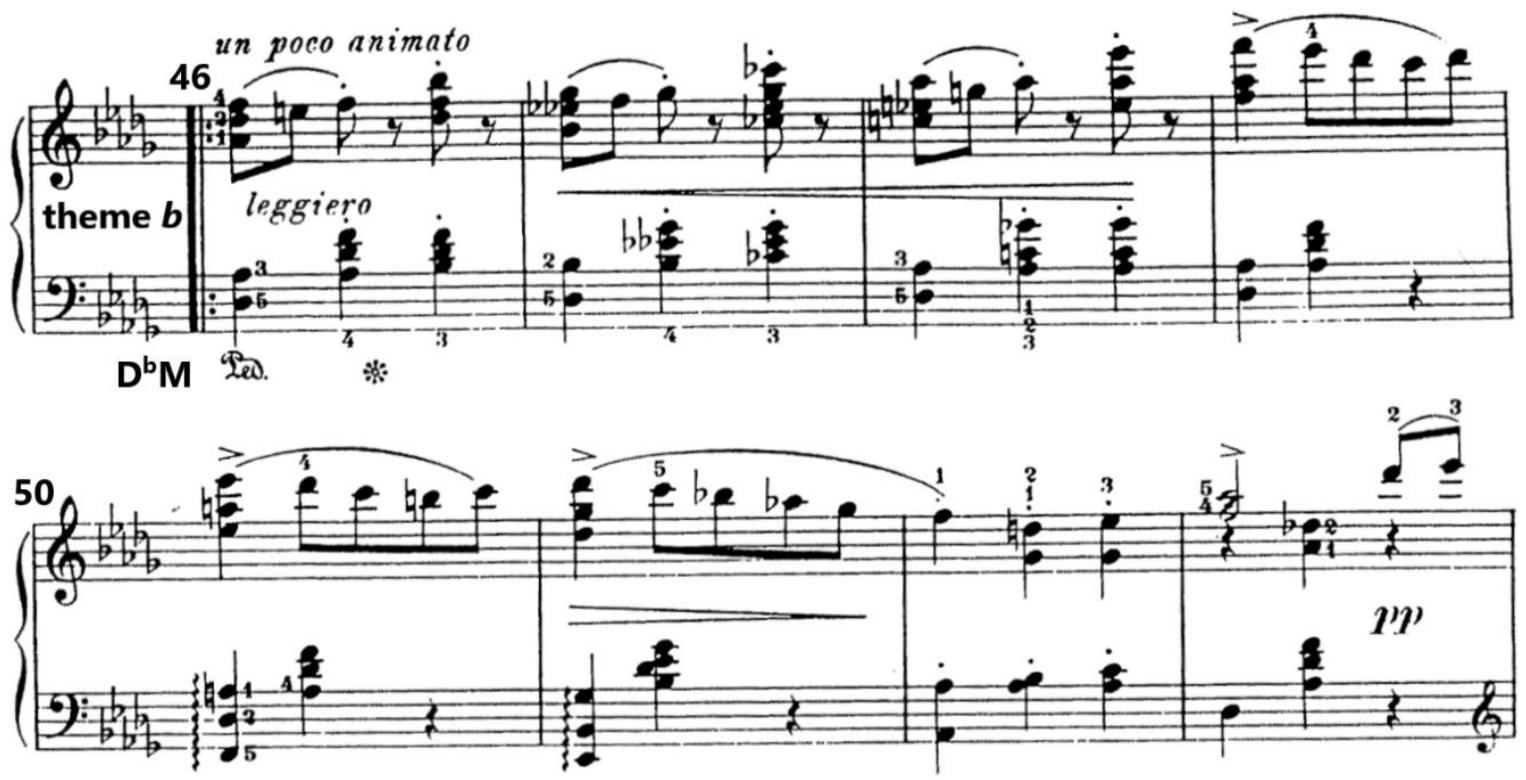

(C) 2002 by Wilhelm Hansen Publisher. Used with Permission.

Figure 4.2.3 Selim Palmgren, Tres Piezas para Piano, op. 54, “Mignonne Waltz,” mm. 46-53.

Section C starts in $\mathrm{m} .67$, right after the second ending of section B. The key modulates from $\mathrm{D}^{\mathrm{b}}$ major to $\mathrm{f}$ minor, with the instruction con grand espressione. The mood suddenly becomes languid, revealing a great contrast to the previous section. The accompaniment in section $\mathrm{C}$ begins with vertical chords and then changes into relatively fast arpeggios at the second half, perhaps trying to diminish the lamenting characteristics in order to rejoin the next playful section (see Figure 4.2.4). 

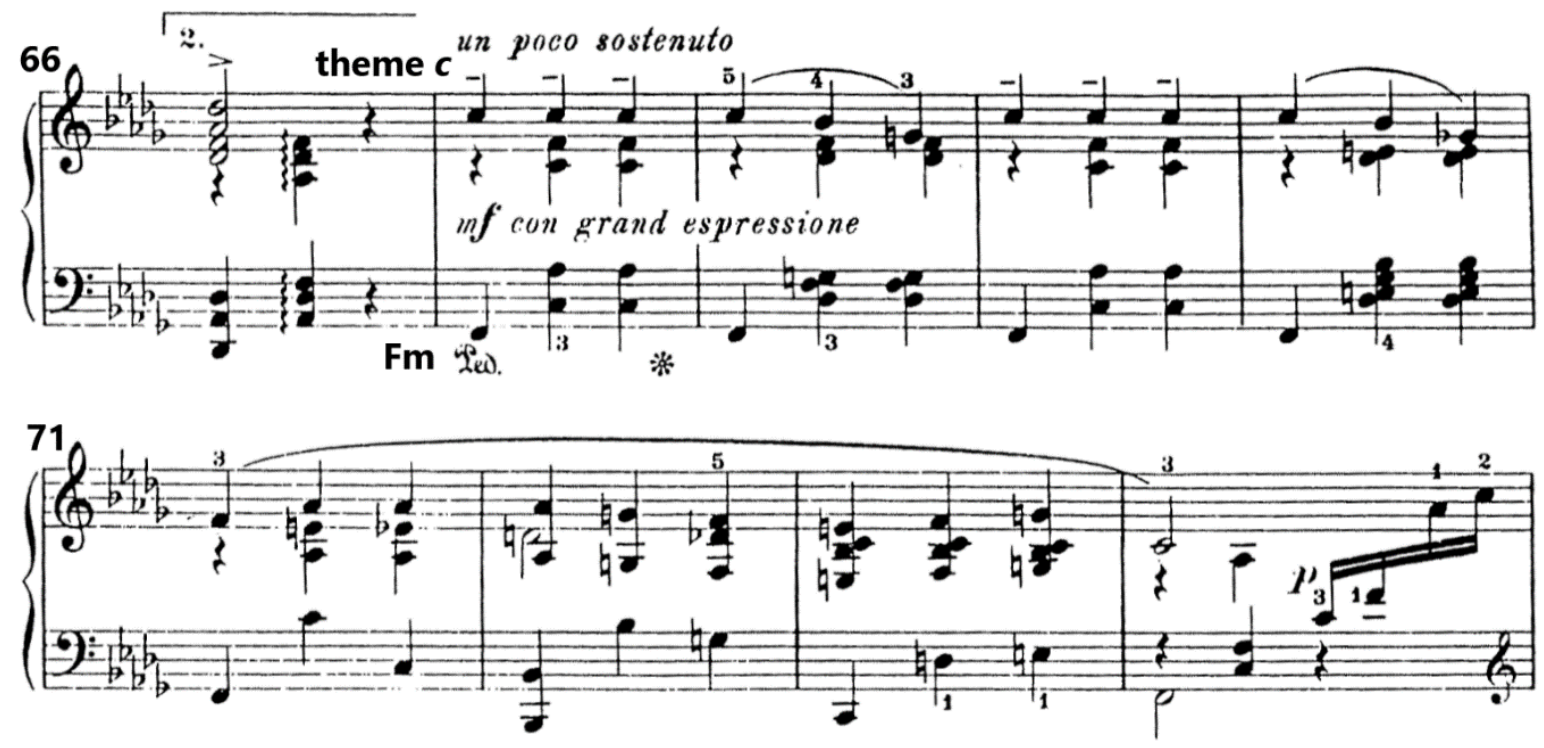

(C) 2002 by Wilhelm Hansen Publisher. Used with Permission.

Figure 4.2.4 Selim Palmgren, Tres Piezas para Piano, op. 54, “Mignonne Waltz,” mm. 66-74.

Section $\mathrm{D}$ enters in $\mathrm{m} .87$, with a sudden key change from $\mathrm{f}$ minor to $\mathrm{A}^{\mathrm{b}}$ major. Theme $d$ in this section resembles theme $b$ in both textural and character aspects: both themes consist of staccato and slurred rhythms that convey a cheerful spirit. Moreover, theme $d$ contains even stronger dynamic variety; with the animato, con fuoco expression indication, it also offers a greater contrast to the next section, the recurring theme $c$ that returns to $\mathrm{f}$ minor in a melancholy mood.

There is a short transition section (mm. 121-129) that employs the materials from theme $a$, leading the piece back to $\mathrm{D}^{\mathrm{b}}$ major and introducing the next section, the restatement of section $\mathrm{A}$. The piece ends with a brief coda that begins at the upbeat to $\mathrm{m}$. 163, borrowing materials from theme $b$. Both hands play the thematic motive in reverse motion, with the left hand playing the $\mathrm{D}^{\mathrm{b}}$ tonic every third beat to reinforce the key (see Figure 4.2.5). 

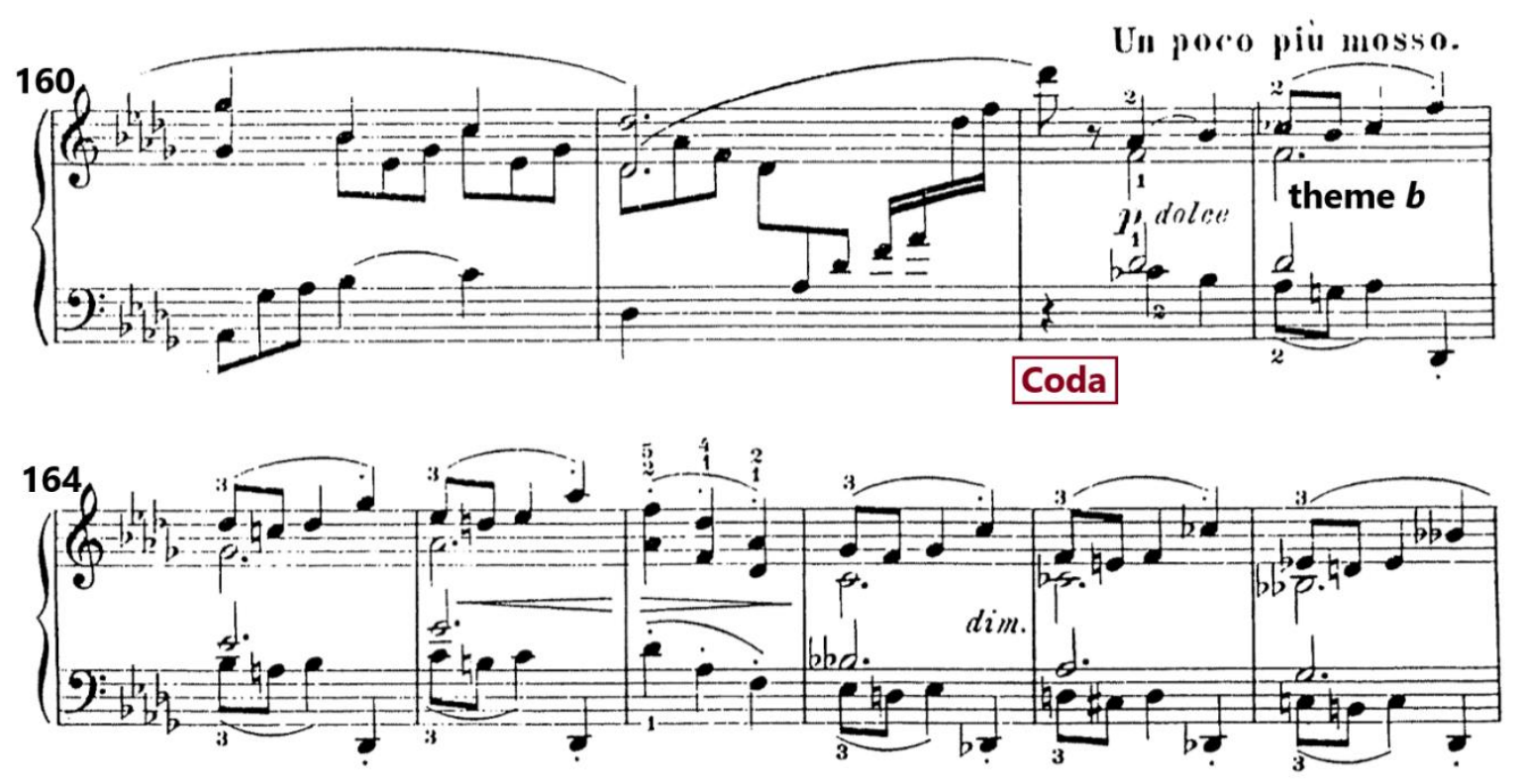

(c) 2002 by Wilhelm Hansen Publisher. Used with Permission.

Figure 4.2.5 Selim Palmgren, Tres Piezas para Piano, op. 54, “Mignonne Waltz,” mm. 160-169.

As the title suggests, the second movement is a lovely waltz that is full of emotion. The various sections have their own expressions, all of which combine to build the whole piece with diversity, like a painting with multiple, but well-blended, graceful colors.

\subsection{Luz de luna "Moonlight"}

Interestingly, the last movement of this suite features many compositional schemes similar to those in the first piece. For instance, both movements are written in an impressionistic style. The themes of both pieces are presented exclusively by the left-hand thumb, which plays the melody as the top notes of arpeggiated chords. Also, in both pieces, with one brief exception in the third piece, the right hand plays ostinato figures that create tranquil backgrounds. Palmgren reveals a vivid picture of a silent and charming night scene that perfectly fits its title Moonlight. 
This movement is written in F minor. The structure can be shown in the Diagram 2 below:

\begin{tabular}{lccccr} 
& Introduction & A & B & Transition & A' \\
\cline { 2 - 6 } Theme & & a & b & running passages & a \\
Tonality & Fm & & & C Major tonal area & Fm \\
Measure & 1 & 3 & 21 & 43 & 52
\end{tabular}

Diagram 2 Formal Structure of Selim Palmgren's Tres Piezas para Piano, op. 54, "Moonlight."

Moonlight starts with a two-bar introduction in the right hand, setting up the mood for the entire piece. The ostinato in the right hand consists of repeated chords that are presented rhythmically on the offbeat eighths throughout the A section. The left hand enters on the downbeat of $\mathrm{m} .3$, providing a series of rolling chords in $\mathrm{f}$ minor. The top notes of the rolling chords together form theme $a$. Section A contains a series of phrases that ends with an F in the highest register and with the dynamic pppp, reinforcing the key as well as enhancing the serene atmosphere (see Figure 4.3.1). 

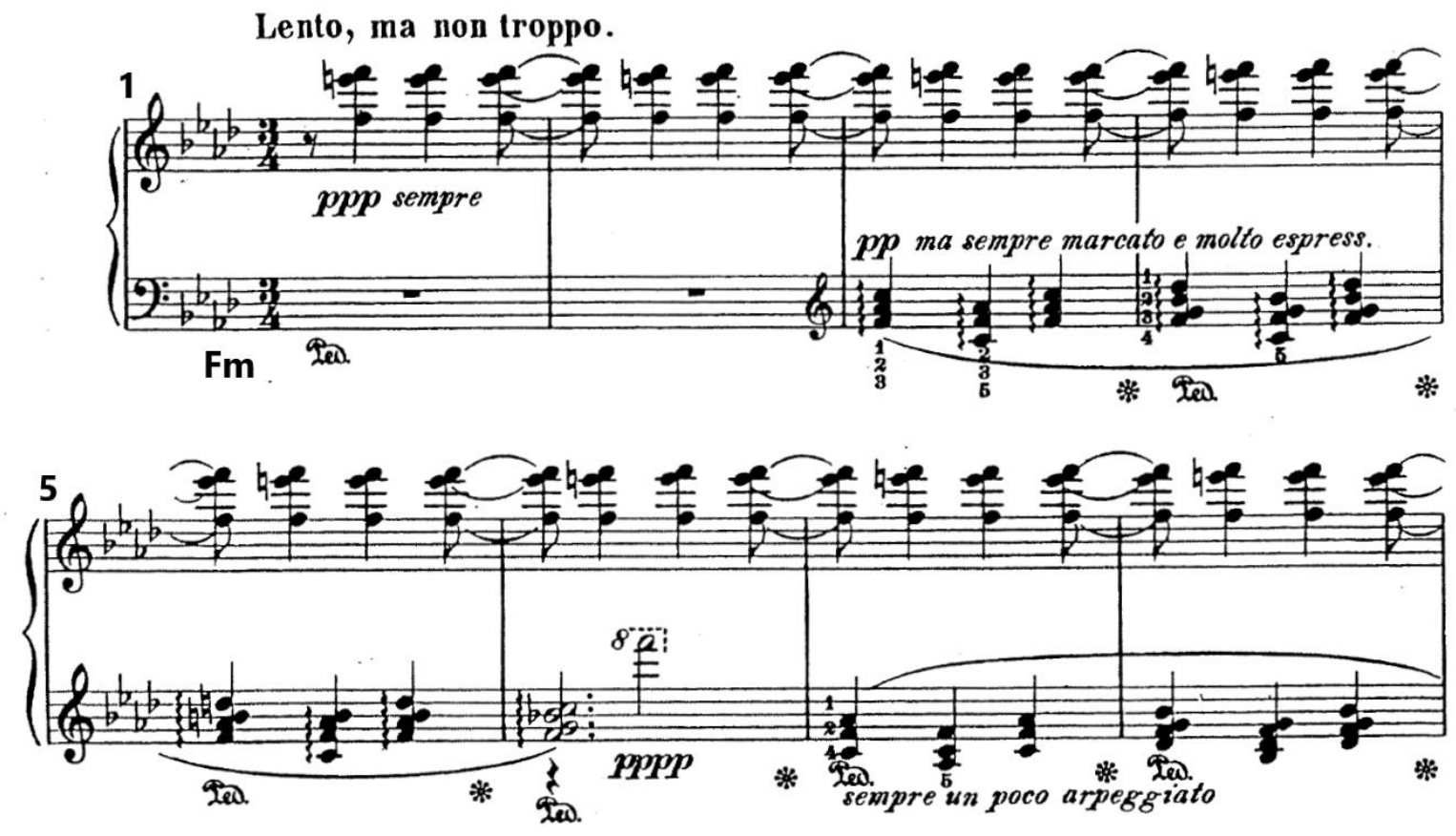

(C) 2002 by Wilhelm Hansen Publisher. Used with Permission.

Figure 4.3.1 Selim Palmgren, Tres Piezas para Piano, op. 54, “Moonlight.” mm. 1-8.

Section B begins from the downbeat of $\mathrm{m} .21$, where the ostinato in the right hand changes into a triplet figure. The $b$ theme, also beginning at the downbeat of the same measure, appears mostly in conjunct motion. An additional arpeggiated voice is added in the left-hand bass line to enrich the layers. Starting from m. 29, the left hand retains the same rhythmic pattern. However, the rhythm of the ostinato changes from triplets into sixteenth notes, creating a feeling of rhythmic acceleration (see Figure 4.3.2). 

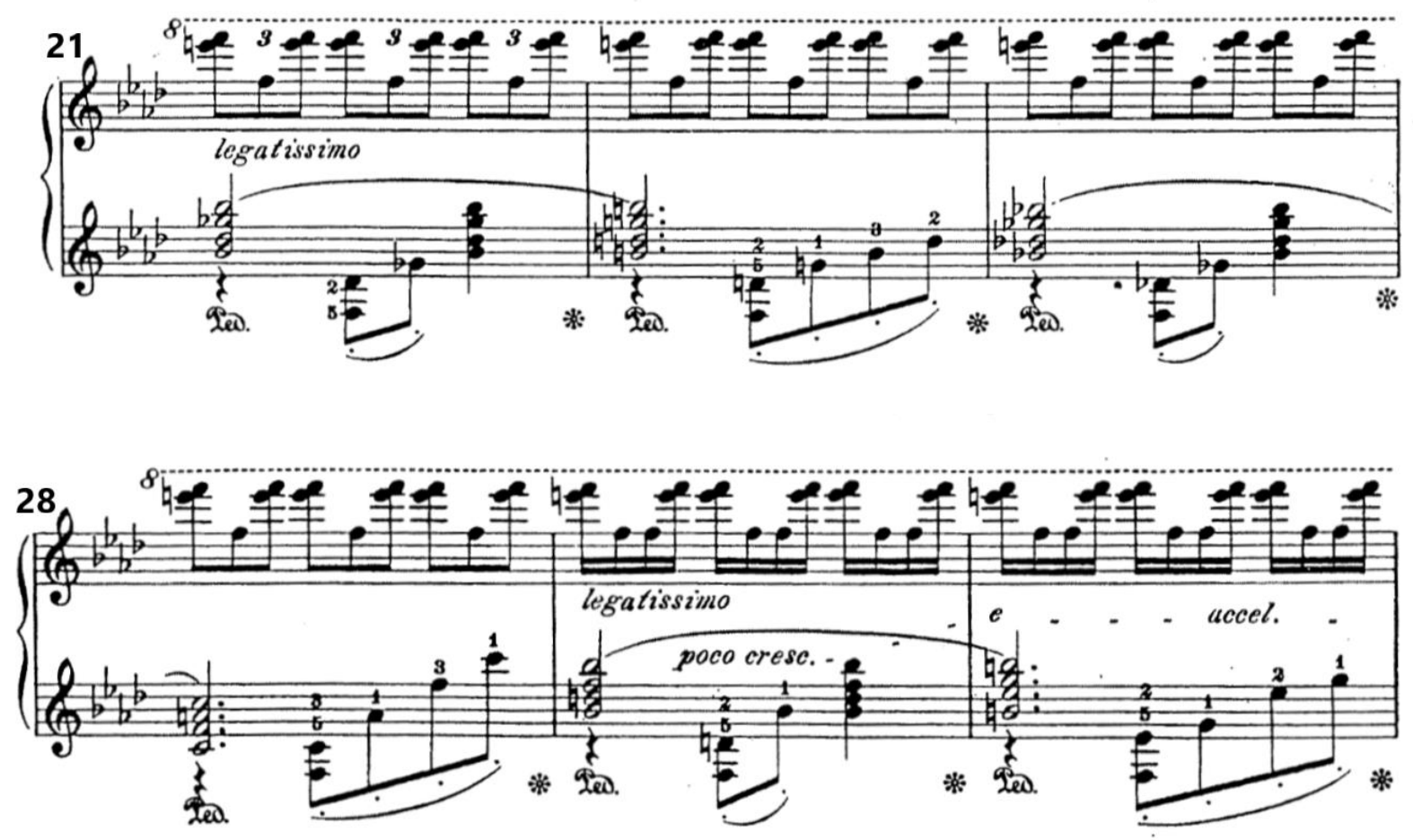

(C) 2002 by Wilhelm Hansen Publisher. Used with Permission.

Figure 4.3.2 Selim Palmgren, Tres Piezas para Piano, op. 54, “Moonlight,” mm. 21-23, 28-30.

There is a transition section that extends from $\mathrm{m}$. 43 to $\mathrm{m}$. 51, featuring a chromatic running passage that provides a hazy and mysterious atmosphere. Although the first two measures indicate the tonal area of $\mathrm{C}$ major (as the bass line plays the $\mathrm{C}$ in the downbeat, a dominant seventh on the second beat, and a subdominant chord over a dominant $\mathrm{G}$ on the third beat, while the right hand features a running passage which, although containing a few chromatic notes not found in C major, mostly mirrors the diatonic harmonies in the left hand) (see Figure 4.3.3). 


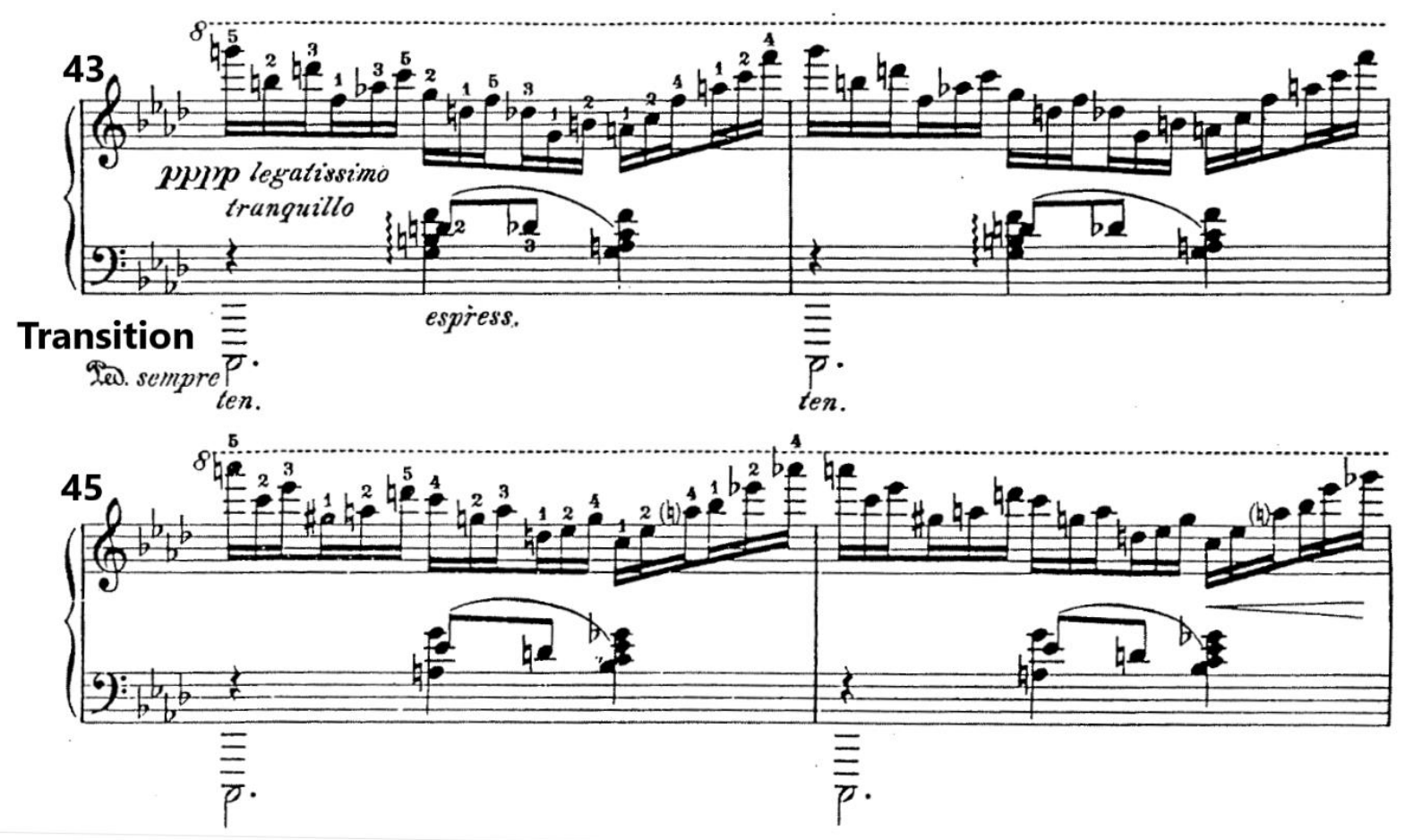

(C) 2002 by Wilhelm Hansen Publisher. Used with Permission.

Figure 4.3.3 Selim Palmgren, Tres Piezas para Piano, op. 54, “Moonlight,” m. 43-46.

A few bars of more ambiguous harmonies follow, after which we return to the key of C major in measure 47. After an arpeggiated descending passage from mm. 48-51, the $a$ theme returns and the piece enters the last section. This extends from m. 52 to the end and repeats the opening section, but changes the last note of each phrase from the high $\mathrm{F}$ into a low $\mathrm{A}^{\mathrm{b}}$. The right-hand ostinato, although retaining a rapid arpeggiated pattern, changes from triplet sixteenths into thirty-second notes (see Figure 4.3.4). As in the first movement, after the $a$ theme is completely restated, the piece ends in pppp with a perdendosi indication. 

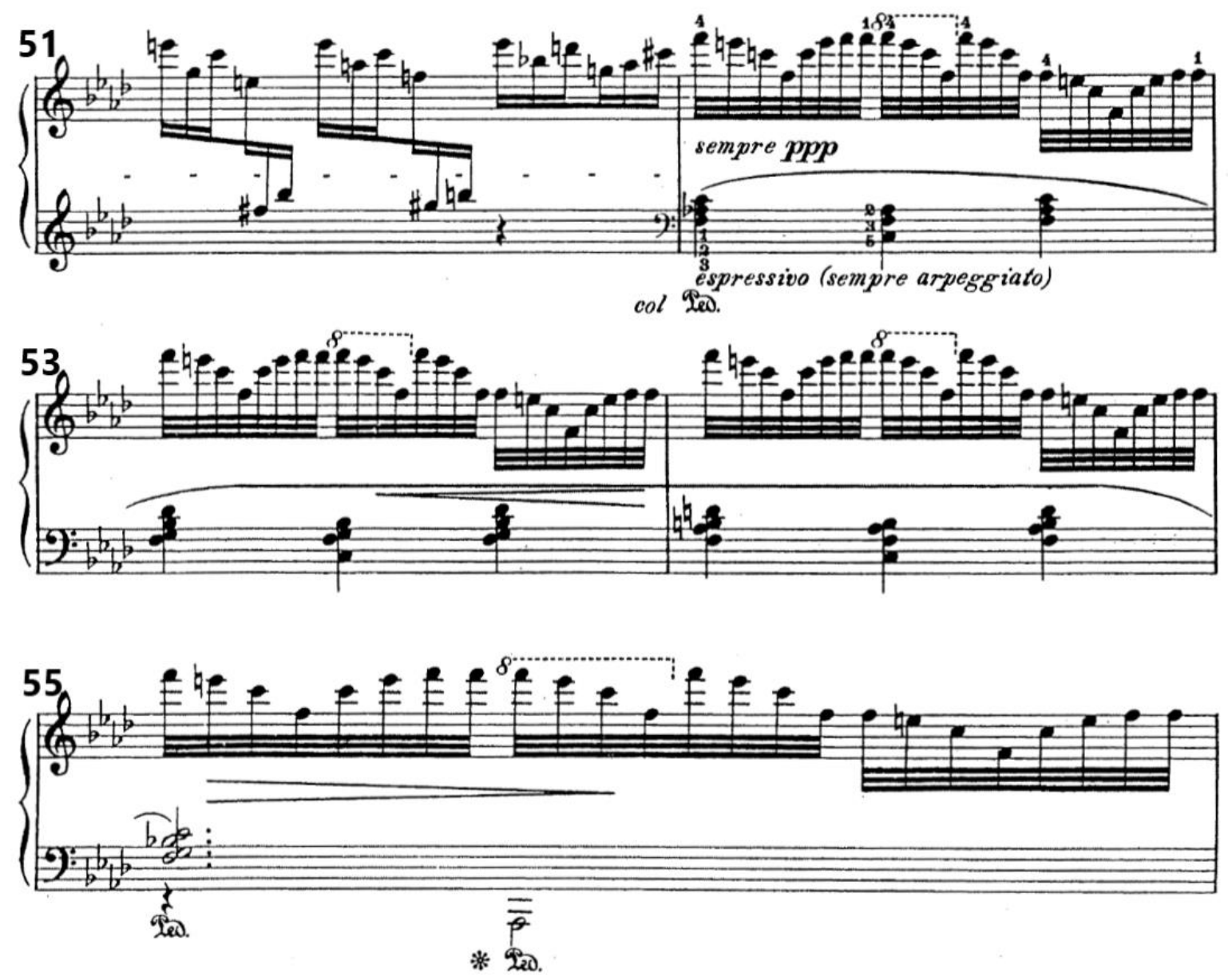

(C) 2002 by Wilhelm Hansen Publisher. Used with Permission.

Figure 4.3.4 Selim Palmgren, Tres Piezas para Piano, op. 54, “Moonlight,” mm. 51-55.

Palmgren composed Tres Piezas para Piano, op. 54, using a cyclic approach, with the two outer movements written in impressionistic styles with similar textural structures, surrounding a traditional waltz scheme. This setting not only reveals Palmgren's great imagination within impressionistic language, but also his skills in writing traditional music. This format renders the suite as a "sandwich": the outer two movements keep the same structural shape while the middle one enriches the taste of the entire suite. The three together form a delicious musical feast. 


\section{Chapter 5}

\section{Conclusion}

The prelude can be traced back to the early Baroque era. Over the centuries, composers have contributed to the genre, constantly developing and expanding its boundaries, a process that continues till modern times. At first, preludes were short improvisational pieces, intended to warm up the fingers and show off technical abilities. However, over time, although their brevity remained relatively constant, they diversified to the point that there cannot be said that either their form or their character has any common characteristics. Nowadays, the prelude can be paired with a fugue (or with a dance, ballade, or any of several other forms chosen at the whim of the composer), or as a piece that stands by itself. Moreover, it may be grouped by specific harmonic sequences (sets of 24 preludes in all the major and minor keys are common, several of these works covering these keys using the circle of fifths) or may be grouped in no particular harmonic order. As there is now no strict definition of a prelude, this very diversity and flexibility offers composers nearly unlimited opportunities to continue to contribute to the genre.

Selim Palmgren also makes his contribution to the category of preludes. As a Finnish composer who took many tours out of his country, he combines a Finnish national spirit with European or American musical styles (such as impressionistic, whole-tone, or bitonal methods), infusing new blood into and enriching the color of the genre. Although from a technical aspect Palmgren's 24 preludes are not as virtuosic as those of some of his contemporaries, such as Rachmaninoff, Alkan, and Blumenfeld, their pedagogical function still has significant meaning for many pianists, especially for intermediate to advanced students. The set not only contains many genres such as Sarabande, Lullaby, Round Dance, etc., but it also explores many musical 
styles from Baroque counterpoint to Romantic impressionism and nationalism. Also, it has manifold useful pedagogical materials to which teachers may introduce their students, including new musical concepts and technical skills.

Tres Piezas para Piano, op. 54, reflects Selim Palmgren's capability of writing both impressionistic and traditional music styles. The first and last movements reveal his astonishing imagination and his ability to present in musical language vivid natural scenes such as raindrops and moonlight. The beautiful waltz movement in the middle is evidence of Palmgren's lyricism and his ease in composing music in a traditional form.

Although Palmgren was a prolific composer, his works are seldom mentioned or performed in public outside of Finland. I was surprised that I could find only a few research materials about him or his works. This dearth of information could occur in part because some people may consider many of his piano works to be merely entertaining salon pieces. However, in my view, his music deserves to be more widely known. His 24 Preludes, op. 17 contribute to the genre, and his many character pieces broaden the entire piano repertory. The beauty of his works merits more appreciation by performers and audiences. 


\section{Bibliography}

Ala-Könni, Erkki, Tuula Kaurinkoski and Heidi Granholm, Otavan iso Musiikkitietosanakirja 3, (Helsinkin Otava, 1978), 308.

Barnett, Rob, "Palmgren Piano Concertos," Classical Music Reviews, accessed April 10, 2019, http://www.musicweb-international.com/classrev/2016/Aug/Palmgren_PCs_ABCD385.htm.

Boyd, Malcolm, "Wiegenlied," Grove Music Online, accessed April 10, 2019, https://doiorg.www.libproxy.wvu.edu/10.1093/gmo/9781561592630.article.30270.

Gordon, Stewart, "French Keyboard Music of the Early Twentieth Century," A History of Keyboard Literature. (Schirmer, Cengage Learning, 1996), 366.

Hamilton, Kenneth L, "Berceuse," Grove Music Online, accessed April 10, 2019, https://doiorg.www.libproxy.wvu.edu/10.1093/gmo/9781561592630.article.02749.

Hong, Barbara Blanchard, "The Five Piano Concertos of Selim Palmgren: A Finnish Nationalist Meets the Challenge of the Twentieth Century." (PhD diss., Indiana University, 1992).

Hurwitz, David. "Selim Palmgren: 'Chopin of the North'," Classics Today, accessed April 10, 2019, https://www.classicstoday.com/review/selim-palmgren-chopin-of-the-north/.

Ilari, Beatriz and Megha Sundara. "Music Listening Preferences in Early Life: Infants' Responses to Accompanied versus Unaccompanied Singing," Journal of Research in Music Education 56, no. 4 (January 2009): 357.

Kangas, Laila, "Säveltäjä Selim Palmgrenin Lyhyt Suruaika-Musiikin Syntymäpäiväkalenteri," accessed April 10, 2019, https://yle.fi/aihe/artikkeli/2019/02/16/saveltaja-selim-palmgreninlyhyt-suruaika-musiikin-syntymapaivakalenteri.

Korhonen, Kimmo, “The Mighty Spring Tide of Finnish Music," Inventing Finnish Music. (Finnish Music Information Centre, 2003), 53-54. 
Layton, Robert. "Palmgren's Early and Middle Period Piano Pieces," Gramophone, accessed April 10, 2019, https://www.gramophone.co.uk/review/palmgren-early-middle-period-pianopieces.

Mikkilä, Timo. "Preface," Selim Palmgren 24 Prelude Op. 17. (Fennica Gehrman, 2004), 1.

O'Neill, Colleen T., Laurel J. Trainor, Trehub and Sandra E. “Infants' Responsiveness to Fathers' Singing," Music Perception: An Interdisciplinary Journal, 18, no. 4 (Summer 2001): 410.

Oramo, Ilkka. "Palmgren, Selim," Grove Music Online, accessed April 10, 2019, https://doiorg.www.libproxy.wvu.edu/10.1093/gmo/9781561592630.article.20779.

Parsons, Charles H, "Palmgren: Daniel Hjort," The Record Connoisseur's Magazine, March/April 1998, 174-175.

Perry, Nina, “The Universal Language of Lullabies,” BBC News, accessed April 10, 2019, https://www.bbc.com/ news/magazine-21035103.

Poroila, Heikki., Selim Palmgren Work Catalogue. (Helsinki, 2014), accessed April 10, 2019, https://www.musiikkikirjastot.fi/wp-content/uploads/2016/11/Palmgren_luettelo.pdf.

Sears, Meredith, and Harold. "What is Round Dancing," Round Dancing-Choreographed Ballroom, assessed April 10, 2019, http://www.rounddancing.net/ dance/articles/what.html.

Tawaststjerna, Erik Thomas, "Finnish Piano Music Since 1945," (PhD diss., New York University, 1982).

Wright, David, “Selim Palmgren,” accessed April 10, 2019, https://www.wrightmusic.net/ pdfs/selim-palmgren.pdf.

Anadiplosis, Literary Devices, accessed April 10, https://literarydevices.net/anadiplosis/. 
"Järnefelt Maikki," Database of the Finnish Record Archives, accessed April 10, 2019, http://www.aanitearkisto.fi/firs2/nimi.php?Id=J\%E4rnefelt+Maikki.

"Selim Palmgren," accessed April 10, 2019, https://www.fennicagehrman.fi/composers -works/palmgren-selim/. 


\section{APPENDIX}

Sequence of Selim Palmgren's 24 Preludes, op. 17

\begin{tabular}{|c|c|c|c|}
\hline Prelude Number & Key & Prelude Number & Key \\
\hline No. 1 & E minor & No. 2 & A major \\
\hline No. 3 & E major & No. 4 & $\mathrm{C}^{\#}$ minor \\
\hline No. 5 & G major & No. 6 & G minor \\
\hline No. 7 & D major & No. 8 & $\mathrm{~B}$ minor \\
\hline No. 9 & $\mathrm{G}^{\#}$ minor & No. 10 & $\mathrm{~A}^{\mathrm{b}}$ major \\
\hline No. 11 & $\mathrm{C}$ major & No. 12 & A minor \\
\hline No. 13 & B major & No. 14 & D minor \\
\hline No. 15 & $\mathrm{~B}^{\mathrm{b}}$ major & No. 16 & F major \\
\hline No. 17 & F minor & No. 18 & $\mathrm{~F}^{\#}$ minor \\
\hline No. 19 & $\mathrm{~F}^{\#}$ major & No. 20 & $\mathrm{E}^{\mathrm{b}}$ minor \\
\hline No. 21 & $\mathrm{C}$ minor & No. 22 & $\mathrm{E}^{\mathrm{b}}$ major \\
\hline No. 23 & $\mathrm{~B}^{\mathrm{b}}$ minor & No. 24 & $\mathrm{D}^{\mathrm{b}}$ major \\
\hline
\end{tabular}

